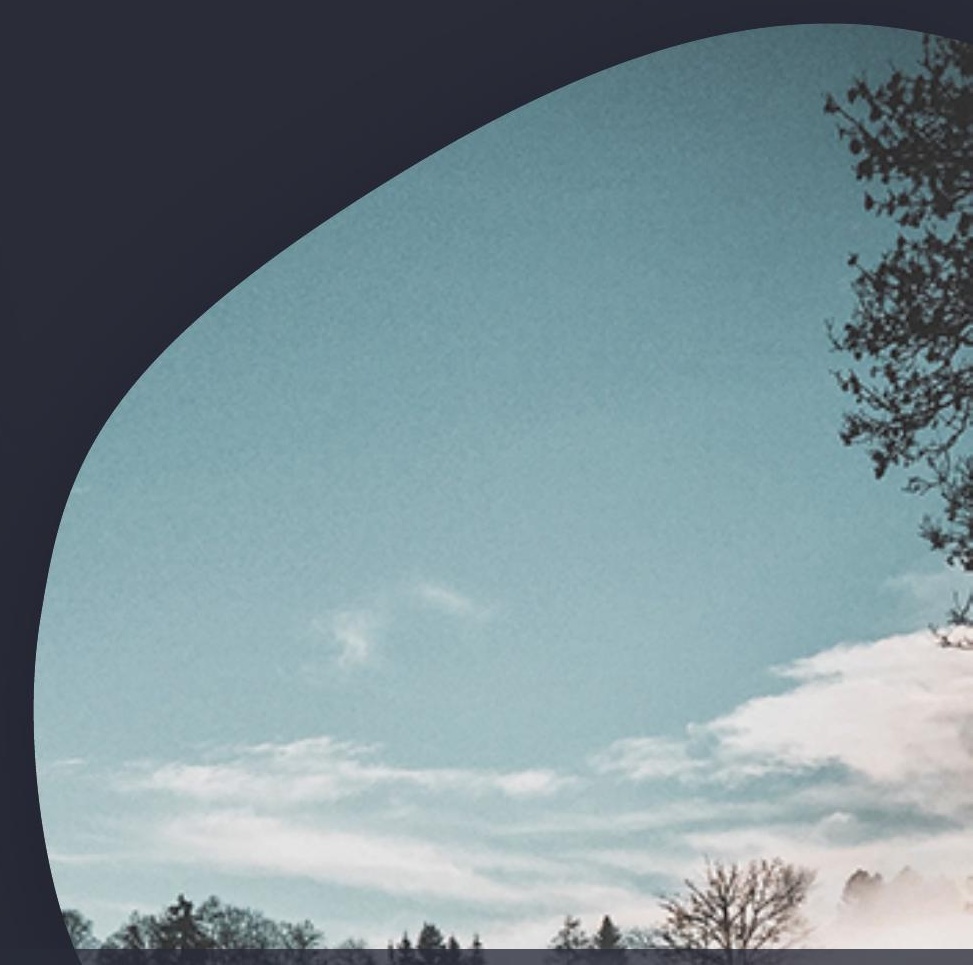

\title{
Mimetismo conductual como marcador de afiliación
}

TESIS DOCTORAL

A NTONIO MARÍN MANRIOUE

DIRIGIDA POR:

AZUCENA GARCÍA PALACIOS HÉCTOR M. MANRIOUE 


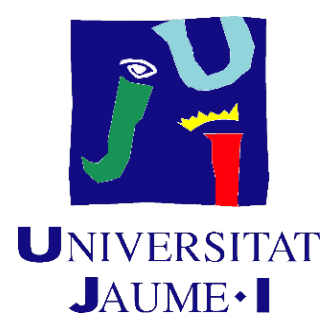

\section{Mimetismo conductual como marcador de afiliación}

Memoria presentada por Antonio Marín Manrique para optar al grado de doctor/a en régimen de cotutela por la Universitat Jaume I y por la Universidad de Zaragoza

Programa de Doctorado en Diseño, Gestión y Evaluación de Políticas Públicas de Bienestar Social

Escuela de Doctorado de la Universitat Jaume I

Departamento de Psicología y Sociología

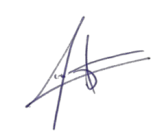

Antonio Marín Manrique

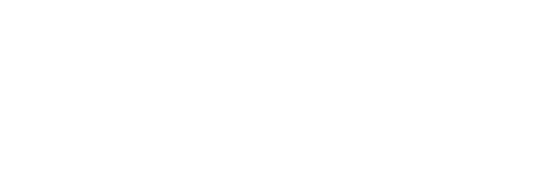

Dra. Azucena García Palacios

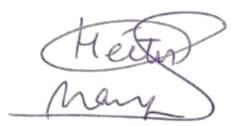

Dr. Héctor M. Manrique

Castelló de la Plana, noviembre de 2021 


\section{Licencia CC Reconocimiento - Compartir igual (BY-SA).}

(c) (-) (-) Se puede reutilizar contenido de tu tesis indicando expresamente que cc) tu eres el autor/a. También se pueden crear otras obras a partir de la tuya, siempre con la misma licencia que la de tu tesis.

Esta tesis no ha recibido financiación de agencias públicas o privadas. 
A la familia..

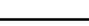





\section{Agradecimientos}

Quiero expresar mi más profundo agradecimiento a mis directores, Azucena García Palacios y Héctor M. Manrique. A Azucena por su incondicional confianza y apoyo constante ante cada imprevisto que ha aparecido en este periplo. A Héctor, por su perenne disponibilidad, por la transmisión de conocimiento, las discusiones y debates que no han hecho más que enriquecerme y llevar a buen puerto esta empresa. A Henriette, por brindarme la oportunidad de llegar a los Samburu y por hacer lo complejo sencillo. A Jenny Amanda Ortiz Muñoz, y a la Universidad del Rosario, por el acogimiento y enseñanzas que me han brindado en la estancia doctoral. A mi familia, la que me vio nacer, a mis padres Carmen y Antonio, por su bondad, por sus valores y por su esfuerzo, lo bueno que haya en mí se debe a ellos. A mi hermano, por estar siempre a mi lado, confiar en mí, y juntos mantener viva la esencia de nuestros padres. A mi abuelo Pascual, por las historias y cuentos de mi niñez y por su sonrisa que nunca olvidaré. A mi esposa Paula, la mujer de mi vida. Por estar siempre a mi lado incondicionalmente, por su corazón, fortaleza y principios, y por la bonita familia que hemos formado, esta tesis se la dedicó especialmente a ella. Al niño Matías, por arrancarme siempre una sonrisa y enseñarme cada día lo bonita que puede ser la vida. 

Resumen/Abstract/Resum 



\section{Resumen}

Existe una abundante literatura científica que establece que la sincronía y el mimetismo conductual fomenta la afiliación, y puede usarse para inferir la "entitatividad" o la medida en que varias personas forman una unidad social. Sin embargo, estos estudios no separan la contingencia de tiempo entre los gestos de los interactuantes de la contingencia en la forma de los mismos y, por lo tanto, es imposible establecer cuál de los dos desempeña un papel más importante. El presente trabajo tiene como objetivo separar experimentalmente estas dos variables que aparecen normalmente acopladas, para ver cuál es más determinante para atribuir afiliación. Para probar esta hipótesis, presentamos a los participantes de una sociedad occidental a gran escala (Experimento 1) y una sociedad tradicional a pequeña escala en Kenia (Experimento 2) tres videos de 5 minutos en los que dos actores mostraban exactamente los mismos gestos, excepto por el grado de correspondencia temporal entre sus gestos en cada uno de los videos. Se utilizó un filtro oscuro para eliminar las marcas ostensivas de pertenencia a grupo, como son el fenotipo o la ropa. Los participantes de ambas sociedades atribuyeron el mayor grado de afiliación a los actores cuando se imitaban en cuanto a la forma de los gestos, y el menor grado cuando se movían en sincronía, pero mostraban gestos diferentes. En el Experimento 3, eliminamos el filtro de video que oscurecía los rasgos y vestimenta de los actores y observamos que el fenotipo y el estilo de ropa bloquearon el efecto afiliativo que la contingencia de gestos produjo en los experimentos previos. Concluimos, por tanto, que la imitación de los gestos en cuanto a la contingencia en su forma (y no tanto en el tiempo) es un sistema universal complementario para establecer el grado de pertenencia conjunta o "entitatividad".

Palabras clave: afiliación, transculturalidad, entitatividad, intragrupo, mimetismo, shibboleth. 



\section{Abstract}

There is an abundant scientific literature that establishes that synchrony and mimicry of behaviour fosters affiliation, and can be used to infer "entitativity" or the extent that people form a social unit. However, these studies fail to separate the matching in time of the behaviour from its matching in form, and hence it is wellnay impossible to establish which of the two play a more important role. The present work is intended at disentangling these two normally coupled variables in order to see which one (if any) is more determinant in order to attribute affiliation. To test this hypothesis, we presented participants from a large-scale, Western society (Experiment 1) and a traditional, small-scale society in Kenya (Experiment 2) with three 5-minutes videos in which two actors displayed the exact same gestures, except for the degree of temporal correspondence between their gestures in each of the videos. A dark filter was used to eliminate ostensive group membership marks, such us phenotype or clothing. Participants from both cultural backgrounds attributed the highest degree of affiliation to the actors when they mimicked each others' gestures, and the lowest degree when they moved in synchrony, but displayed different gestures. In Experiment 3 we lifted the video filter that obscured the actors' features and observed that phenotype and clothing style trump behavioural contingency when it comes to inferring others' affiliative status. We conclude that the the imitation of gestures in terms of contingency in their form (and not so much in time) is a complementary universal system to establish social units.

Keywords: affiliation, cross-cultural, entitativity, in-group, mimicry, shibboleth. 



\section{Resum}

Hi ha una abundant literatura científica que estableix que la sincronia i el mimetisme conductual fomenta l'afiliació, i pot usar-se per inferir la "entitativitat" o la mesura que diverses persones formen una unitat social. No obstant això, aquests estudis no separen la contingència de temps entre els gestos dels interactuants de la contingència en la forma dels mateixos $i$, per tant, és impossible establir quin dels dos té un paper més important. El present treball té com a objectiu separar experimentalment aquestes dues variables que apareixen normalment acoblades, per veure quina és més determinant per atribuir afiliació. Per provar aquesta hipòtesi, presentem als participants d'una societat occidental a gran escala (Experiment 1) i una societat tradicional a petita escala a Kenya (Experiment 2) tres videos de 5 minuts en què dos actors mostraven exactament els mateixos gestos, excepte pel grau de correspondència temporal entre els seus gestos en cadascun dels vídeos. Es va utilitzar un filtre fosc per eliminar les marques més reveladores de pertinença a grup, com són el fenotip o la roba. Els participants de les dues societats van atribuir el major grau d'afiliació als actors quan es imitaven pel que fa a la forma dels gestos, $\mathrm{i}$ el menor grau quan es movien en sincronia, però mostraven gestos diferents. En l'Experiment 3, varem eliminar el filtre de vídeo que ocultava els trets i vestimenta dels actors i vam observar que el fenotip i l'estil de roba bloquegen l'efecte afiliatiu que la contingència de gestos produia en els experiments previs. Concloem, per tant, que la imitació dels gestos quant a la contingència en la seua forma (i no tant en el temps) és un sistema universal complementari per a establir el grau de pertinença conjunta o "entitatividad".

Paraules clau: afiliació, transculturalitat, entitativitat, intragrup, mimetisme, shibboleth. 

Índice 



\section{Índice}

Capítulo 1. Marco conceptual ......................................................23

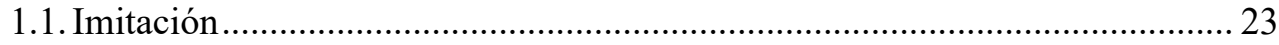

1.1.1. El problema de correspondencia percepción-acción "the correspondence problem"..

1.1.2. Las neuronas espejo: ¿mecanismo biológico innato que resolvería el pro-

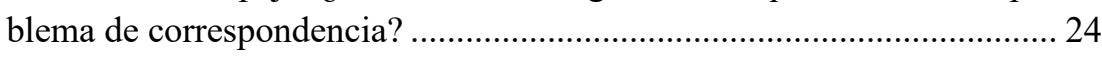

1.2. Imitación para aprender versus imitación para afiliar: Mimetismo o "efecto

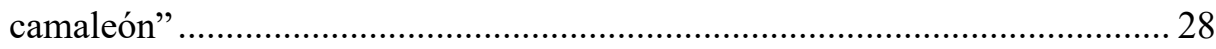

1.2.1. Factores que modulan el mimetismo conductual ...................................... 30

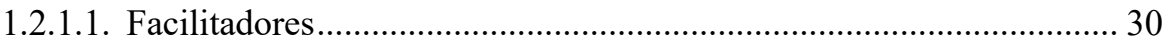

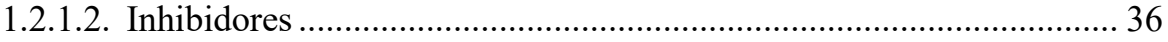

1.2.2. Efectos atribuidos al mimetismo conductual ............................................. 37 
1.3. Mimetismo conductual y pertenencia a grupo (“in-group vs out-group") ...... 37

1.4. ¿Qué función cumple/ha cumplido el mimetismo conductual "efecto cama-

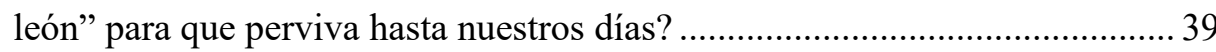

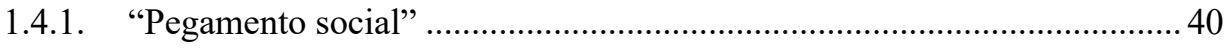

1.5. Sincronía interpersonal vs mimetismo conductual ........................................ 41

Capítulo 2. Objeto y pregunta de investigación ...................... 47

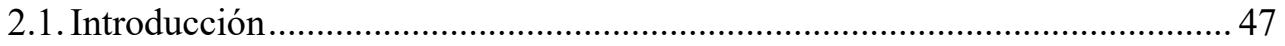

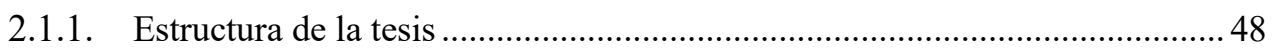

2.2. Objetivo y pregunta de investigación ........................................................... 49

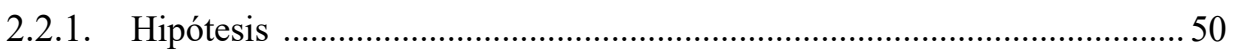

Capítulo 3. Experimento I. El papel de la sincronía y/o mimetismo conductual como marcador de afiliación ............................. 53

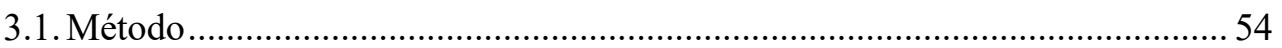

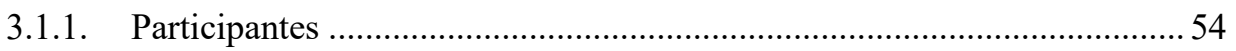

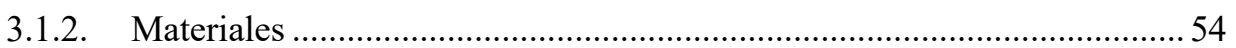

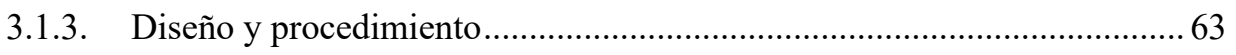

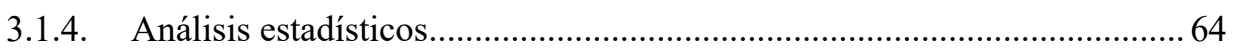

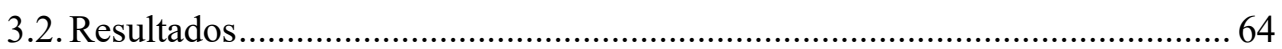

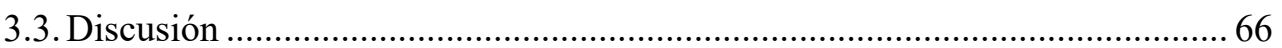

Capítulo 4. Experimento II. ¿Tiene el mimetismo conductual el mismo papel afiliativo en otro tipo de sociedades?.................... 69

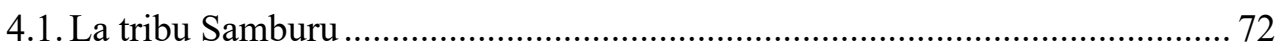

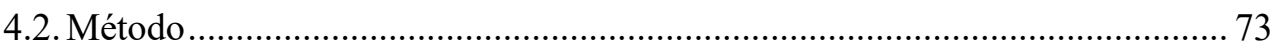

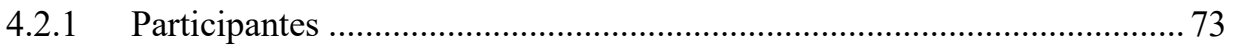

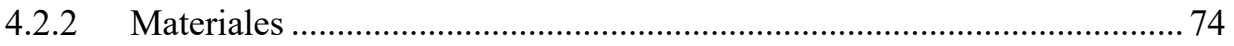




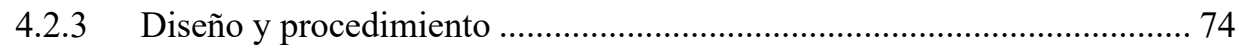

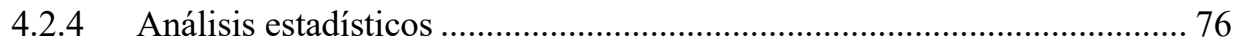

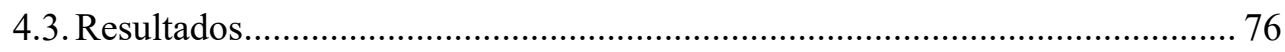

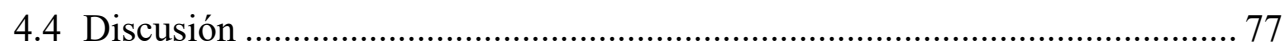

Capítulo 5. Experimento III. ¿Es el mimetismo conductual un indicador del grado de afiliación principal o secundario en rela-

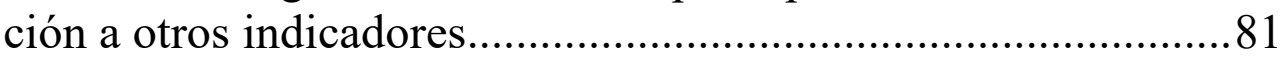

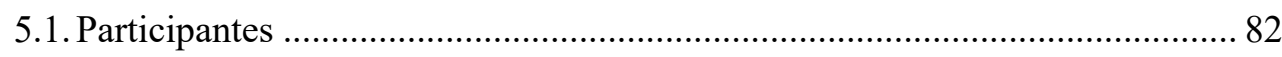

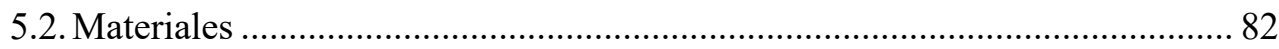

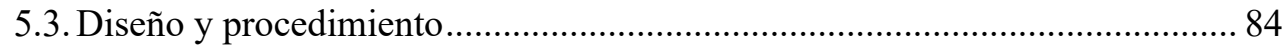

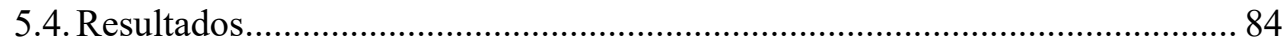

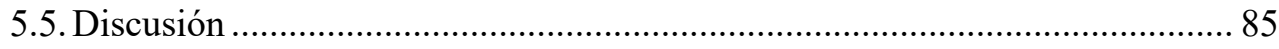

Capítulo 6. Discusión General y Conclusiones.............................91

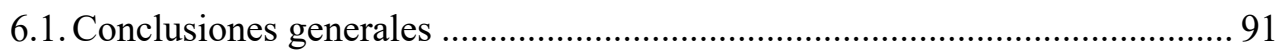

6.2. Aspectos proximales y funcionales que podrían ayudar a diferenciar entre la sincronía interpersonal y el mimetismo conductual, y apuntar a su posible unidad en la adaptación al ambiente............................................................. 97

6.3. Limitaciones y futuras líneas de investigación........................................ 101

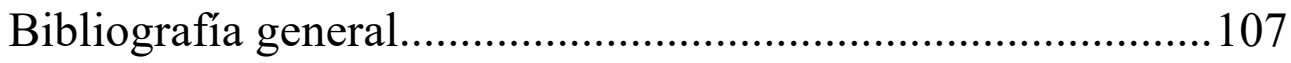

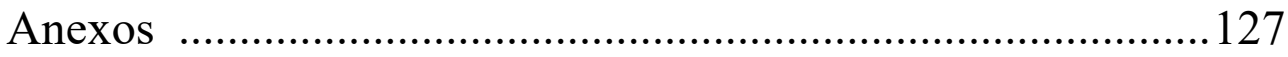



Capítulo 1. Marco conceptual 



\section{Capítulo 1}

\section{Marco conceptual}

\subsection{Imitación.}

La imitación parafraseando a la profesora Cecilia Heyes, es el Lamborghini del aprendizahe social (Heyes, 2018). Consideramos imitación cuando el observador reproduce las acciones del modelo de manera fiel, sin omitir ningún paso, repitiendo la misma secuencia de acciones observada en el mismo orden, sería similar al concepto de "impersonation" introducido en Byrne y Russon (1998). A diferencia de otros modos de transmisión de información por vía contacto social, como la emulación, la imitación permite el aprendizaje de procedimientos y conductas complejas en un tiempo record. La imitación se ha considerado tradicionalmente como un instinto, una predisposición innata que ha jugado un papel central en la capacidad del ser humano para usar herramientas (Washburn, 1913). Lo cual explicaría la transmisión horizontal (entre miembros de la comunidad) y vertical (entre generaciones) de aprendizajes complejos y costumbres que son útiles para la vida en sociedad y que permiten la adaptación humana a nichos ecológicos muy variados. 
Existen dos nociones claramente diferenciadas respecto a lo que constituye imitación: la primera, muy extendida sobre todo entre los psicólogos experimentales, se refiere a la capacidad de un individuo para reproducir un acto perteneciente a su patrimonio motor, tras haber visto a otros realizarlo; la segunda, más desarrollada entre los etólogos, supone que, mediante la observación, un individuo aprende un patrón de acción nuevo y es capaz de reproducirlo en sus varios detalles, en esta segunda perspectiva no es necesario entender la meta que persigue el modelo (Byrne, 2003; Tomasello \& Call, 1997).

\subsubsection{El problema de la correspondencia percepción-acción "the correspondence problem".}

Andrew Metzoff proporciona una definición precisa del llamado "correspondence problem". En un trabajo pionero se preguntaba como un sistema cognitivo puede "connect the felt but unseen movements of the self with the seen but unfelt movements of the other?" (Meltzoff \& Moore, 1997:179).

En la década de los setenta las teorías sobre la imitación de Meltzoff, consideraban a los recién nacidos capaces de imitar de manera intencional, y no solo como un reflejo de actos simples del modelo (principalmente sacar la lengua), eran el paradigma imperante y la observación de que los recién nacidos ya mostraban indicios de imitación de gestos faciales y movimientos sencillos de las manos. Esto llevó a algunos autores (Meltzoff \& Moore, 1977) a postular que el problema de la correspondencia o la superposición topográfica de la percepción y la acción motora de los gestos imitados, se resolvía por medio de un mecanismo biológico innato.

\subsubsection{Las neuronas espejo: ¿mecanismo biológico innato que re- solvería el problema de correspondencia?}

Diversos experimentos psicofisiológicos han descubierto un tipo de neuronas o circuitos neuronales presentes en monos y humanos, que son capaces de trazar las 
Capitulo 1. Marco conceptual.

acciones manuales observadas y vincularlas con la misma acción motora efectuada por el observador. En concreto, los mismos circuitos neurales de la corteza parietal temporal, se activarían al realizar una acción motora y también al observar a alguien realizar la misma acción (Di Pellegrino et al., 1992; Gallese et al., 1996; Iacoboni et al., 1999; Keysers \& Fadiga, 2008; Nelissen et al., 2011; Papadourakis \& Raos, 2018; Rizzolatti \& Craighero, 2004; Rizzolatti \& Sinigaglia, 2006; 2008; Rizzolatti et al., 2004).

En la actualidad, contamos con una ingente cantidad de literatura científica sobre la acción y el posible papel que juegan las neuronas espejo en muy diversos procesos cognitivos, que abarcan el aprendizaje instrumental, la capacidad de pantomima, la resonancia emocional y/o la empatía. Las neuronas espejo son mecanismos sensoriomotores presentes, tanto en áreas sensoriales y motoras del cerebro como en el lóbulo temporal (Mukamel et al., 2010), asociado con la memoria.

Hay estudios que demuestran que cuando se entrena a macacos en el uso de herramientas sencillas, estas herramientas son asimiladas topográficamente en la representación cerebral del propio cuerpo de los macacos, es decir, serán tratadas como un apéndice biológico más, integrado en el esquema corporal del propio animal. Esta asimilación topográfica se produciría probablemente porque, a diferencia de lo que ocurre en macacos no entrenados, el entrenamiento habría inducido una extensión anatómica de los axones eferentes que parte de las neuronas temporo-parietales, en las capas superficiales del surco intraparietal (que contiene neuronas canónicas), donde podrían hacer contacto sináptico con las neuronas parietales (Iriki 2006; Iriki $\&$ Sakura 2008); lo más interesante es que la asimilación de la herramienta a la representación interna de la acción manual, cesaría cuando el mono no sujeta la herramienta y por tanto no la está utilizando. Tal vez, estudios como estos implican la existencia en monos de un mecanismo neurológico para el recuerdo episódico de patrones de acción secuenciales motores, reforzados a través del ensayo-error. Una 
conjetura plausible es que la expansión del lóbulo parietal, característica de la evolución cerebral humana, estaría ligada al uso regular de herramientas. En relación al problema de la correspondencia, el hecho de que la experiencia motora con instrumentos externos, permita la representación topográfica de los mismos en el propio esquema corporal, indica la plausibilidad de que la conducta motora de otros individuos también pueda ser integrada en el propio esquema corporal (ej: corporeizada), en este caso, y por motivos obvios de economía energética, activando los mismas áreas motoras implicadas en el movimiento observado y posibilitando la imitación fidedigna de la conducta observada.

El aprendizaje incide en el desarrollo de la llamada multimodalidad o polimodalidad, además de la plasticidad de los circuitos neurales intracorticales. Esta polimodalidad permite la integración de lo que es mantenido en el campo de visión con las acciones motoras espacio-temporales; en particular, parece que existirían circuitos neurales específicos que se ocuparían de integrar aquellos elementos del campo visual que están siendo atendidos con los movimientos corporales, proporcionando una correspondencia temporal y de orientación (Maravita \& Iriki, 2004; Maravita et al., 2003).

Es interesante resaltar que la activación de las neuronas espejo, refleja su capacidad para representar y/o anticipar las potenciales acciones ajenas (Maranesi et al., 2014), pero sin embargo observar a alguien hacer pantomimas "imitación de gestos sin una meta instrumental específica" no provoca la activación de las neuronas espejo en monos, a diferencia de lo que ocurre en humanos. Esto podría conferir una ventaja exclusiva en los niños humanos a la hora de aprender por imitación no solo conductas dirigidas a meta que involucran el uso de herramientas sino todo tipo de gestos, incluidos aquellos que se relacionan con el mimetismo conductual, objeto de la presente tesis y que más adelante definiremos (Oberman \& Ramachandran, 2007). A diferencia de lo que ocurre en otros simios antropomorfos, los niños captan de manera casi inmediata la naturaleza y propósito de los gestos que realiza un mimo. 
Resulta plausible pensar que la respuesta de las neuronas espejo posibilitaría la conducta de imitación (Iacoboni et al., 1999) y estas neuronas serían por tanto reclutadas durante el aprendizaje por observación. Iacoboni $(2005 ; 2009)$ propone que el circuito de neuronas espejo estaría involucrado en la conducta de imitación del siguiente modo: La información visual se codifica en el cortex temporal superior; posteriormente se manda una señal al cortex parietal posterior, que proporciona información sensoriomotora sobre la acción observada por medio de las neuronas canónicas; en ese momento la señal sería enviada, a su vez, a las neuronas espejo frontales que codificarían la meta/objetivo de la acción a ser imitada. Sin embargo, antes de que la señal sea enviada al cortex motor primario, una copia eferente de la orden motora es mandada de vuelta al surco temporal superior para ver si hay un acoplamiento "match", perfecto entre las consecuencias sensoriales previstas de la conducta a imitar y la descripción visual de la conducta observada. Si el acoplamiento entre ambas es adecuado el cortex motor primario iniciará la acción.

La activación de las neuronas de las cortezas motora suplementaria y temporal (hipocampal) se corresponde con la ejecución y observación de actos manuales, aunque la observación de estos últimos en ocasiones induce respuestas inhibitorias, quizás reflejando la capacidad de diferenciar los aspectos perceptivos y motores llevados a cabo por otras personas de los propios (Mukamel et al., 2010).

La junción temporoparietal derecha "right temporoparietal junction" también se ha visto involucrada en la capacidad para distinguir la imitación de las acciones propias, respecto de la imitación de las conductas ajenas (Sowden \& Catmur, 2015). Iacoboni (2009) propone que la generación de acciones nuevas implica la descomposición de estas en actos familiares más sencillos cuya representación mental se podría reorganizar vía circuitos de neuronas espejo para permitir la imitación, posiblemente a través de la conexión de vías neurales caudales y dorsolaterales de la corteza prefrontal. 
Parece ser que el sistema de neuronas espejo no se encargaría de almacenar recuerdos, aunque sí, como propone Iacoboni, estaría involucrado en el aprendizaje por imitación. Es concebible que a través del acoplamiento "match" acción-observación, pueda jugar un papel relevante en la iniciación y la creación de memorias que serán consolidadas y almacenadas a largo plazo (Ashby et al., 2010; Doyon \& Benali, 2005; Pennartz et al., 2011; Balsters \& Ramnani, 2011; Balsters et al., 2013).

Tal como se desprende de todo lo discutido en este apartado, el estudio de las neuronas espejo se ha llevado a cabo fundamentalmente en el campo del uso de herramientas, y el aprendizaje instrumental, y no tanto en el de la imitación gestual tipo pantomima que estaría más alineada con el mimetismo conductual que más adelante definiremos. Sin embargo, el comportamiento de este sistema neuronal evidencia su potencial para registrar las acciones observadas y acoplarlas con los sistemas motores propios involucradas en su producción, y por ello parece un sistema privilegiado, a la hora de solucionar el problema del acoplamiento percepción-acción a que Meltzoff hacía referencia (Meltzoff \& Moore, 1997).

\subsection{Imitación para aprender versus imitación para afi- liar: Mimetismo conductual o "efecto camaleón".}

Cuando dos o más personas interaccionan entre sí, es habitual que adquieran las mismas posturas, o realicen los mismos gestos — tocarse la cara, jugar con el pelo-, o empleen el mismo vocabulario; todo esto sin que ninguno de ellos lo registre de manera consciente. Este tipo de mimetismo social se conoce como efecto camaleón ("chameleon effect"), y se ha definido como aquel mimetismo por el cual una persona adopta las posturas, las expresiones faciales, los manierismos, los patrones de habla y otros comportamientos de su interlocutor, de manera pasiva e inconsciente, fundiéndose con su entorno social, de ahí la metáfora del camaleón (Chartrand \& Bargh, 1999). 
Dado que el mimetismo conductual, también conocido como "efecto camaleón", es el que centra la atención de este trabajo de tesis, queremos proporcionar una definición operativa y clara que sirva de referencia para todo el trabajo. En este sentido consideramos mimetismo conductual cuando un integrante de una interacción social repite gestos sencillos (tocarse el pelo, cruzar las piernas, agitar el pie, etc.) observados en el otro integrante de la interacción en una ventana temporal que va de los 2 segundos a los 5 segundos.

Se han documentado diferentes tipos de mimetismo, aunque podemos clasificarlos en cuatro grandes grupos (Chartrand \& Lakin, 2013, Duffy \& Chartrand, 2015): mimetismo facial, donde uno imita las expresiones faciales de otra persona; mimetismo emocional, donde uno imita las expresiones emocionales de otro, como por ejemplo sonreír al recibir un cumplido; mimetismo verbal, donde uno imita los patrones y las características del habla del otro, como por ejemplo los acentos, la latencia de respuesta o la sintaxis; y mimetismo comportamental, donde uno imita los manierismos, las posturas, los gestos y los movimientos motores de otro, como por ejemplo bostezar, mover la pierna o tocarse la cara. Este tipo de mimetismo, que también recibe el nombre de "efecto camaleón", se suele producir en interacciones directas, es decir participan el imitador e imitado. Nuestro estudio aporta una novedad en este sentido, en cuanto a que la atribución de afiliación se lleva a cabo por parte de observadores externos.

Pero no es suficiente que dos personas interactúen para que se dé el mimetismo; los seres humanos no pueden imitar a todo el mundo en todo momento. A lo largo del estudio del mimetismo, se han encontrado moderadores que afectan a su aparición pertenecientes tanto al imitador (mimicker) como al imitado (mimickee), los cuales serán explicados brevemente a continuación. 


\subsubsection{Factores que modulan el mimetismo conductual.}

A continuación, presentamos una relación de factores tanto facilitadores como inhibidores que modulan los niveles de mimetismo conductual. Nos hemos servido de una extensa revisión realizada por Chartrand y Lakin (2013), que hemos enriquecido y completado con otros estudios para concluir esta sección.

\subsubsection{Facilitadores.}

Relación preexistente o agrado mutuo: se ha visto que tener una relación afiliativa previa (ej: amistad) hace que la cantidad de mimetismo conductual se incremente en la interacción, también si hay agrado entre las personas que interactúan, con independencia de que tuvieran ya una relación previa (Mclntosh 2006; Likowski 2008) Tener una meta afiliativa explícita: en un experimento controlado, Lakin y Chartrand (2003) explicaron al grupo experimental que iban a interactuar con una persona con la que posteriormente tendrían que colaborar para resolver una tarea conjuntamente, por ello sería conveniente que se llevaran bien. Esta necesidad de llevarse bien hizo que la cantidad de imitación (mimetismo) se incrementara.

Intento de afiliación truncado: en el mismo experimento de Lakin y Chartrand (2003) que acabamos de describir, se observó que aquellos participantes que habían intentado afiliarse con el compañero de interacción, pero fracasado porque este último se había mostrado hostil, incrementaron considerablemente su mimetismo conductual en una interacción posterior; es decir, pareciera que trataban de compensar el fracaso afiliativo previo.

Un estudio reciente obtiene resultados similares en niños ("todlers") de 30 meses; concretamente cuando los niños observaban vídeos en los que una forma geométrica (shape) había sido "marginada" ("ostrasized") por otras formas, incrementaban el mimetismo facial posterior hacia modelos humanos grabados en vídeo (de Klerk, et 
al, 2020). Este estudio es especialmente interesante en relación a la presente tesis, ya que los bebés son observadores externos y sin embargo los efectos que produce el ser testigos de "ostracismo" son equivalentes a los experimentados por aquellos que sufren el "ostracimo" en primera persona.

Semejanza percibida con el imitado o pertenencia conjunta ("belonging together"): cosas tan triviales como compartir el mismo nombre (Guéguen \& Martin, 2009), o usar la misma bufanda o brazalete (Over, Vaish \& Tomasello, 2016) aumentan el mimetismo conductual.

También se ha visto que se imita más a aquellas personas que tienen opiniones similares a las nuestras (Van Swol \& Drury, 2006). En general, se imita más a las personas que encajan con el estereotipo propio (Clark \& Kashima, 2007) o lo que es lo mismo, aquellas que comparten nuestra identidad de grupo (Tsai, 2011). En este sentido, Over y Carpenter (2015) proponen que imitamos más a las personas que se asemejan a nosotros debido a una tendencia biológica natural a desarrollar agrado por aquellos que presentan rasgos comunes.

Expectativas normativas: Tal como proponen Dalton y colaboradores (2010), el mimetismo parece ser dependiente del contexto y describir cierto grado de normatividad (Dalton et al., 2010). Por ejemplo, se espera que un amigo imite, y que un enemigo no imite, nuestros manierismos (normatividad). Basándose en esto, Dalton y colaboradores describen como los sujetos experimentales que interactuaban con un cómplice de su misma raza hicieron mejor una tarea de control inhibitorio tipo Stroop, cuando el cómplice les imitaba (vs. Cuando no les imitaba). Sin embargo, si el cómplice pertenecía a otra raza el efecto se revertía. En otro experimento incluido en el mismo estudio, los participantes asignados al grupo "jefes" se desempeñaron peor en una tarea tipo Stroop cuando el cómplice (al que se le asignó el papel de trabajador) no los imitó, en comparación a cuando sí les imitó. En cambio, los 
participantes asignados al grupo "trabajadores" experimentaron una mayor interferencia negativa en la tarea de Stroop cuando el cómplice ("jefe") los imitó en comparación a cuando no lo hizo.

En esta misma línea, Leander y colaboradores (Leander et al., 2012) describen como los participantes que interactúan con una persona perteneciente a otra raza hacen estimaciones más bajas sobre la temperatura de la habitación cuando son imitadas.

Por el contrario, los participantes que interactúan con un cómplice de la misma raza también estiman que la temperatura ambiente es más baja, pero esta vez cuando no son imitados (vs. imitados).

Estos experimentos de Dalton y Leander y sus colaboradores parecen indicar por tanto que hay ciertas expectativas normativas "implícitas" en cuanto a en qué contexto es correcto o no mimetizarse.

Los ejemplos anteriores investigaban como la violación de una expectativa "normativa" de ser imitado afectaba al desempeño en una tarea atencional, o a la capacidad de estimar la temperatura ambiente. Inspirados por estos hallazgos Majka y colaboradores (Majka y cols., 2020) comprobaron si los sentimientos de afiliación respecto de un imitador se verían afectados por la violación o no de a las expectativas normativas, y vieron que esto no sucedía. Concretamente, el ser imitados por alguien de su misma raza no hizo que aumentara el sentimiento afiliativo hacia el cómplice, así como tampoco disminuyó el sentimiento afiliativo hacia alguien de una raza diferente cuando imitaba al participante. Por tanto, parece que son necesarios más estudios con el fin de dilucidar hasta que punto hay o no expectativas normativas respecto al mimetismo conductual.

Estado de ánimo positivo: se ha visto que si se tiene un estado de ánimo positivo se tenderá a imitar más las expresiones de felicidad (Likowski, 2011). En general, se tiende a mimetizar más las expresiones positivas, a excepción de una emoción 
secundaria como es la culpa. Por ejemplo, cuando alguien ha causado un daño a otra persona y se siente culpable por ello, tiende a imitar más a este último con el objetivo probable de congraciarse o hacer las paces (Martin, 2010).

Orientación prosocial: las personas más orientadas socialmente o más empáticas exhiben mayor cantidad de mimetismo conductual (Chartrand \& Bargh, 1999). De hecho, se ha visto que las personas que son más empáticas tienden a imitar más las expresiones faciales de otras personas, ya sean estas de alegría o de tristeza (Sonnoby-Borgstrom, 2002).

Empatía emocional: a menudo se diferencia entre empatía cognitiva y empatía emocional, la primera haría referencia a la capacidad de ponerse en el lugar del otro a nivel cognitivo-racional y entender que su situación puede ser percibida por el otro como positiva o negativa; la segunda hace referencia a entrar en congruencia emocional con el otro.

En un estudio de Drimalla, Landwehr, Hess y Dziobek (2019) se registró electromiografícamente la expresión facial de los sujetos experimentales mientras completaban la "Multifaceted Empathy Test" y observaron mayores grados de mimetismo en los participantes cuando resolvían tareas de empatía emocional, que cuando resolvían las de empatía cognitiva, sugiriendo que la congruencia emocional podría ser un facilitador del mimetismo.

Culturas colectivistas: se sabe que algunas culturas tienen una idea del "yo" conectada con el contexto. Es decir, interdependiente del contexto. En otras palabras, son menos individualistas y su "yo" se incorpora al grupo al que pertenecen. Se ha visto que los miembros de culturas colectivistas (ej: japonesa), muestran mayores niveles de mimetismo que los miembros de culturas más individualistas (ej: estadounidense) (van Baaren et al., 2003). 
Estilo de procesamiento dependiente de contexto: se sabe que hay diferencias en el grado en que los individuos diferencian los objetos focales del contexto a la hora de procesar la información visual, este fenómeno es conocido como dependencia de campo/contexto (Witkin \& Goodenough, 1981; Witkin, Goodenough, \& Karp, 1967), y se ha asociado también con el grado en que la imagen de uno mismo incorpora a los demás, siendo las culturas colectivistas más tendentes a incorporar al otro en su imagen propia, y también a procesar los objetos en relación a su contexto. Como acabamos de describir la tendencia a incorporar al otro en la imagen propia va asociada con un mayor nivel de mimetismo conductual (van Baaren et al., 2003). Van Baaren, et al. (2004) realizaron una serie de experimentos en los que ponían a los sujetos experimentales a resolver tareas, en las cuales se primaba uno u otro estilo cognitivo, y vieron que aquellos sujetos que resolvían tareas que requerían integrar figura y contexto exhibían mayores niveles de mimetismo conductual, y viceversa. Además, se vio que si los sujetos se veían expuestos a mimetismo conductual (ej: se les imitaba de manera sutil), antes de realizar las tareas tendían a mostrar un estilo de procesamiento más dependiente del contexto. Es decir, el estilo cognitivo dependiente de contexto y el mimetismo conductual se retroalimentarían mutuamente.

Hormonas: en un estudio controlado sobre mimetismo de la expresión facial (Korb, et al., 2016) se comprobó que la administración nasal (spray) de oxitocina aumentaba significativamente los niveles de mimetismo facial en varones adultos. Curiosamente, el efecto de la oxitocina sobre el mimetismo era mayor cuando el modelo a imitar era un bebé, y cuando la expresión era de enfado en comparación a cuando era de alegría.

Contacto ocular: en un estudio reciente, de Klerk, Hamilton y Southgate (2018), expusieron a bebés de cuatro meses a vídeos donde se mostraban distintas expresiones faciales y codificaron el grado de mimetismo facial exhibido por los bebés y el grado 
de contacto visual con los modelos de los videos. Hallaron que cuanto mayor era el contacto visual bebé-modelo mayor era también el grado de mimetismo registrado. Por lo tanto, el contacto ocular podría ser un elemento desencadenante o facilitador del mimetismo. Cabría determinar si el mismo efecto que se describe en este estudio para la expresión facial, se puede generalizar al mimetismo conductual de gestos y manierismos, que es el foco de interés de la presente tesis doctoral. El mimetismo de la expresión facial, es muy dependiente de micro movimientos musculares y está altamente relacionado con la expresión emocional.

Actitud positiva hacia el imitado: Likowski et al. (2008) realizaron un estudio similar al que acabamos de describir con participantes adultos. En este caso les presentaron tres tipos de avatares, que describieron con adjetivos que mostrarían un personaje bondadoso, otro neutro y otro maligno. Posteriormente, los sujetos experimentales observaron a los avatares reflejar distintas expresiones emocionales, como tristeza y alegría y comprobaron que el mimetismo de la expresión facial, se producía ante las expresiones faciales de los avatares que habían sido presentados de manera positiva. Los que habían sido descritos de manera negativa generaban niveles más bajos de mimetismo e incluso expresiones faciales incongruentes entre avatar-participante. Por lo tanto, tener una buena percepción del otro es un facilitador del mimetismo.

\subsubsection{Inhibidores.}

Estigma social percibido: Johnston (2002) encontró que las personas imitan menos cuando no quieren afiliarse con una persona. Por ejemplo, los participantes imitarían menos a personas que están estigmatizadas de alguna manera (por ejemplo, presentan obesidad, una cicatriz en el rostro, etc.).

Pertenencia a "out-group": Otra variable que conduce a una menor imitación es la pertenencia a otro grupo. Yabar (2006), encontró que mujeres creyentes que conocen 
e identifican la religión de otras personas como distinta a la propia reducirán la cantidad de mimetismo hacia estas últimas.

Tener una relación de pareja: en un estudio controlado aquellos participantes que tenían pareja, mostraron niveles más bajos de imitación de un compañero de interacción atractivo, que los participantes solteros. Al evitar el mimetismo de las personas atractivas, los participantes intentarían presumiblemente proteger sus relaciones actuales (Karremans \& Verwijmeren (2008).

Tener rasgos autistas: Hermans et al. (2009) registraron los niveles de mimetismo de la expresión facial en mujeres con y sin autismo cuando eran instruidas, explícitamente, a que imitaran las expresiones faciales. Cuando lo hacían de manera espontánea, comprobaron que el mimetismo facial espontáneo se veía reducido cuanto mayor puntuación en el espectro autista presentaban las participantes.

Ansiedad social: Vrijsen et al. (2010) registraron el grado de mimetismo en mujeres que puntuaban alto y bajo en ansiedad social ante los movimientos de cabeza de un avatar masculino y comprobaron que el mimetismo espontáneo del avatar era menor en aquellas mujeres que puntuaban alto en ansiedad social.

\subsubsection{Efectos atribuidos al mimetismo conductual.}

Los efectos de ser imitado se pueden resumir en inducir una actitud más positiva hacia el imitador (Chartrand \& Bargh, 1999; Guéguen \& Martin, 2009), facilitar su aceptación (Lakin \& Chartrand, 2003; Lakin, Chartrand, \& Arkin, 2008) o crear la sensación de que el imitador es digno de confianza (Overet al., 2013). De hecho, se ha visto como imitar en un contexto de negociación aumenta la posibilidad de alcanzar un acuerdo (Fischer-Lokou et al., 2014). 
Fisher y Hess (2017) demostraron que las personas imitan las expresiones emocionales de los demás solo cuando existe la posibilidad de afiliación. Por tanto, el mimetismo conductual parece servir como un "pegamento social" o una demostración externa de similaridad con los otros (Lakin et al., 2003). Sin embargo, el efecto afiliativo del mimetismo conductual no se produce siempre, sino que depende de que se den una serie de parámetros. Por ejemplo, si la imitación del compañero de interacción no ocurre dentro de la ventana temporal correcta ( 2 a 5 segundos después), es demasiado exacta o demasiado obvia, la imitación puede ser contraproducente y producir resultados negativos como el rechazo del imitador (Ashton-James et al., 2007; Parrill \& Kimbara, 2006).

\subsection{Mimetismo conductual y pertenencia a grupo ("in- group vs out-group").}

Tal como ya se expuso anteriormente, la detección de pertenencia a grupo ("belonging together") que puede depender de cosas tan triviales como compartir el mismo nombre (Guéguen \& Martin, 2009), o usar la misma bufanda o brazalete (Over, Vaish \& Tomasello, 2016) aumenta el mimetismo conductual (Cheng \& Chartrand, 2003; Tsai, 2011). Lo contrario también se ha descrito, el detectar que alguien no pertenece al grupo propio porque por ejemplo profesa otra religión, reduce el mimetismo (Yabar, 2006).

Otro hecho interesante en relación al papel que el grupo ejerce sobre el mimetismo conductual es que la imitación de los gestos y manierismos de terceros solo aumenta el agrado experimentado hacia ellos si son reconocidos como "in-group" (van der Schalk et al., 2011). Además, se ha visto que haber sido excluido en una interacción, que sería equiparable a ser tratado como "out-group", incrementa la cantidad de mimetismo registrado en interacciones posteriores (Lakin, Chartrand, \& Arkin, 2008), presumiblemente en un intento por ser aceptado. 
Otra relación interesante e intrigante entre la pertenencia a grupo y el mimetismo conductual, es que las personas que son imitadas tienden a comportarse más en línea con los estereotipos de género y raciales que se vinculan a sus grupos de pertenencia. Así pues, Leander, Chartrand y Wood (2011) demostraron que los participantes americanos de origen asiático que eran imitados obtenían resultados por encima de los controles en la resolución de problemas matemáticos, y lo contrario ocurría con participantes americanos de origen africano. Esto indicaría que el ser "mimetizado" hace que las personas tiendan a comportarse de acuerdo con las expectativas ajenas. La razón por la cual el mimetismo se ve incrementado por la pertenencia a grupo, podría obedecer a la tendencia natural a reproducir las conductas de aquellos que guardan similitud con nosotros, originariamente aquellos que pertenecían al mismo grupo étnico; o a un intento consciente y controlado por agradar a aquellos que se reconocen como pertenecientes al grupo propio.

En el primer caso el mimetismo sería una conducta automática biológica dirección abajo-arriba, en el segundo sería una conducta más controlada dirección arriba-abajo que tendría un objetivo estratégico, ser aceptado por el grupo de referencia.

Genschow y Schindler (2016) trataron de averiguar si es la similitud percibida en los miembros del grupo propio, o la motivación por afiliarse con ellos por el hecho de que son identificados como "in-group" lo que potenciaría el mimetismo. En su diseño experimental manipularon la similitud que los supuestos miembros "in-group" y "out-group" guardaban con los sujetos experimentales y vieron que la mayor similitud no generaba por si misma una mayor imitación de los miembros del "outgroup". Es decir, su estudio parecería apoyar la idea de que el mimetismo de los miembros del grupo propio, es una estrategia consciente que tiene como objetivo conseguir la aceptación de los otros significativos. 
Capitulo 1. Marco conceptual.

\section{4.¿Qué función podría haber cumplido el mimetismo con- ductual o "efecto camaleón" para que perviva hasta nues- tros días?}

Algunos autores proponen que el mimetismo podría haber servido originalmente para facilitar el aprendizaje, la coordinación y la sincronía, poniendo el foco en el vínculo necesario entre la percepción y la acción subyacente (Chartrand \& Bargh, 1999; Heyes, 2011; Preston \& de Waal, 2002). Sin embargo, esta explicación resulta insatisfactoria, ya que tanto la coordinación como la sincronía ya están presentes en muchas interacciones animales, sin la necesidad de adoptar la forma específica de mimetismo (repetición demorada de los gestos), que es exclusiva de los humanos. Cuando dos animales están peleando, sincronizan sus movimientos monitorizando de manera precisa los del adversario, pero no se imitan entre sí, y mucho menos se afilian dado el claro carácter antagónico de la interacción.

Tampoco parece muy convincente proponer que el mimetismo conductual se seleccionó como un mecanismo de aprendizaje, ya que el repertorio conductual de los humanos ya incluye mecanismos intencionales para la enseñanza y el aprendizaje que funcionan extraordinariamente bien, y que a menudo se basan en la capacidad de compartir la atención (Bandura, 1977; Carpenter, Tomasello \& Savage-Rumbaugh, 1995; Csibra \& Gergely, 2006). A continuación, proponemos dos posibles funciones alternativas que, en nuestra opinión, podrían haber conferido al mimetismo conductual un valor adaptativo.

\subsection{1. "Pegamento social".}

Como ya describimos anteriormente el "efecto camaleón" se refiere a la tendencia a adoptar las posturas, gestos y costumbres de los compañeros de interacción (Chartrand \& Bargh, 1999). Este mimetismo se produce fuera de la conciencia, y por tanto 
sin control voluntario. La evidencia empírica sugiere una relación bidireccional entre el mimetismo no consciente, por un lado, y el agrado y la afiliación por el otro. Es decir, la imitación no consciente crea afiliación, y a su vez la afiliación se expresa también a través de la imitación no consciente.

Tal y como discuten Lakin y Chartrand (2005), desde una perspectiva darwiniana afiliarse con otros miembros del grupo constituye una ventaja adaptativa evidente. Nuestros antepasados vivían en un entorno donde los individuos que "iban por su cuenta" no siempre eran capaces de sobrevivir y reproducirse con éxito. Las exigencias de un entorno hostil y demandante, empujó a los individuos a depender los unos de los otros para completar actividades de supervivencia (por ejemplo: localizar y custodiar las fuentes de alimento y refugio, defenderse de los depredadores, cuidar de la descendencia, etc.).

La organización grupal, por tanto, se convirtió en la manera más eficiente de solucionar los problemas ecológicos $\mathrm{y}$, satisfacer las necesidades biológicas individuales. De hecho, la vida en grupo, más allá de la familia directa, que implicaría colaborar tanto con parientes como con no parientes, sería un factor determinante en relación a la capacidad del ser humano para sobrevivir y reproducirse (Foley \& Gamble, 2009). En este contexto, aquellos individuos que mejor toleraran la proximidad con otros congéneres, y/o tuvieran una disposición más pro social serían los que gozarían de mayor aceptación en sus respectivos grupos, y por tanto, de mayores probabilidades de reproducirse. En otras palabras, la orientación social sería un factor selectivo y "seleccionable" importante.

Siguiendo con este argumento, los comportamientos que permitieron a las personas mantener relaciones grupales más armoniosas, se habrían extendido al resto de la población (Barkow, Cosmides \& Tooby, 1992). Hemos visto como el mimetismo 
conductual, o la tendencia a adoptar los comportamientos, posturas y gestos de los compañeros de interacción, facilita la afiliación (Duffy y Chartrand, 2015).

Por tanto, es probable que este mecanismo se hubiera seleccionado porque permitiría a los individuos mantener relaciones más armoniosas con los miembros de su grupo (Chartrand \& Bargh,1999), o en palabras de Lakin et al. (2003), el mimetismo conductual se habría seleccionado porque actúa como una especie de "pegamento social", y ejerce por tanto una función cohesionadora. Una gran ventaja del mimetismo conductual en relación a la cohesión de grupo es que es un mecanismo barato en términos energéticos, ya que es automático, y este mismo hecho hace que no interfiera ni compita por recursos atencionales con otros procesos cognitivos superiores.

\subsection{Sincronía interpersonal vs mimetismo conductual.}

Un fenómeno similar al mimetismo conductual y que produce efectos afiliativos casi idénticos es la llamada sincronía interpersonal, o "entrainment". A diferencia del mimetismo conductual, que no requiere de claves rítmicas externas, la sincronía interpersonal consiste en que dos o más personas se mueven siguiendo un mismo ritmo/tempo externo y común (Hove \& Risen, 2009). Lakens y Stel (2011) investigaron los efectos de la sincronía interpersonal pidiendo a los sujetos experimentales que visionaran grabaciones donde aparecían dos personas saludando con la mano, para después pedirles que juzgaran su grado de relación. Lo que hallaron fue que cuando las personas del vídeo saludaban siguiendo el mismo ritmo (velocidad) se les atribuía automáticamente un mayor grado de afiliación y entidad conjunta "entitativity" en relación a cuando saludaban siguiendo ritmos distintos. Por lo tanto, se vio que no era tanto la contingencia en la forma de la conducta de saludar (mimetismo), sino la contingencia en el tiempo o ritmo común del movimiento (sincronía) lo que evocaba nociones de afiliación y entidad conjunta. 
Otro hallazgo interesante del mismo estudio es que cuando los participantes veían a dos actores que se movían sincronizando sus pasos porque se les había instruido así, no se generaba esta idea de afiliación o entidad conjunta. Es decir, al igual que el mimetismo surte sus efectos sin que haya consciencia de imitar o ser imitado, la sincronía interpersonal funcionaría también a un nivel no consciente.

Cirelli, Einarson, \& Trainor (2014) demostraron que bebés de catorce meses que habían sido mecidos por un adulto eran más solícitos a la hora de ayudar a otro adulto que se había balanceado a su mismo ritmo, que a uno que se había balanceado a un ritmo distinto. En línea con estos resultados, Fawcet y Tuncgenc (2017), observaron que bebés de quince meses inferían que dos personajes que se habían movido en sincronía (mismo ritmo) tenderían a afiliarse.

Otras investigaciones han demostrado, que no solo ver dos o más personas moverse al mismo ritmo evoca nociones de afiliación o pertenencia conjunta, el mero hecho de escuchar los pasos de dos personas es suficiente para activar regiones más amplias del cerebro, que cuando se escuchan los pasos de una única persona (Saarela \& Hari, 2008). Miles, Nind y Macrae (2009) demostraron que el modo de sincronía interpersonal influye de manera importante en la afiliación, y que las formas más estables de coordinación (movimiento en fase y anti-fase) producen los mayores efectos de " $r a$ port”. Catmur y Heyes (2013), quisieron averiguar si es la similitud de los gestos y/o la contingencia temporal de los mismos lo que produce afiliación y encontraron que es el ritmo compartido de las conductas y no su similitud en la forma lo que actúa creando lazos afiliativos.

Algo similar hallaron Hove y Risen (2009), quienes vieron que dos personas que tamborileaban sus dedos en la mesa en sincronía desarrollaban sentimientos más positivos el uno hacia el otro, y este efecto se debía a que seguían el mismo ritmo y no a que realizaban la misma conducta. 
Estos últimos estudios de Catmur y Heyes (2013) y Hove y Risen (2009), nos impulsaron a realizar el presente trabajo de tesis doctoral. Como explicaremos en el siguiente apartado, el primer experimento de esta tesis tiene como objetivo ver si es la contingencia en tiempo, o en forma (mimetismo) la que induce nociones de afiliación o entidad conjunta.

A diferencia de los estudios que acabamos de citar, nosotros queremos explorar que ocurre cuando los actores se mueven al unísono realizando acciones distintas, pero sin que exista un ritmo externo común que los vincule. Si moverse al unísono per se no produce nociones de afiliación sería el ritmo el factor clave.

Nótese que en los experimentos previos de Catmur y Heyes (2013) y Hove y Risen (2009) se estudiaba si era la similitud en la forma de los gestos o el ritmo la que tendría poder afiliativo, pero no implementaron una condición control donde los actores se movían simultáneamente, pero sin seguir un ritmo común.

Otro de los objetivos de la presente tesis es llevar los estudios sobre mimetismo y sincronía interpersonal, fuera de las típicas muestras de universitarios occidentales procedentes de sociedades industrializadas, y extenderlos a tipos de sociedades tradicionales pastoralistas, que raramente se investigan.

La idea es comprobar si los mecanismos afiliativos descritos para nuestras sociedades modernas industrializadas funcionan de igual manera en sociedades de tamaño reducido donde la mayoría de las personas se conocen. 



\section{Capítulo 2. Objeto y pregunta de}

investigación. 



\section{Capítulo 2 \\ Objeto y pregunta de investigación}

\subsection{Introducción.}

Existe una abundante literatura científica que establece que la sincronía y el mimetismo conductual fomenta la afiliación, y puede usarse para inferir la "entitativity", en adelante "pertenencia conjunta", o la medida en que varias personas forman una unidad social. Sin embargo, los estudios previos no suelen separar experimentalmente el factor contingencia de tiempo (sincronía) del factor contingencia de forma (mimetismo conductual) de los gestos, y por tanto, es imposible saber qué factor es más determinante a la hora de atribuir estatus afiliativo y/o pertenencia conjunta. Además, en los estudios previos otros factores que ayudan a inferir el posible estatus afiliativo y/o pertenencia conjunta de personas que interactúan socialmente, los rasgos físicos (fenotipo) y estilo de vestir podrían también afectar a los juicios de los sujetos experimentales. Por último, son escasos, si no inexistentes los estudios sobre sincronía y/o mimetismo conductual realizados con tipos de sociedades tradicionales o de pequeña escala, y por ello, es imposible generalizar los resultados 
más allá de las sociedades industrializadas democráticas de gran escala donde estos se suelen realizar.

El presente estudio tiene dos objetivos principales: el primer objetivo persigue desligar todos los posibles factores que influyen en la atribución de estatus afiliativo y/o pertenencia conjunta y poder tratarlos como variables independientes para así determinar si es la contingencia en tiempo, forma ${ }^{1} \mathrm{u}$ otros factores asociados (fenotipo y/o estilo de vestir) o una combinación de todos ellos, los que influyen en los juicios de nuestros sujetos experimentales. El segundo objetivo busca generalizar los resultados a distintos tipos de sociedades de manera que los resultados puedan ser generalizados a la especie humana en su conjunto.

\subsubsection{Estructura de la tesis}

La tesis se estructura en seis capítulos. En el capítulo 1 se presenta el marco teórico conceptual en el que se expondrán los principales enfoques del mimetismo conductual y la sincronía interpersonal. En el capítulo 2 se abordará el objeto de estudio y las hipótesis. El capítulo 3 plantea el experimento I "Papel de la sincronía y/o mimetismo conductual en la atribución de pertenencia al grupo". En el capítulo 4 se expone el experimento II "¿Es el mimetismo conductual igualmente válido en la identificación de pertenencia a grupo de otras culturas?”. El capítulo 5 exhibe el

\footnotetext{
${ }^{1}$ Cuando nos referimos a contingencia de tiempo significa que los componentes de la interacción inician todos sus movimientos simultáneamente, cuando hablamos de contingencia de forma nos referimos al conocido como "efecto camaleón" donde uno de los integrantes de la interacción realiza un gesto y el otro imita ese gesto en la ventana temporal comprendida entre los 2 y 5 segundos que siguen a este gesto. Queremos dejar constancia de que en la condición contingencia de forma también hay cierta contingencia de tiempo, en tanto en cuanto la imitación se produce tras un corto lapso de tiempo tras el gesto del modelo. No obstante, no hay una sincronía perfecta que sí se produce en nuestra condición contingencia de tiempo.
} 
experimento III: “¿Es el mimetismo conductual un mecanismo de detección de pertenencia a grupo principal o secundario (emergencia) en relación con otros indicadores?”. Finalmente, el capítulo 6 recoge las principales conclusiones obtenidas.

\section{Figura 2.1. Estructura de la Tesis}

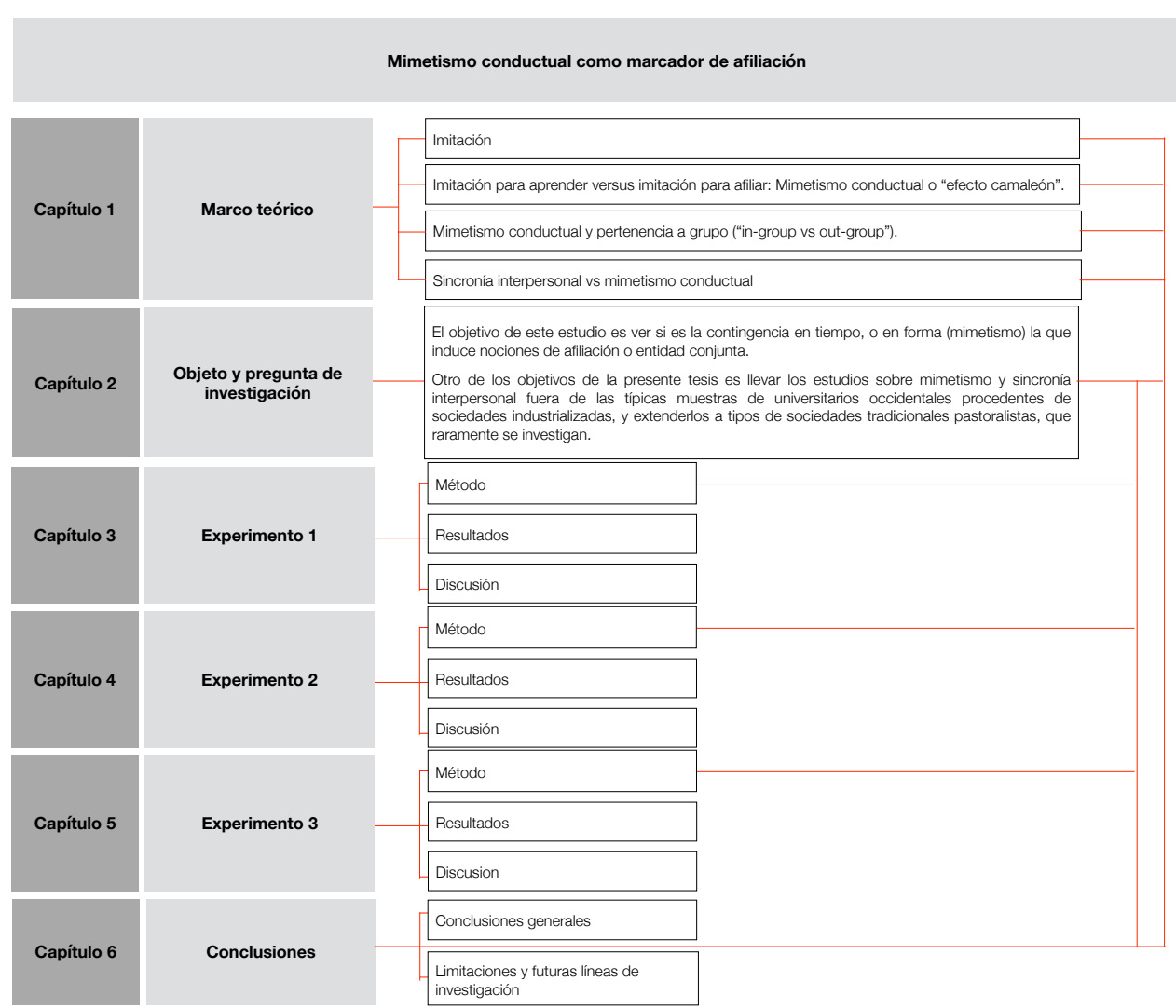

Fuente: Elaboración propia.

\subsection{Objetivo y pregunta de investigación.}

El objetivo de este estudio es ver si es la contingencia en tiempo, o en forma (mimetismo) la que induce nociones de afiliación o entidad conjunta. 
Otro de los objetivos de la presente tesis es llevar los estudios sobre mimetismo y sincronía interpersonal fuera de las típicas muestras de universitarios occidentales procedentes de sociedades industrializadas, y extenderlos a tipos de sociedades tradicionales pastoralistas, que raramente se investigan.

\subsubsection{Hipótesis.}

Proposición 1a: La sincronía, definida como contingencia en el tiempo de los gestos entre personas interactuantes, evoca nociones de afiliación y "pertenencia conjunta".

Proposición 1b: El mimetismo conductual, definido como contingencia en la forma de los gestos entre personas interactuantes, evoca nociones de afiliación y "pertenencia conjunta".

Proposición 1c: El mimetismo conductual es un indicador del estatus afiliativo y/o pertenencia conjunta también en otras culturas.

Proposición 1d: El mimetismo conductual es un mecanismo de detección de pertenencia conjunta y estatus afiliativo secundario (complementario) en relación con otros indicadores más ostensibles. 
Capítulo 3. Experimento I. 



\section{Capítulo 3 \\ Experimento I. EI papel de la sincronía y/o mi- metismo conductual como marcador de afi- liación.}

Lakin et. al., (2003) sugieren que el mimetismo sirve como "pegamento social" que demuestra similitud con otros. Over y Carpenter (2015) comparten esta visión del mimetismo como demostración externa de semejanza, quienes sostienen que la capacidad del mimetismo para ganarse el favor de los demás se debe a una tendencia biológica a agradar y a que nos agraden aquellos que se parecen a nosotros. $\mathrm{Si}$ bien todos estos estudios apuntan al mimetismo como un marcador potencial de pertenencia a un grupo, a menudo ignoran las circunstancias exactas que deben darse para que el mimetismo genere afiliación. De hecho, los efectos descritos parecen depender de un conjunto ajustado de parámetros. Por ejemplo, si la imitación del compañero de interacción no ocurre dentro de la ventana temporal correcta ( 2 a 5 segundos después), es demasiado exacta u obvia, la imitación puede ser contraproducente y producir resultados negativos como el rechazo del imitador (Parrill \& Kimbara, 2006; Ashton-James et al., 2007). 
El objetivo del presente estudio es investigar dos de los factores potenciales involucrados en los efectos afiliativos que produce el mimetismo conductual, y comprobar si es la contingencia temporal de los gestos observados, su contingencia en la forma, o ambas, las que son importantes para juzgar si los individuos que interactúan forman una unidad social (tienen lazos afiliativos).

Recordamos al lector que en este trabajo cuando hablamos de mimetismo nos referimos a la repetición de gestos simples que se produce en la ventana temporal que abarca de los 2 a los 5 segundos posteriores.

\subsection{Método.}

\subsubsection{Participantes.}

En este experimento participaron un total de sesenta y cuatro estudiantes universitarios españoles de edades comprendidas entre los 18 y los 37 años. Cuarenta y ocho estudiantes (40 mujeres, 8 hombres) procedían de la Universidad de Zaragoza (edad media $=19,14, \mathrm{SD}=1,63)$ y dieciséis estudiantes $(15$ mujeres, 1 hombre $)$ procedían de la Universidad Jaume I (Edad media $=25,5, \mathrm{SD}=3,75)$. La participación fue totalmente voluntaria y no formaba parte de las actividades propias del grado. El estudio fue aprobado por el comité ético de la Universidad Jaume I y se adhirió a las normas aplicables a la experimentación humana.

\subsubsection{Materiales.}

Se grabaron tres videos diferentes en los que dos actores estaban sentados uno al lado del otro en dos sillas separadas por 0,5 metros y cuyos respaldos tocaban la pared trasera. Durante la grabación, los actores siempre miraban al frente. Debido a que los sujetos experimentales debían calificar el grado de afiliación existente entre los actores, no se aconsejaba sentar a dichos actores uno enfrente del otro. 
Tenerlos sentados cara a cara durante cinco minutos sin hablar crearía una situación muy artificial, y permitirles hablar daría la impresión de que ya se conocían. Grabarlos uno al lado del otro crearía una situación más natural que podría aplicarse a extraños sentados en una sala de espera, y también a familiares o amigos que se conocen tan bien que no tienen nada nuevo que comentar durante 5 minutos.

Las tablas 3.1, 3.2 y 3.3 describen en detalle los gestos y manierismos adoptados por cada actor en los tres videos y el momento exacto en que se producen. Ambos actores realizaban el mismo tipo de gestos en los tres videos, pero se manipuló la contingencia en forma y tiempo de los mismo para crear las tres condiciones/videos siguientes:

- Video 1) Condición contingencia nula: Se organizaron posturas y gestos para evitar cualquier contingencia entre los actores;

Tabla 3.1 Descripción de los comportamientos mostrados por cada actor en la condición de "Contingencia nula".

\begin{tabular}{llll}
\hline & & CONTINGENCIA NULA & $\begin{array}{c}\text { Tiempo } \\
\text { en el que } \\
\text { empieza } \\
\text { la acción }\end{array}$ \\
\hline $\begin{array}{l}\text { Postura } \\
\text { Inicial }\end{array}$ & $\begin{array}{l}\text { Izquierda } \\
\text { Derecha }\end{array}$ & $\begin{array}{l}\text { las piernas forman un ángulo de } 90^{\circ}, \text { las manos des- } \\
\text { cansan sobre las rodillas piernas cruzadas, brazos } \\
\text { cruzados }\end{array}$ & $\begin{array}{l}\mathbf{0 : 0 0 : 0 0} \\
\mathbf{0 : 0 0 : 0 0}\end{array}$ \\
\hline Acción 1 & Izquierda & se rasca la cabeza con la mano derecha & $\mathbf{0 : 0 0 : 0 5}$ \\
\hline Acción 2 & Derecha & comienza a bostezar & $\mathbf{0 : 0 0 : 1 7}$ \\
\hline Acción 3 & Izquierda & $\begin{array}{l}\text { estira las piernas y las mantiene estiradas, cruza los } \\
\text { tobillos (el derecho hacia arriba) } \\
\text { mueve levemente su cuello de derecha a izquierda }\end{array}$ & $\mathbf{0 : 0 0 : 3 4}$ \\
\hline Acción 4 & Derecha & $\begin{array}{l}\text { piernas formando un ángulo de } 90^{\circ}, \\
\text { manos apoyadas en las rodillas }\end{array}$ & $\mathbf{0 : 0 0 : 4 7}$ \\
\hline Acción 5 & Izquierda & $\begin{array}{l}\text { descruza las piernas y las mantiene alineadas, } \\
\text { se toca el pelo con la mano derecha }\end{array}$ & $\mathbf{0 : 0 1 : 0 7}$ \\
\hline
\end{tabular}




\begin{tabular}{|c|c|c|c|}
\hline & & CONTINGENCIA NULA & $\begin{array}{c}\text { Tiempo } \\
\text { en el que } \\
\text { empieza } \\
\text { la acción }\end{array}$ \\
\hline Acción 6 & Derecha & $\begin{array}{l}\text { se frota los ojos como si estuviera cansado (sin exage- } \\
\text { rar ni cambiar de posición) }\end{array}$ & 0:01:20 \\
\hline Acción 7 & Izquierda & $\begin{array}{l}\text { trae sus piernas y apoya su tobillo derecho sobre su } \\
\text { rodilla izquierda }\end{array}$ & 0:01:45 \\
\hline Acción 8 & Derecha & mantiene su posición y se cruza de brazos & 0:02:04 \\
\hline Acción 9 & Izquierda & $\begin{array}{l}\text { comienza a mover las piernas rápidamente, golpeando } \\
\text { el piso con los pies (mientras mantiene su posición } \\
\text { general) }\end{array}$ & 0:02:16 \\
\hline Acción 10 & Derecha & $\begin{array}{l}\text { mantiene su posición y visiblemente muerde primero } \\
\text { su labio inferior y luego su labio superior }\end{array}$ & 0:02:33 \\
\hline Acción 11 & Izquierda & $\begin{array}{l}\text { vuelve a estirar las piernas y cruza los tobillos (el } \\
\text { derecho hacia arriba) con las manos apoyadas en las } \\
\text { rodillas }\end{array}$ & 0:02:50 \\
\hline Acción 12 & Derecha & $\begin{array}{l}\text { mantiene su posición general, endereza la espalda, } \\
\text { encorva ligeramente los hombros }\end{array}$ & 0:03:05 \\
\hline Acción 13 & Izquierda & mantiene su posición y cruza los brazos & 0:03:24 \\
\hline Acción 14 & Derecha & $\begin{array}{l}\text { mantiene su posición y cruza los tobillos (uno derecho } \\
\text { hacia arriba) }\end{array}$ & 0:03:38 \\
\hline Acción 15 & Izquierda & $\begin{array}{l}\text { Las piernas forman un ángulo de } 90^{\circ} \text {, las manos } \\
\text { descansando sobre las rodillas }\end{array}$ & 0:03:50 \\
\hline Acción 16 & Derecha & comienza a bostezar & 0:04:02 \\
\hline Acción 17 & Izquierda & se rasca la cabeza con la mano derecha & 0:04:11 \\
\hline Acción 18 & Derecha & mantiene su posición y se frota ligeramente los ojos & 0:04:26 \\
\hline Acción 19 & Izquierda & $\begin{array}{l}\text { Mantiene su posición general, comienza a tamborilear } \\
\text { ligeramente con los dedos sobre las rodillas, como si } \\
\text { siguiera un pequeño ritmo }\end{array}$ & 0:04:42 \\
\hline Acción 20 & Derecha & Estira los brazos, mueve el cuello y cruza las manos & 0:04:55 \\
\hline Acción 21 & Izquierda & $\begin{array}{l}\text { mantiene su posición y se rasca la cabeza con la mano } \\
\text { derecha }\end{array}$ & 0:05:08 \\
\hline
\end{tabular}


Capitulo 3. Experimento I.

Fuente: elaboración propia.

- Video 2) Condición de contingencia temporal: Ambos actores cambiaron de postura y se movieron exactamente al mismo tiempo, pero sus posturas y sus gestos nunca coincidieron en forma; y

Tabla 3.2. Descripción de los comportamientos mostrados por cada actor en la condición "Contingencia temporal".

\begin{tabular}{|c|c|c|c|}
\hline \multicolumn{3}{|r|}{ CONTINGENCIA TEMPORAL } & $\begin{array}{l}\text { Tiempo } \\
\text { en el que } \\
\text { empieza } \\
\text { la acción }\end{array}$ \\
\hline \multirow{2}{*}{$\begin{array}{l}\text { Postura } \\
\text { Inicial }\end{array}$} & Izquierda & $\begin{array}{l}\text { las piernas forman un ángulo de } 90^{\circ}, \text { los brazos cru- } \\
\text { zados }\end{array}$ & 0:00:00 \\
\hline & Derecha & piernas cruzadas, brazos cruzados & 0:00:00 \\
\hline \multirow{2}{*}{ Acción 1} & Izquierda & se rasca la cabeza con la mano derecha & 0:00:07 \\
\hline & Derecha & mantiene su posición general y comienza a bostezar & 0:00:07 \\
\hline \multirow[b]{2}{*}{ Acción 2} & Izquierda & $\begin{array}{l}\text { cruza la pierna derecha y da golpecitos con los dedos } \\
\text { de los pies }\end{array}$ & 0:00:26 \\
\hline & Derecha & $\begin{array}{l}\text { estira las piernas y las mantiene estiradas, cruza los } \\
\text { tobillos (el derecho hacia arriba); mueve levemente su } \\
\text { cuello de derecha a izquierda }\end{array}$ & 0:00:26 \\
\hline \multirow{2}{*}{ Acción 3} & & $\begin{array}{l}\text { descruza las piernas, se toca el pelo con la mano dere- } \\
\text { cha }\end{array}$ & 0:00:46 \\
\hline & Derecha & $\begin{array}{l}\text { se frota los ojos como si estuviera cansado (sin exage- } \\
\text { rar ni cambiar de posición) }\end{array}$ & 0:00:46 \\
\hline \multirow{2}{*}{ Acción 4} & Izquierda & $\begin{array}{l}\text { alinea las piernas y las coloca en un ángulo de } 90^{\circ} \text { y } \\
\text { las manos descansan en las rodillas }\end{array}$ & 0:01:05 \\
\hline & Derecha & mantiene la posición de las piernas y cruza los brazos & 0:01:05 \\
\hline \multirow[t]{2}{*}{ Acción 5} & Izquierda & $\begin{array}{l}\text { comienza a mover las piernas rápidamente, golpeando } \\
\text { el piso con los pies (mientras mantiene su posición } \\
\text { general) }\end{array}$ & 0:01:25 \\
\hline & Derecha & $\begin{array}{l}\text { mantiene su posición y visiblemente muerde primero } \\
\text { su labio inferior y luego su labio superior de nuevo }\end{array}$ & 0:01:25 \\
\hline \multirow[b]{2}{*}{ Acción 6} & Izquierda & cruza los tobillos (derecho arriba) & 0:01:46 \\
\hline & Derecha & $\begin{array}{l}\text { coloca las piernas en un ángulo de } 90^{\circ} \text {, endereza la } \\
\text { espalda, encorva ligeramente los hombros }\end{array}$ & 0:01:46 \\
\hline
\end{tabular}




\begin{tabular}{|c|c|c|c|}
\hline \multicolumn{3}{|r|}{ CONTINGENCIA TEMPORAL } & \multirow{3}{*}{$\begin{array}{c}\begin{array}{c}\text { Tiempo } \\
\text { en el que } \\
\text { empieza } \\
\text { la acción }\end{array} \\
0: 02: 06 \\
\text { 0:02:06 }\end{array}$} \\
\hline \multirow[b]{2}{*}{ Acción 7} & Izquierda & mantiene la posición de las piernas y cruza los brazos & \\
\hline & Derecha & $\begin{array}{l}\text { mantiene su posición general, despliega los brazos y } \\
\text { las manos descansan sobre las rodillas mantiene }\end{array}$ & \\
\hline \multirow{2}{*}{ Acción 8} & Izquierda & su posición general y comienza a bostezar & 0:02:26 \\
\hline & Derecha & se rasca la cabeza con la mano derecha & 0:02:26 \\
\hline \multirow[b]{2}{*}{ Acción 9} & Izquierda & $\begin{array}{l}\text { mantiene las piernas cruzadas y se toca el cabello con } \\
\text { la mano derecha }\end{array}$ & 0:02:46 \\
\hline & Derecha & $\begin{array}{l}\text { mantiene su posición general, comienza a golpear } \\
\text { ligeramente con los dedos sobre las rodillas, como si } \\
\text { siguiera un pequeño ritmo }\end{array}$ & 0:02:46 \\
\hline \multirow{2}{*}{ Acción 10} & Izquierda & mantiene su posición general y abre los brazos & 0:03:05 \\
\hline & Derecha & se rasca la cabeza con la mano derecha & 0:03:05 \\
\hline \multirow{2}{*}{ Acción 11} & Izquierda & $\begin{array}{l}\text { frota suavemente sus ojos mientras mantiene su posi- } \\
\text { ción }\end{array}$ & 0:03:26 \\
\hline & Derecha & general bosteza mientras mantiene su posición & 0:03:26 \\
\hline \multirow{2}{*}{ Acción 12} & & $\begin{array}{l}\text { general mantiene su posición general y comienza a } \\
\text { mover los dedos }\end{array}$ & 0:03:45 \\
\hline & Derecha & $\begin{array}{l}\text { con las piernas estiradas, cruza el tobillo derecho } \\
\text { sobre el izquierdo }\end{array}$ & 0:03:45 \\
\hline \multirow{2}{*}{ Acción 13} & Izquierda & $\begin{array}{l}\text { mantiene su posición general y se rasca la cabeza con } \\
\text { la mano derecha }\end{array}$ & 0:04:06 \\
\hline & Derecha & $\begin{array}{l}\text { mantiene su posición general y alinea sus piernas } \\
\text { extendidas }\end{array}$ & 0:04:06 \\
\hline \multirow{2}{*}{ Acción 14} & Izquierda & mantiene su posición general y cruza los brazos & 0:04:25 \\
\hline & Derecha & $\begin{array}{l}\text { mantiene su posición y comienza a mover su pie dere- } \\
\text { cho en círculos }\end{array}$ & 0:04:25 \\
\hline \multirow[t]{2}{*}{ Acción 15} & Izquierda & $\begin{array}{l}\text { mantiene su posición y mueve su cuello de derecha a } \\
\text { izquierda }\end{array}$ & 0:04:45 \\
\hline & Derecha & mantiene su posición y estira los brazos hacia el techo & 0:04:45 \\
\hline \multirow{2}{*}{$\begin{array}{l}\text { Acción } 16 \\
\text { Postura } \\
\text { Inicial }\end{array}$} & $\begin{array}{l}\text { Izquierda } \\
\text { Derecha }\end{array}$ & mantiene su posición general y abre los brazos & 0:05:06 \\
\hline & & $\begin{array}{l}\text { mantiene su posición general y levanta su pierna dere- } \\
\text { cha sobre la izquierda }\end{array}$ & 0:05:06 \\
\hline
\end{tabular}


- Video 3) Condición de contingencia de la forma: Cada vez que un actor mostraba un manierismo o adoptaba una nueva postura, el otro hacía lo mismo 4 a 5 segundos después, de modo que había una coincidencia perfecta, aunque ligeramente retardada, de posturas y manierismos entre ambos actores.

Tabla 3.3. Descripción de los comportamientos mostrados por cada actor en la condición de "Contingencia de forma".

\begin{tabular}{|c|c|c|c|}
\hline \multicolumn{3}{|c|}{ CONTINGENCIA DE FORMA } & \multirow{3}{*}{$\begin{array}{c}\begin{array}{r}\text { Tiempo } \\
\text { en el que } \\
\text { empieza } \\
\text { la acción }\end{array} \\
0: 00: 00 \\
0: 00: 00\end{array}$} \\
\hline Postura & Izquierda & $\begin{array}{l}\text { las piernas forman un ángulo de } 90^{\circ} \text {, los brazos cru- } \\
\text { zados }\end{array}$ & \\
\hline Inicial & Derecha & $\begin{array}{l}\text { las piernas forman un ángulo de } 90^{\circ} \text {, los brazos cru- } \\
\text { zados }\end{array}$ & \\
\hline \multirow[b]{2}{*}{ Acción 1} & Izquierda & se rasca la cabeza con la mano derecha & 0:00:15 \\
\hline & Derecha & $\begin{array}{l}\text { se rasca la cabeza con la mano derecha (o hace lo } \\
\text { mismo) }\end{array}$ & 0:00:19 \\
\hline \multirow{2}{*}{ Acción 2} & Derecha & despliega los brazos y apoya las manos en las rodillas & 0:00:35 \\
\hline & Izquierda & despliega los brazos y apoya las manos en las rodillas & 0:00:39 \\
\hline \multirow{2}{*}{ Acción 3} & Izquierda & $\begin{array}{l}\text { cruza la pierna derecha y da golpecitos con los dedos } \\
\text { de los pies }\end{array}$ & 0:00:54 \\
\hline & Derecha & $\begin{array}{l}\text { cruza la pierna derecha y da golpecitos con los dedos } \\
\text { de los pies }\end{array}$ & 0:00:59 \\
\hline \multirow{2}{*}{ Acción 4} & Derecha & $\begin{array}{l}\text { Mantiene las piernas cruzadas y se toca el cabello con } \\
\text { la mano derecha.. }\end{array}$ & 0:01:15 \\
\hline & Izquierda & $\begin{array}{l}\text { Mantiene las piernas cruzadas y se toca el cabello con } \\
\text { la mano derecha.. }\end{array}$ & 0:01:20 \\
\hline \multirow{2}{*}{ Acción 5} & Izquierda & $\begin{array}{l}\text { estira las piernas y las mantiene estiradas, cruza los } \\
\text { tobillos (el derecho hacia arriba); mueve levemente su } \\
\text { cuello de derecha a izquierda }\end{array}$ & 0:01:33 \\
\hline & Derecha & $\begin{array}{l}\text { estira las piernas y las mantiene estiradas, cruza los } \\
\text { tobillos (el derecho hacia arriba); mueve levemente su } \\
\text { cuello de derecha a izquierda }\end{array}$ & 0:01:38 \\
\hline \multirow{2}{*}{ Acción 6} & Derecha & $\begin{array}{l}\text { se frota los ojos como si estuviera cansado (sin exage- } \\
\text { rar ni cambiar de posición) }\end{array}$ & 0:01:53 \\
\hline & Izquierda & $\begin{array}{l}\text { se frota los ojos como si estuviera cansado (sin exage- } \\
\text { rar ni cambiar de posición) }\end{array}$ & 0:01:57 \\
\hline
\end{tabular}




\begin{tabular}{|c|c|c|c|}
\hline CONTING & ENCIA DI & E FORMA & $\begin{array}{l}\text { Tiempo } \\
\text { en el que } \\
\text { empieza } \\
\text { la acción }\end{array}$ \\
\hline & Izquierda & alinea sus piernas y las coloca en un ángulo de $90^{\circ}$ & 0:02:12 \\
\hline Accio & Derecha & alinea sus piernas y las coloca en un ángulo de $90^{\circ}$ & 0:02:16 \\
\hline & Derecha & mantiene la posición de las piernas y cruza los brazos & 0:02:31 \\
\hline & Izquierda & mantiene la posición de las piernas y cruza los brazos & 0:02:35 \\
\hline & Izquierda & $\begin{array}{l}\text { comienza a mover las piernas rápidamente, golpeando } \\
\text { el piso con los pies (mientras mantiene su posición } \\
\text { general) }\end{array}$ & 0:02:49 \\
\hline Accion 9 & Derecha & $\begin{array}{l}\text { comienza a mover las piernas rápidamente, golpeando } \\
\text { el piso con los pies (mientras mantiene su posición } \\
\text { general) }\end{array}$ & 0:02:54 \\
\hline Acción 10 & & $\begin{array}{l}\text { mantiene su posición y visiblemente muerde primero } \\
\text { su labio inferior y luego su labio superior }\end{array}$ & 0:03:09 \\
\hline & Izquierda & $\begin{array}{l}\text { mantiene su posición y visiblemente muerde primero } \\
\text { su labio inferior y luego su labio superior }\end{array}$ & 0:03:13 \\
\hline Acción 11 & Izquierda & $\begin{array}{l}\text { vuelve a estirar las piernas y cruza los tobillos (el de- } \\
\text { recho hacia arriba) }\end{array}$ & 0:03:28 \\
\hline Accion 10 & Derecha & $\begin{array}{l}\text { vuelve a estirar las piernas y cruza los tobillos (el de- } \\
\text { recho hacia arriba) }\end{array}$ & 0:03:32 \\
\hline Acción 12 & & $\begin{array}{l}\text { mantiene su posición general, endereza la espalda, } \\
\text { encorva ligeramente los hombros }\end{array}$ & 0:03:44 \\
\hline Accion 12 & Izquierda & $\begin{array}{l}\text { mantiene su posición general, endereza la espalda, } \\
\text { encorva ligeramente los hombros }\end{array}$ & 0:03:48 \\
\hline Alón 12 & & $\begin{array}{l}\text { Mantiene la posición de las piernas, despliega los } \\
\text { brazos y apoya las manos en las rodillas. }\end{array}$ & 0:04:06 \\
\hline Accion 13 & Derecha & $\begin{array}{l}\text { Mantiene la posición de las piernas, despliega los } \\
\text { brazos y apoya las manos en las rodillas. }\end{array}$ & 0:04:10 \\
\hline & Derecha & $\begin{array}{l}\text { mantiene su posición general, comienza a golpear } \\
\text { ligeramente con los dedos sobre las rodillas, como si } \\
\text { siguiera un pequeño ritmo }\end{array}$ & 0:04:25 \\
\hline Acci & Izquierda & $\begin{array}{l}\text { mantiene su posición general, comienza a golpear } \\
\text { ligeramente con los dedos sobre las rodillas, como si } \\
\text { siguiera un pequeño ritmo }\end{array}$ & 0:04:29 \\
\hline & Izquierda & $\begin{array}{l}\text { coloca sus piernas en un ángulo de } 90^{\circ} \text { mientras man- } \\
\text { tiene su posición general }\end{array}$ & 0:04:45 \\
\hline Acción 1 & Derecha & $\begin{array}{l}\text { coloca sus piernas en un ángulo de } 90^{\circ} \text { mientras man- } \\
\text { tiene su posición general }\end{array}$ & 0:04:50 \\
\hline
\end{tabular}


Capitulo 3. Experimento I.

\begin{tabular}{cclc}
\hline CONTINGENCIA DE FORMA & $\begin{array}{c}\text { Tiempo } \\
\text { en el que } \\
\text { empieza } \\
\text { la acción }\end{array}$ \\
\hline \multirow{2}{*}{ Acción 16} & Derecha & mantiene su posición general y comienza a bostezar & $\mathbf{0 : 0 5 : 0 2}$ \\
& Izquierda & mantiene su posición general y comienza a bostezar & $\mathbf{0 : 0 5 : 0 5}$ \\
\hline
\end{tabular}

Fuente: elaboración propia.

Para que la situación grabada pareciera más natural, los actores se turnaron para cambiar de postura. Debido a que el objetivo del estudio era ver si el movimiento por sí solo puede evocar nociones de afiliación, aplicamos un potente filtro para oscurecer los marcadores de pertenencia a grupo de los actores, como son sus rasgos fenotípicos y el estilo de vestir. Por lo tanto, lo que se veía en los videos consistía únicamente en las siluetas de ambos actores y sus movimientos (ver Figura 3.1). La duración de los tres videos fue de 5 minutos y 15 segundos. 
Figura 3.1. Capturas de pantalla de secuencias típicas (A-B) de las tres condiciones.

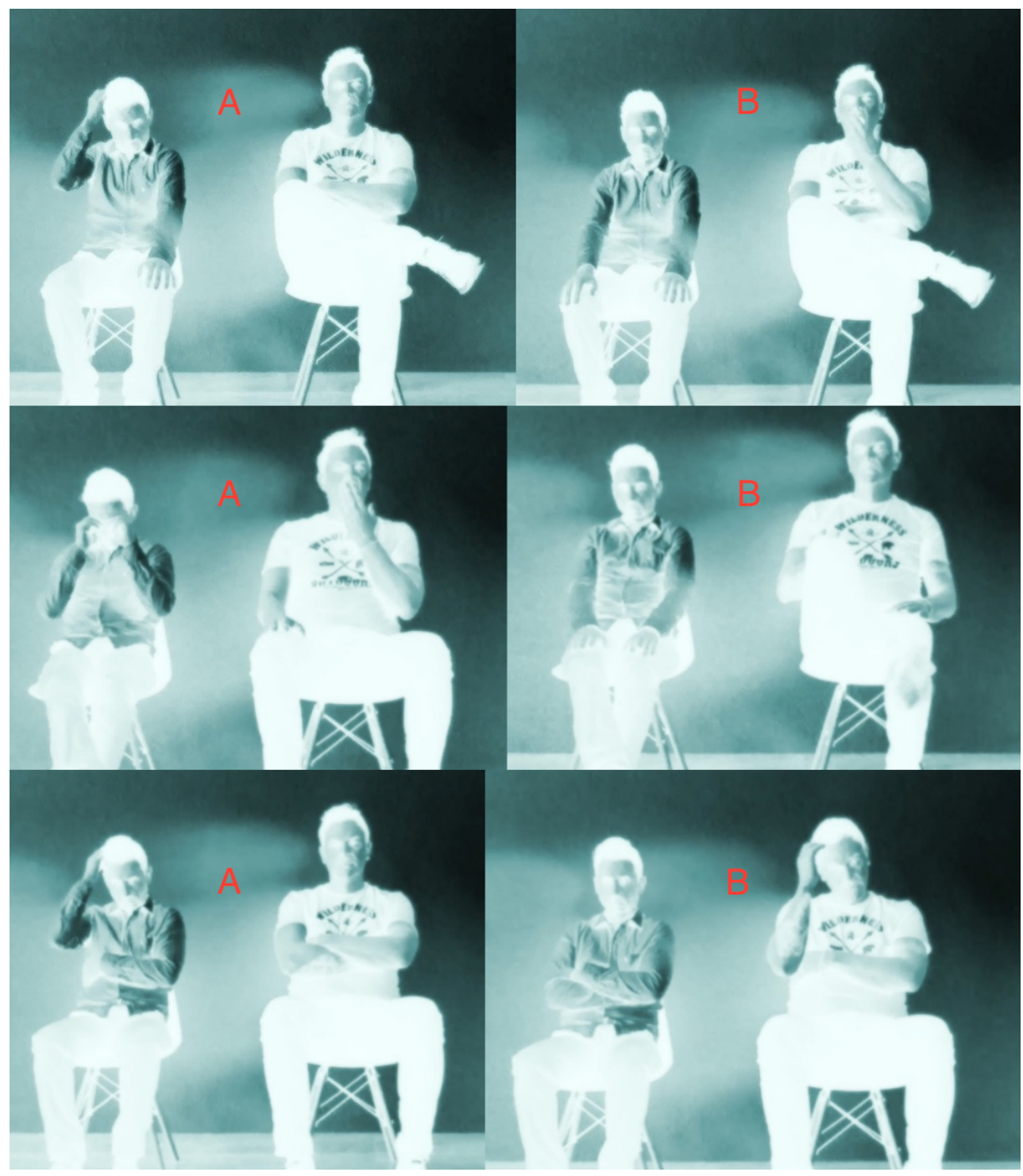

Fuente: elaboración propia

Nota: Filtro oscuro eliminado en gran parte para una mejor claridad de imagen; consulte SOM para ver videos originales. Arriba: Sin condición de contingencia. Sentado en dife- 
rentes posiciones, el actor 1 se rasca la cabeza mientras el actor 2 permanece quieto (A). Once segundos después, el actor 2 comienza a bostezar, mientras que el actor 1 conserva su posición anterior (B). Medio: condición de contingencia temporal. Sentado en diferentes posiciones, el actor 1 se frota suavemente los ojos mientras el actor 2 bosteza simultáneamente (A). Veinte segundos después, el actor 2 comienza a cruzar las piernas y el actor 1 comienza a golpear sus rodillas con los dedos simultáneamente (B). Abajo: Condición de contingencia del formulario. Compartiendo la misma posición general, el actor 1 se rasca la cabeza con la mano derecha mientras el actor 2 permanece quieto (A). Cuatro segundos después, el actor 2 se rasca la cabeza con la mano derecha mientras el actor 1 permanece quieto (B).

\subsubsection{Diseño y procedimiento.}

Los sujetos experimentales fueron asignados aleatoriamente a una de las tres condiciones experimentales/vídeos: Contingencia Nula $(\mathrm{N}=22, \mathrm{Edad}$ media $=19.5$, $\mathrm{SD}=1.89)$, Contingencia Temporal $(\mathrm{N}=21$, Edad media $=21.8, \mathrm{SD}=4.05), \mathrm{y}$ Contingencia de Forma $(\mathrm{N}=22$, Edad media $=21, \mathrm{SD}=4.33)$. Se les indicó que visionaran el video que se les había asignado con gran atención porque luego tendrían que responder una pregunta sobre el mismo. Cuando terminaba el video, se les pedía que calificaran el grado de afiliación que creían existía entre los dos actores en una escala de 1 (mínimo posible) a 7 (máximo posible). Ver hoja de respuesta en el Anexo 3.1.

Cada uno de los vídeos fue visionado en grupo, es decir, los participantes asignados a cada una de las tres condiciones experimentales vieron el vídeo juntos en una pantalla grande en el mismo aula donde se imparte la docencia en su respectiva universidad.

Para ayudar a los sujetos experimentales a emitir su respuesta, se les decía que marcar 1 en nuestra escala equivalía a la afiliación existente entre dos personas de diferentes países que no se conocen con anterioridad a la grabación; un 4 en nuestra 
Mimetismo conductual como marcador de afiliación.

escala (el valor intermedio) equivaldría a dos personas que comparten su nacionalidad, pero que tampoco se conocían; y un 7 (el valor máximo en nuestra escala) equivaldría a un padre y un hijo, o a dos hermanos.

Se hizo hincapié en que estas etiquetas verbales que acompañaban estos tres números en la escala servían únicamente para ilustrar el grado de afiliación entre los actores, y no implicaba en ningún caso que la relación real entre ellos fuera la descrita. También se les recordó a los sujetos que podían marcar cualquier número en nuestra escala del 1 al 7 para ilustrar el grado percibido de afiliación entre los actores.

La mayor parte de los participantes (estudiantes de grado) fueron testados por el doctorando, mientras que algunos estudiantes de máster que completaban la muestra fueron testados por los codirectores en sus respectivas asignaturas. Con independencia del experimentador, el protocolo seguido fue idéntico.

\subsubsection{Análisis estadísticos}

Los datos obtenidos se analizaron por medio de la prueba Tukey HSD (Honest Significant Difference) (XLSTAT versión 2021.1) para determinar si las diferencias en la contingencia de gestos (Nula, Temporal, Forma) influía en la afiliación atribuida a los actores en los tres vídeos.

\subsection{Resultados.}

Los resultados para la contingencia de gestos observada entre los actores pueden verse en la Figura 2. A simple vista, la variable Contingencia de Forma parece ejercer el mayor efecto sobre la atribución de afiliación, seguida por la condición Contingencia Nula y la condición Contingencia Temporal. 
Figura 3.2. Significancia y desviaciones estándar del estado afiliativo percibido atribuido a los actores en función del grupo de participantes y el video visto.

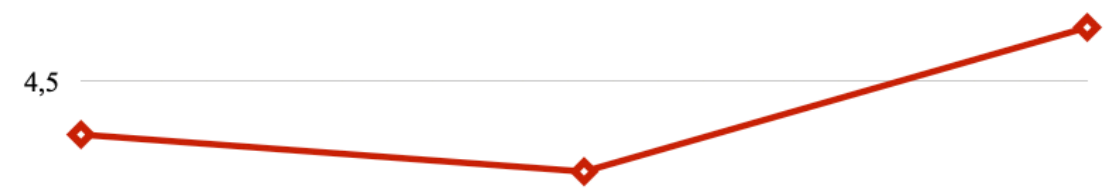

\begin{tabular}{c|l|c|c|c}
$\begin{array}{c}2 \\
\text { Contingencia nula }\end{array}$ & \multicolumn{1}{c}{ Contingencia temporal } & \multicolumn{3}{c}{ Contingencia de forma } \\
\hline Grupo & \multicolumn{1}{|c|}{ Video } & $\mathbf{n}$ & $\mathbf{M}$ & SD \\
\hline \multirow{2}{*}{ Españoles } & Contingencia de forma & 22 & 5.05 & 1.46 \\
& Contingencia nula & 22 & 3.95 & 1.09 \\
& Contingencia temporal & 21 & 3.57 & 1.25 \\
\hline
\end{tabular}

Fuente: elaboración propia

A diferencia de lo que se ha publicado con anterioridad, nosotros sí encontramos diferencias significativas entre las condiciones de Contingencia Nula y Contingencia de Forma ("Tukey's standardized d score" $=2.47, \mathrm{p}=0.014, \alpha=0.05$ ). Curiosamente, no hubo diferencias significativas entre las condiciones Contingencia Nula y Contingencia Temporal (Tukey's standardized d score $=0.859, \mathrm{p}=0.96$, $\alpha=0.90$ ), pero sí hubo diferencias significativas entre las puntuaciones otorgadas a la condición Contingencia Temporal y Contingencia de Forma (Tukey's standardized d score $=3.30, \mathrm{p}=0.001, \alpha=0.001)$. 


\subsection{Discusión.}

La condición Contingencia de Forma recibió las mayores puntuaciones en afiliación, confirmando los resultados de estudios previos que describen como el mimetismo conductual evoca nociones de afiliación. El hecho de que las puntuaciones atribuidas a las condiciones de Contingencia Temporal y Nula no varíen significativamente sugiere que observar a dos personas moverse al mismo tiempo no es suficiente para inferir que tienen algún tipo de relación. De hecho, más bien parece que ocurre lo contrario, ya que la condición contingencia temporal es la que produjo las puntuaciones más bajas. Cabe la posibilidad de que observar a dos personas realizar conductas dispares al unísono evoque distancia afectiva entre ellos, volveremos sobre este tema cuando discutamos conjuntamente este experimento y el siguiente que se realizó con miembros de la tribu Samburu en Kenia reproduciendo exactamente el mismo protocolo experimental.

Un estudio reciente de Cross, Turgeon y Atherton (2019) sugiere que los efectos afiliativos del mimetismo conductual dependerían de la existencia de una relación previa entre las personas que interactúan. En línea con esta afirmación, se ha visto que la coordinación de la conducta entre niños crea afiliación solo entre aquellos niños que ya pertenecen al mismo grupo (Fawcett \& Tunçgenç, 2017), y lo mismo parece ocurrir en adultos (Levin \& Angelone, 2002). Hasta la fecha casi todos los estudios (si no todos) sobre los efectos del mimetismo conductual se han realizado con poblaciones occidentales procedentes de países industrializados. Cabe la posibilidad de que el mimetismo conductual se haya seleccionado en sociedades a gran escala para facilitar la coordinación y/o cooperación con personas más allá de la familia o la comunidad. Para comprobar si el mimetismo conductual es un fenómeno universal o restringido a determinados tipos de sociedades en el siguiente estudio repetiremos el mismo experimento, pero con sujetos experimentales procedentes de la tribu Samburu en Kenia. 
Capítulo 4. Experimento II. 



\section{Capítulo 4 \\ Experimento II. ¿Tiene el mimetismo conduc- tual el mismo papel afiliativo en otros tipos de sociedades?}

En un influyente artículo que lleva por título: The weirdest people in the world?, Henrich, Heine, y Norenzayan (2010) se preguntaban si las muestras procedentes de "Western, Educated, Industrialized, Rich, and Democratic (WEIRD) societies", en adelante WEIRD, empleadas habitualmente en los estudios enmarcados en las ciencias del comportamiento eran representativas de la especie humana en su conjunto. Esta pregunta no es baladí puesto que tradicionalmente los resultados obtenidos con este tipo de sujetos se generalizan a la especie humana en su totalidad.

Arnett (2008) revisó los estudios publicados en las revistas más prestigiosas de Psicología entre los años 2003 y 2007 y halló que el 68\% de los trabajos se habían llevado a cabo con muestras de sujetos procedentes de Estados Unidos, y hasta un 96\% de los mismos tenían como participantes personas pertenecientes a países occidentales industrializados. En su revisión del tema, Henrich et al., (2010) con- 
Mimetismo conductual como marcador de afiliación.

cluyen que las muestras de sujetos WEIRD no solo no son representativas de la especie en su conjunto, sino que de hecho constituyen la muestra menos representativa y minoritaria posible de la especie. Esta conclusión se vería reforzada por estudios como el de Miller et al. (1995) donde comprueban que los niños chinos de entre 3 y 5 años son más competentes que los norteamericanos a la hora de operar con números comprendidos entre 10 y 20 , y esto se debe a que la lógica del sistema numérico decimal es más obvia en este intervalo numérico en la nomenclatura china.

Varios estudios con adultos (Masuda y Nisbett, 2001; Nisbett, 2004) han encontrado que las personas pertencientes a culturas orientales son más holísticas (es decir, más propensas a centrarse en una escena completa y sus estructuras relacionales), mientras que las de las culturas occidentales son más analíticas ( es decir, atienden a los objetos focales). En este sentido, las madres estadounidenses suelen dirigir la atención de sus bebés a objetos individuales y sus atributos, mientras que las madres japonesas tienden a hablar sobre varios objetos dentro de una escena (Fernald y Morikawa, 1993). Se encontraron resultados similares en un estudio de descripción de viñetas con niños y padres de 7 a 9 años: los participantes japoneses hablaron más sobre el contexto, mientras que sus equivalentes canadienses destacaron los objetos focales (Senzaki et al., 2016). Las diferencias en los estilos de atención parecen aparecer desde el principio. Un estudio reciente de Waxman (Waxman et al., 2016) y sus colegas mostró que los niños chinos de 2 años prestan más atención a las relaciones entre un agente y un objeto que sus pares estadounidenses. A su vez, los niños estadounidenses de 3 años superan a sus pares japoneses en el reconocimiento y el nombrado de objetos atendiendo a sus partes (Kuwabara \& Smith, 2016), y los niños estadounidenses de 4 años obtienen mejores resultados que sus pares japoneses en una tarea de búsqueda de objetos (Kuwabara y Smith, 2012). 
La "whorfian hypothesis" introducida por Whorf (1956) propone que el lenguaje condiciona de manera dramática el pensamiento $\mathrm{y}$, por tanto, los estudios sobre comportamiento y/o cognición serían altamente dependientes de la cultura y poco generalizables. Aunque la hipótesis de Whorf es quizás demasiado categórica, sí existen indicios de que la lengua influye en el pensamiento; Gordon (2004) investigó la capacidad de emparejar conjuntos de objetos con base en su número en la tribu Piraha de Brasil, que es famosa por no poseer nombres específicos para los números.

Se dio cuenta de que eran incapaces de emparejar más allá de tres objetos; es decir, si se les pedía formar dos conjuntos iguales de 4 palos y 4 nueces se mostraban incapaces. La capacidad de comparar colecciones de objetos hasta tres unidades se sabe se lleva a cabo de manera analógica, sin necesidad de contar. Esto explicaría que los Piraha se encuentren perdidos más allá de las colecciones de 3 ítems, donde contar el número de elementos en cada colección es esencial a la hora de determinar si ambas colecciones tienen el mismo número de elementos.

El famoso psicólogo ruso Alexander Luria $(1931,1971)$ también se interesó por la manera de procesar la información en poblaciones no industrializadas y/o con distintos grados de instrucción y comprobó que en los campesinos de Uzbek, en Asia Central, el grado de alfabetización era clave a la hora de resolver problemas silogísticos propios del razonamiento formal. De hecho, si no estaban instruidos tendían a rehusar contestar a problemas silogísticos ya que estaban planteados en términos abstractos, poco familiares para ellos. Segall, Campbell, y Serkovits (1996) investigaron si podía haber diferencias a nivel perceptivo derivados del tipo de construcciones en las que se organizaban las sociedades, y empleando la ilusión Müller-Lyer, descubrieron que así era. Concretamente, las sociedades que construían casas con ángulos rectos (casas de madera) se veían más afectadas por esta ilusión óptica. 
Mimetismo conductual como marcador de afiliación.

Estos estudios son solo una muestra de que el tipo de sociedad, cultura y/o lenguaje pueden influir en la manera de procesar la información y por tanto nos obligan a plantearnos si los resultados que obtenemos en las muestras WEIRD son extrapolables a la especie. Para verificar si los resultados obtenidos en el experimento 1 pueden generalizarse a la especie humana en su conjunto, decidimos replicar el experimento en un tipo de sociedad radicalmente diferente a los estudiantes españoles que participaron en el experimento 1, y que no encajaría en absoluto en las llamadas muestras WEIRD. Concretamente, nos referimos a la tribu Samburu. A continuación, proporcionamos información básica relativa a la organización social de la tribu objeto de estudio.

\subsection{La tribu Samburu.}

Los Samburu son pastores de ganado que viven en las llanuras áridas y escasamente pobladas del norte de Kenia, y actualmente suman alrededor de 300.000 individuos. Hablan Samburu, una lengua nilótica relacionada con la lengua Maa. A diferencia de otros grupos étnicos en Kenia, los Samburu han mantenido en gran medida sus tradiciones culturales, y abrazado la occidentalización en un grado mucho menor. Sus actividades económicas se organizan principalmente en torno al hogar (Holtzmann, 1996), y las interacciones con extraños son poco frecuentes y, por lo general, se limitan a visitas a ciudades más pequeñas.

Aunque la mayoría de los Samburu hoy en día poseen teléfonos móviles, la comunicación a menudo se ve restringida por la falta de red o energía para la carga de las baterías, y el acceso a los medios de comunicación como la televisión o Internet se restringe a los centros urbanos. 
La organización social de los Samburu se basa en gran medida en la edad, y los líderes son significativamente mayores que la mayoría de la población adulta (Spencer, 2013).

El género es otro factor igualmente importante para determinar el estatus social, siendo los varones los jefes indiscutibles de la familia. Los niños son altamente valorados, y las familias suelen tener cinco o más. Los bebés son tratados con indulgencia hasta que tienen alrededor de 3 años, pero a medida que crecen, aumenta la cantidad de obediencia requerida.

Los niños comienzan a ayudar en casa cuando tienen aproximadamente cuatro años. Las niñas cuidan a los hermanos menores y ayudan a acarrear agua y leña, mientras que los niños suelen cuidar del ganado de la familia. Los niños pequeños suelen formar parte de grupos de juego que comprenden varias edades y los juegos implican actividades tanto colaborativas como competitivas.

El juego de simulación incluye la típica imitación de las actividades propias de los adultos y/o las conductas de los animales; a menudo imitan los movimientos de los toros, que son animales que juegan un papel central en la cultura Samburu. Un elemento clave en la cultura Samburu es la danza. Los rituales también implican sincronizarse con otros, aunque tanto las canciones como los bailes a menudo tienen un componente competitivo, en el que los participantes intentan superarse entre sí, en lugar de igualar los movimientos de sus compañeros de baile en tiempo y forma (Spencer, 1985).

\subsection{Método.}

\subsubsection{Participantes.}

Un total de cincuenta y ocho estudiantes del "Wamba Mixed High School" de edades comprendidas entre los 15 y los 22 años ( 25 mujeres, 33 hombres, Edad media 
$=18.08, \mathrm{SD}=1.44)$ participaron en el estudio. La participación fue totalmente voluntaria y no formaba parte de las actividades docentes propias de su instituto. El estudio fue aprobado por el comité de ética de la Universidad Jaume I y se adhirió a las normas aplicables a la experimentación humana. Se obtuvo también un permiso de la Comisión Nacional para la Ciencia, Tecnología, e Innovación de Kenia (NACOSTI). Los participantes firmaron una hoja de consentimiento informado antes de realizar el experimento, y también se obtuvo permiso de los tutores en el caso de los participantes menores. Justo antes de realizar la prueba se volvió a pedir consentimiento verbal por parte de los sujetos experimentales.

\subsubsection{Materiales.}

Los mismos videos empleados en el Experimento I.

\subsubsection{Diseño y procedimiento.}

Con el fin de familiarizar a los participantes Samburu con las escalas de respuesta tipo Likert, se les entrenó en el uso de las mismas previo al estudio. Para ello se les enseñaban 15 diapositivas que mostraban dibujos de animales, tipos de comida, y diferentes deportes, y se les pedía que puntuaran en un rango de 1 a 7 cuanto se parecía entre si el dibujo de un animal con el animal real, y/o cuanto les gustaban las comidas y deportes representados en las diapositivas. El hecho de hacerles puntuar cuanto les gustaba un deporte o una comida era una manera de evitar que buscaran únicamente similitudes entre los estímulos presentados (dibujo del animal y el animal real), ya que esto podría primar la búsqueda de similaridades entre los actores en el experimento real posterior, y sesgar los resultados. Aquellos estudiantes que al acabar este entrenamiento no parecían entender la lógica de las escalas Likert fueron descartados del estudio. Queremos aclarar que los estudiantes españoles que participaron en el experimento 1 no fueron entrenados en el uso de escalas tipo Likert porque ya estaban familiarizados con las mismas. 
Tal y como hicimos con los participantes españoles en el experimento 1, los sujetos experimentales del grupo Samburu también fueron asignados de manera aleatoria a una de las tres condiciones/videos: Contingencia Nula $(\mathrm{N}=18$, Edad media $=$ 18.11, $\mathrm{SD}=1.77)$, Contingencia Temporal $(\mathrm{N}=20$, Edad media $=18.15, \mathrm{SD}=$ 1.34), y Contingencia de Forma $(\mathrm{N}=20$, Edad media $=18, \mathrm{SD}=1.29)$. Cada uno de los vídeos fue visionado en grupo, es decir, los participantes asignados a cada una de las tres condiciones experimentales vieron el vídeo juntos en una pantalla grande en el mismo aula donde se imparte la docencia.

Los datos de dos estudiantes inicialmente asignados al grupo experimental Contingencia Nula fueron excluidos de los análisis porque habían marcado dos números en la escala Likert. Los métodos y procedimiento empleados en este estudio fueron idénticos a los descritos para el experimento I previo.

A pesar de que la tribu Samburu mantiene sus tradiciones, los estudiantes manejan habitualmente, y por tanto, están familiarizados con las tecnologías occidentales. Se descarta que el modo de presentación del experimento pudiera ser por tanto un elemento de sesgo a la hora de comparar los resultados con los obtenidos con la muestra occidental. Situación diferente sería si los participantes fueran las personas mayores de la tribu, en cuyo caso sí habría un elemento diferencial importante.

A diferencia del experimento anterior, quien administró la prueba con los Samburu fue Henriette Zeidler (HZ), investigadora que realiza trabajo de campo y conoce bien a esta tribu y puede comunicarse con sus miembros de manera adecuada. HZ se ciñó al protocolo que ensayamos por videoconferencia de manera previa y pasó un tiempo adicional entrenado a los participantes Samburu en implementar escalas likert hasta que estuvo segura de que entendían como funcionaba. De hecho solo dos participantes fueron excluidos del estudio por marcar en la escala dos valores distintos. 
Mimetismo conductual como marcador de afiliación.

\subsubsection{Análisis estadísticos.}

Los datos obtenidos se analizaron por medio de la prueba Tukey HSD (Honest Significant Difference) (XLSTAT versión 2021.1) para determinar si las diferencias en la contingencia de gestos (Nula, Temporal, Forma) influía en la afiliación atribuida a los actores en los tres vídeos.

\subsection{Resultados.}

Las puntuaciones promedio asignadas a cada una de las tres condiciones/videos se muestran en la Figura 4.1. A simple vista, la Condición Contingencia de Forma parece recibir las mayores puntuaciones de afiliación, seguida de la condición Contingencia Nula y Contingencia Temporal. Este patrón es exactamente el mismo descrito por la muestra española en el experimento 1, si bien se observan puntuaciones promedio más altas para todas las condiciones.

Figura 4.2. Significancia y desviaciones estándar del estado afiliativo percibido atribuido a los actores en función del grupo de participantes y el video visto.

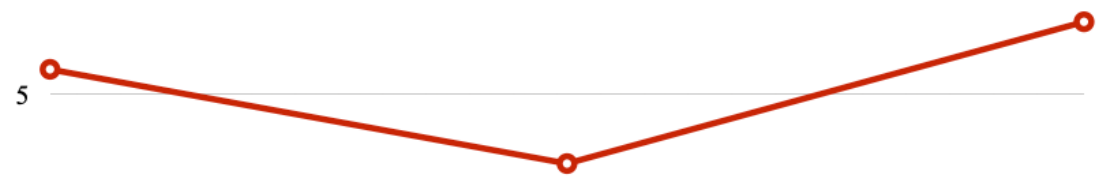

3

11
Contingencia nula
Contingencia temporal 
Capítulo 4. Experimento II.

\begin{tabular}{c|l|c|c|c}
\hline Grupo & \multicolumn{1}{|c|}{ Video } & n & M & SD \\
\hline \multirow{3}{*}{ Samburu } & Contingencia de forma & 20 & 5.95 & 1.64 \\
& Contingencia nula & 18 & 5.33 & 2.06 \\
& Contingencia temporal & 20 & 4.10 & 1.62 \\
\hline
\end{tabular}

Fuente: elaboración propia.

Las puntuaciones Samburu para las condiciones Contingencia Nula y Contingencia de Forma no describieron diferencias estadísticas significativas (Tukey's standardized d score $=0.62, \mathrm{p}=0.54, \alpha=0.50$ ).

Por el contrario, y tomando un nivel de significación $\alpha=0.05$ la condición Contingencia Temporal sí arrojó diferencias significativas respecto de la condición Contingencia Nula (Tukey's standardized $\mathrm{d}=2.60, \mathrm{p}=0.011$ ) y la condición Contingencia de Forma (Tukey's standardized $\mathrm{d}=4.51, \mathrm{p}<0.0001$ ).

\subsection{Discusión.}

En comparación con la muestra española, los Samburu asignaron valores de afiliación más altos en la escala Likert a las condiciones Contingencia de Forma y Contingencia Nula, y relativamente más bajos a la condición Contingencia Temporal. A diferencia de la muestra española no se hallaron diferencias significativas entre la condición Contingencia Nula y Contingencia de Forma.

Aunque esto podría sugerir que el mimetismo conductual juega un papel afiliativo menos importante en sociedades de pequeño tamaño, hay una explicación alternativa. Las personas que pertenecen a otro grupo racial se perciben habitualmente como más similares entre sí que cuando se comparan dos personas que pertenecen a la propia raza (Levin \& Angelone, 2002). 
Mimetismo conductual como marcador de afiliación.

Los actores de los vídeos en los experimentos 1 y 2 eran españoles, y aunque nuestro filtro eliminó casi todas las marcas fenotípicas en los actores, cabe la posibilidad de que para los Samburu los movimientos y manierismos de los actores o su apariencia global todavía les sugiriera que eran de otra raza/etnia.

Si este fuera el caso los actores en los vídeos serían más similares a los ojos de los Samburu, que, a los ojos de los participantes españoles, y esto justificaría que en todos los vídeos los participantes Samburu otorgaran puntuaciones promedio más elevadas en afiliación a los actores.

El hecho de que las puntuaciones más bajas se observaron en la condición Contingencia Temporal podría relacionarse con el hecho de que el movimiento captura la atención, y en este vídeo los momentos de máximo movimiento (ambos actores cambian de postura o realizan un gesto) muestran dos personas haciendo cosas distintas. Es decir, la atención queda orientada y fijada en las diferencias y no en las similitudes.

En la condición Contingencia Nula los actores también realizan diferentes gestos y manierismos, pero al estar más espaciados en el tiempo el contraste entre estos es menor. Tal vez la combinación de mayor similitud percibida en los actores por parte de los Samburu interacciona con las diferentes condiciones de contingencia en los gestos, y ello hace que a pesar de que el patrón de resultados sea muy similar entre ambas muestras, también se observen algunas diferencias. 
Capítulo 5. Experimento III. 



\section{Capítulo 5 \\ Experimento III. ¿Es el mimetismo conduc- tual un indicador del grado de afiliación principal o secundario en relación a otros in- dicadores?}

Los experimentos previos demostraban que el grado de similitud entre los gestos de dos actores era interpretado del mismo modo por miembros de dos grupos raciales/étnicos muy distintos. En concreto, la imitación de gestos entre los actores era interpretada tanto por jóvenes españoles como por jóvenes de la tribu Samburu en Kenia, como un indicador del grado de afiliación existente entre los actores. Para 
demostrar esto tuvimos que introducir un filtro muy potente en los vídeos con el fin de reducir/eliminar el efecto que otros conocidos marcadores de pertenencia a grupo (ej: estilo de vestir, fenotipo) podrían ejercer. Ahora nos preguntamos qué ocurre cuando no hay filtro y las contingencias de movimiento conviven con marcadores ostensibles de pertenencia a grupo: ¿Seguirán los gestos y posturas de los actores jugando un papel importante en los juicios afiliativos de los participantes, o este factor se verá atenuado/bloqueado por la presencia de otros marcadores de grupo que son más ostensibles?

\subsection{Participantes.}

En este experimento participaron 63 nuevos voluntarios en la Universidad de Zaragoza (48 mujeres y 15 hombres) cuyo rango de edades fluctuaba de los 18 a los 28 años $($ Edad media $=20,84, S D=1,48)$. Tal y como hicimos con los participantes en el experimento 1, los nuevos sujetos experimentales fueron asignados de manera aleatoria a una de las tres condiciones/videos, 21 sujetos por condición: Contingencia Nula $(\mathrm{N}=$, Edad media $=, \mathrm{SD}=)$, Contingencia Temporal $(\mathrm{N}=$, Edad media $=$, $\mathrm{SD}=)$, y Contingencia de Forma $(\mathrm{N}=$, Edad media $=, \mathrm{SD}=)$.

\subsection{Materiales.}

Los mismos tres vídeos empleados en el experimento 1. Sin embargo, en este experimento se eliminó el filtro que oscurecía la imagen y por tanto se podían observar tanto los rasgos fenotípicos de los actores como su indumentaria (véase Figura 5.1). Es importante resaltar que ambos actores tenían rasgos fenotípicos distintos y también estilos de vestir que contrastaban. Por ejemplo, un actor era alto y de complexión fuerte y tenía el pelo claro, vestía casual y tenía un tatuaje; el otro era bajito y de complexión delgada, tenía el pelo oscuro y vestía más formal. 
Figura 5.1. Capturas de pantalla de secuencias típicas (A-B) de las tres condiciones.
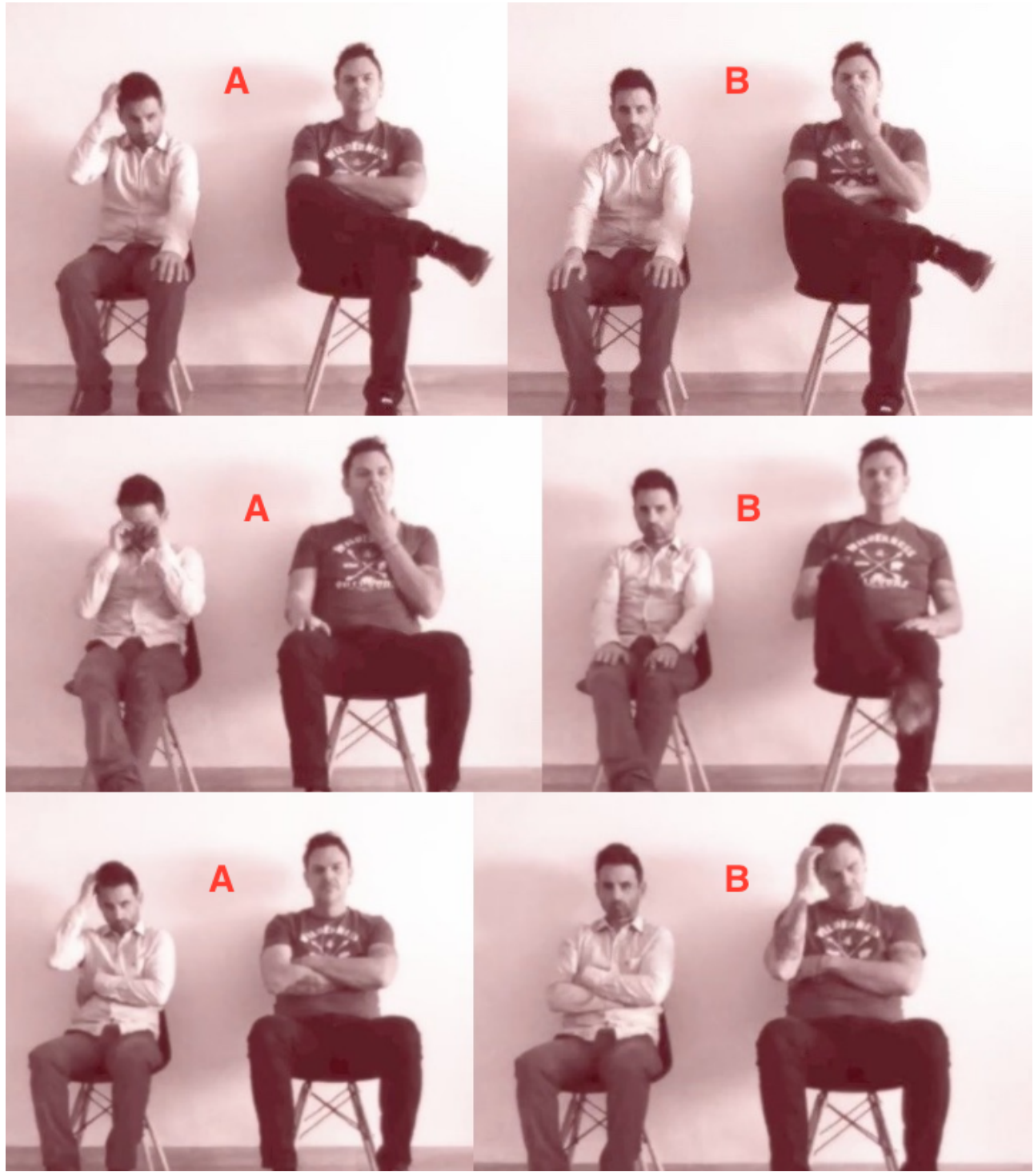

Fuente: elaboración propia

Nota: Arriba: Sin condición de contingencia. Sentado en diferentes posiciones, el actor 1 se rasca la cabeza mientras el actor 2 permanece quieto (A). Once segundos después, el actor 2 comienza a bostezar, mientras que el actor 1 conserva su posición anterior (B). 
Medio: condición de contingencia temporal. Sentado en diferentes posiciones, el actor 1 se frota suavemente los ojos mientras el actor 2 bosteza simultáneamente (A). Veinte segundos después, el actor 2 comienza a cruzar las piernas y el actor 1 comienza a golpear sus rodillas con los dedos simultáneamente (B). Abajo: Condición de contingencia del formulario. Compartiendo la misma posición general, el actor 1 se rasca la cabeza con la mano derecha mientras el actor 2 permanece quieto (A). Cuatro segundos después, el actor 2 se rasca la cabeza con la mano derecha mientras el actor 1 permanece quieto (B).

\subsection{Diseño y procedimiento.}

Idéntico al empleado en el experimento 1.

\subsection{Resultados.}

Aplicamos la prueba Kolmogoroff-Smirnov para comprobar si los datos se ajustaban a una distribución normal, los valores $(\mathrm{D}=0.21825, \mathrm{p}=0$. .00407) nos obligaron a rechazar la Ho. Dado la no normalidad de los datos se realizó una prueba Kruskal-Wallis empleando el software de análisis libre JASP que permite realizar comparaciones múltiples.

\section{Figura 5.2. Significancia y desviaciones estándar del estado afiliativo percibido atribuido a los actores en función del grupo de participantes y el video visto.}

4,2

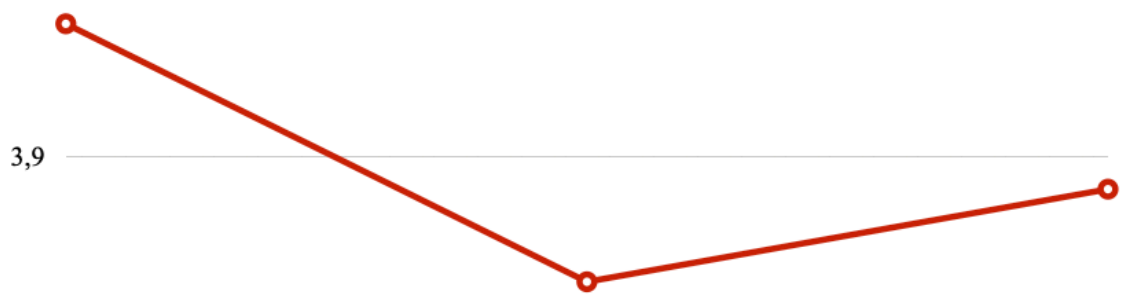


Capitulo 5. Experimento III.

\begin{tabular}{c|l|c|c|c}
\hline Grupo & \multicolumn{1}{|c|}{ Video } & n & M & SD \\
\hline \multirow{3}{*}{ Españoles } & Contingencia de forma & 21 & 3.80 & 1.35 \\
& Contingencia nula & 21 & 4.05 & 0.98 \\
& Contingencia temporal & 21 & 3.66 & 1.35 \\
\hline
\end{tabular}

Fuente: Elaboración propia.

No se encontraron diferencias significativas (Chi cuadrado $=0.495, \mathrm{p}=.78, \mathrm{gl}=2$ ) entre las puntuaciones asignadas a los tres videos (Contingencia Nula, Contingencia Temporal y Contingencia de Foma). El software $G$ * power 3.1.6 estimó que se necesitaría un tamaño de muestra de al menos 597 sujetos para arrojar diferencias significativas. (Ver figura 5.2).

\subsection{Discusión.}

Los resultados de los experimentos 1 y 2 demostraban que en ausencia de marcadores ostensibles de pertenencia a grupo (ej: rasgos fenotípicos y estilo de vestir) el grado de similitud en los gestos de los actores es tomado como un indicador de su grado de afiliación.

Cuando ambos actores realizaban los mismos gestos, con una demora de 4 ó 5 segundos, se les atribuía el grado más alto de afiliación. Por el contrario, cuando se movían al unísono, pero realizando gestos distintos, recibían las puntuaciones más bajas en afiliación.

En estos experimentos se ocultaron de forma intencional marcadores conocidos de pertenencia a grupo, como son los rasgos fenotípicos y/o el estilo de vestir, porque lo que queríamos verificar es si los gestos y manierismos por si solos son usados como indicadores de afiliación/pertenencia conjunta. 
Lickel et al. (2000) definieron "entitativity", que traduciremos por entidad conjunta, a falta de una palabra equivalente en lengua castellana, como el grado en que un grupo de personas son percibidas como "bonded together" (p 224), reforzando la idea de que afiliación y entidad conjunta van unidas.

Se han descrito dos aproximaciones a la atribución de entidad conjunta (Brewer, Hong, \& Li, 2004); la llamada "essence-based entitativity approach" que se centra en las características comunes que presentan los miembros de una entidad perceptiva (grupo), y la llamada "agency-based entitativity approach" que se centra en las actividades comunes que realizan los diferentes sujetos (ej: comparten oficio) como la causa de que se perciban como conformantes de una misma unidad. En este experimento, a diferencia de los experimentos 1 y 2 previos, se podían ver los rasgos físicos de los actores y por tanto el grado de similitud percibida serviría para atribuirles entidad conjunta atendiendo a la idea de "essence-based entitativity", como ya se ha comprobado en estudios previos (Dasgupta, Banaji, \& Abelson, 1999).

En el presente experimento se podían observar tanto las contingencias de gestos entre los actores como otros marcadores ostensibles de pertenencia, y se vio como los efectos afiliativos que evocan los gestos desaparecen, y ahora el grupo Contingencia de Forma no es diferente del de Contingencia Temporal. Es importante recordar al lector que en este experimento 3 se emplearon los mismos vídeos que en los experimentos 1 y 2 , con la única diferencia que ahora el filtro oscuro se eliminó y se pudo observar la apariencia de los actores, y no solo sus siluetas y sus movimientos.

Cabe resaltar como la existencia de marcadores ostensibles de pertenencia a grupo, anularon los efectos que los gestos producían a la hora de juzgar el grado de afiliación existente entre los actores en los dos experimentos previos. Este hecho se ve 
corroborado por los cálculos estadísticos, los cuales predicen que sería necesario contar con una muestra de nada menos que 597 participantes para que se observaran diferencias significativas entre las tres condiciones de contingencia/videos. Nótese que el tamaño actual de la muestra es de 63 sujetos. Como se puede observar en los experimentos 1 y 2 , muestras considerablemente pequeñas (60-70 sujetos) son suficientes para arrojar diferencias estadísticas significativas entre el grado de afiliación atribuido a los grupos Contingencia Temporal y de Forma. Por lo tanto, no podemos decir que los gestos no sean un poderoso marcador de pertenencia conjunta, sino que los rasgos fenotípicos y/o estilo de vestir parecen ser marcadores de afiliación/pertenencia más poderosos aún, y cuando están presentes, bloquearían los efectos derivados de los gestos. Esta influencia de la apariencia sobre la afiliación, es congruente con estudios previos que demostraban que las personas que presentan un alto parecido a nivel físico, también se les atribuye similitud en sus atributos psicológicos o de personalidad (Callahan \& Ledgerwood, 2016).

En los vídeos empleados en los tres experimentos contenidos en esta tesis los dos actores eran muy diferentes en sus marcadores ostensibles de pertenencia a grupo, puesto que uno era muy alto y de complexión fuerte y de pelo claro y vestía de manera muy casual, incluso exhibía un tatuaje. El otro, por el contrario, era bajito y moreno, de complexión delgada y vestía una camisa. Es decir, eran muy diferentes en cuanto a fenotipo y estilos. Por ello, en la condición Contingencia de Forma que era la que inducía los mayores valores de afiliación en los experimentos 1 y 2 habría un conflicto entre el poder de los gestos para evocar afiliación y el de otros marcadores más ostensibles. Como ya expusimos previamente los individuos que se asemejan físicamente se perciben como pertenecientes a un mismo grupo/unidad (Dasgupta, Banaji, \& Abelson, 1999) y, en nuestro caso tenemos dos actores que son muy diferentes en su aspecto físico, y por tanto, lo que evocarían es distancia. 
Creemos por tanto que la coincidencia en los gestos o manierismos actuaría como un marcador secundario de pertenencia que complementaría o ayudaría a juzgar el grado de afiliación percibida en terceros, pero que se vería atenuado o incluso bloqueado si otros indicadores más potentes presentes contradicen la información gestual.

Es posible que si tuviéramos dos actores que fueran similares en su fenotipo y/o estilo de vestir, el papel de la contingencia de gestos a la hora de juzgar su grado de afiliación volvería a cobrar relevancia. Si este fuera el caso, se demostraría el papel de la contingencia de gestos como un mecanismo secundario/complementario de atribución de afiliación/pertenencia. Esto podría constituir un estudio interesante para el futuro. 


\section{Capítulo 6. Discusión General y Conclusiones}





\section{Capítulo 6 Discusión General y Conclusiones}

\subsection{Discusión General y Conclusiones.}

En línea con trabajos previos, los resultados del experimento 1 demuestran que el grado de coordinación de los gestos observados en terceros sirve para atribuirles a estos una entidad colectiva (Pearce, et al., 2016). Cuando dos actores se mueven al mismo tiempo, pero realizan gestos distintos se les asignan valores bajos en cuanto a su grado de afiliación, y lo contrario ocurre cuando realizan los mismos gestos, pero con una pequeña demora de 4 ó 5 segundos; es decir, cuando hay mimetismo conductual entre ellos. De hecho, los efectos derivados del mimetismo conductual descritos en estudios anteriores son muy similares a los que hemos encontrado en el presente trabajo (Chartrand \& Bargh, 1999; Lakin \& Chartrand, 2003). En los estudios anteriores sobre los efectos afiliativos del mimetismo conductual el tiempo de los gestos de los actores y su forma se presentaban de manera solapada, lo cual hacía imposible atribuir los efectos afiliativos descritos a la contingencia en tiempo o a la contingencia en forma de los mismos. Los pocos investigadores que se preocuparon 
Mimetismo conductual como marcador de afiliación.

de desentrañar ambas variables (tiempo vs forma) (Catmur \& Heyes, 2013; Hove \& Risen, 2009) encontraron que era la contingencia en el tiempo de los gestos entre los actores y no tanto la forma de los mismos, lo que produciría efectos prosociales y afiliativos. En línea con estos hallazgos, se ha visto que cuando varias personas bailan juntas, codifican y recuerdan más detalles de aquellos compañeros de pista que se mueven siguiendo su mismo ritmo, con independencia de si los movimientos que producen son iguales en la forma (Woolhaus \& Tidhard, 2016).

En el presente estudio separamos la contingencia en el tiempo de los gestos que producían los actores de la contingencia en su forma, y, además, a diferencia de los estudios que acabamos de mencionar, también eliminamos el ritmo externo que vincularía los gestos de los actores.

Cuando decimos que eliminamos el ritmo externo nos referimos a que no hay un tempo que ambos actores siguen. Hay simultaneidad de movimientos, pero no ritmicidad en los mismos. No hay ciclos que se repiten con periocidad predecible que pudieran ser por ejemplo dictados por un metrónomo.

En nuestra condición Contingencia Temporal ambos actores estaban perfectamente coordinados en el tiempo, puesto que siempre se movían al unísono, aunque los gestos que producían nunca coincidían en su forma. Investigaciones previas demuestran que el movimiento captura inmediatamente la atención (Abrams \& Christ, 2003). Por lo tanto, en la condición Contingencia Temporal, los momentos de máximo movimiento de los actores coincidirían con su divergencia en cuanto a la forma. Es decir, cuando mayor atención despertarían los videos en los participantes el foco estaría puesto en la divergencia en el tipo de gestos que producían, y ello sería lo que revertiría cualquier efecto afiliativo que la simultaneidad de sus movimientos pudiera evocar. Esta idea se ve reforzada por el hecho de que las puntuaciones, en cuanto a afiliación que reciben los actores en la condición Contingencia Nula, son 
intermedias cuando se compara con las condiciones Contingencia Temporal y Contingencia de Forma.

La razón sería que pese a que los actores realizan gestos distintos (no se mimetizan), nunca se mueven al mismo tiempo, y ello hace que la disparidad de gestos no esté en el foco de atención. Otra razón que explicaría que la condición Contingencia Temporal no evoque afiliación es que nuestro diseño experimental está desprovisto de ritmo y cuando los actores se mueven al mismo tiempo, no lo hacen siguiendo una misma velocidad o cadencia. Las investigaciones previas sobre sincronía interpersonal que reportaban efectos afiliativos producidos por la sincronía del movimiento, ponían a los participantes en el experimento a moverse siguiendo un mismo tempo/ritmo (Cirelli, Einarson, Trainor, 2014; Lakens \& Stel, 2011) y es posible que fuera este ritmo común lo que les hacía sentirse en conexión.

Por lo tanto, cuando se habla de sincronía interpersonal es la oscilación regular de los movimientos y/o gestos, bien sean en fase o en anti-fase, lo que conectaría a los participantes de la interacción, y no tanto el hecho de que se muevan al unísono. Es por ello que una vez se elimina el factor cohesionador o de andamiaje que ejerce el ritmo, la simultaneidad de movimientos per se no induciría ninguna noción afilitiva. De hecho, tal como observamos en nuestro experimento, la simultaneidad de movimientos dispares desprovista de un ritmo común evocaría nociones de distanciamiento entre los actores.

Con el experimento 2 demostramos que los efectos afiliativos de la identidad de gestos o mimetismo conductual también parecen producirse en otro tipo de sociedades de tamaño reducido y no industrializadas como son la tribu Samburu. Si bien no encontramos una diferencia significativa entre las condiciones Contingencia Nula y Contingencia de Forma, el patrón de respuesta es idéntico al observado con la 
Mimetismo conductual como marcador de afiliación.

muestra española (ver Figura 6.1). Sí se hallaron diferencias significativas entre las puntuaciones otorgadas a la condición Contingencia Temporal y Contingencia de Forma.

Figura 6.1. Significancia y desviaciones estándar del estado afiliativo percibido atribuido a los actores en función del grupo experimental y el video visto.
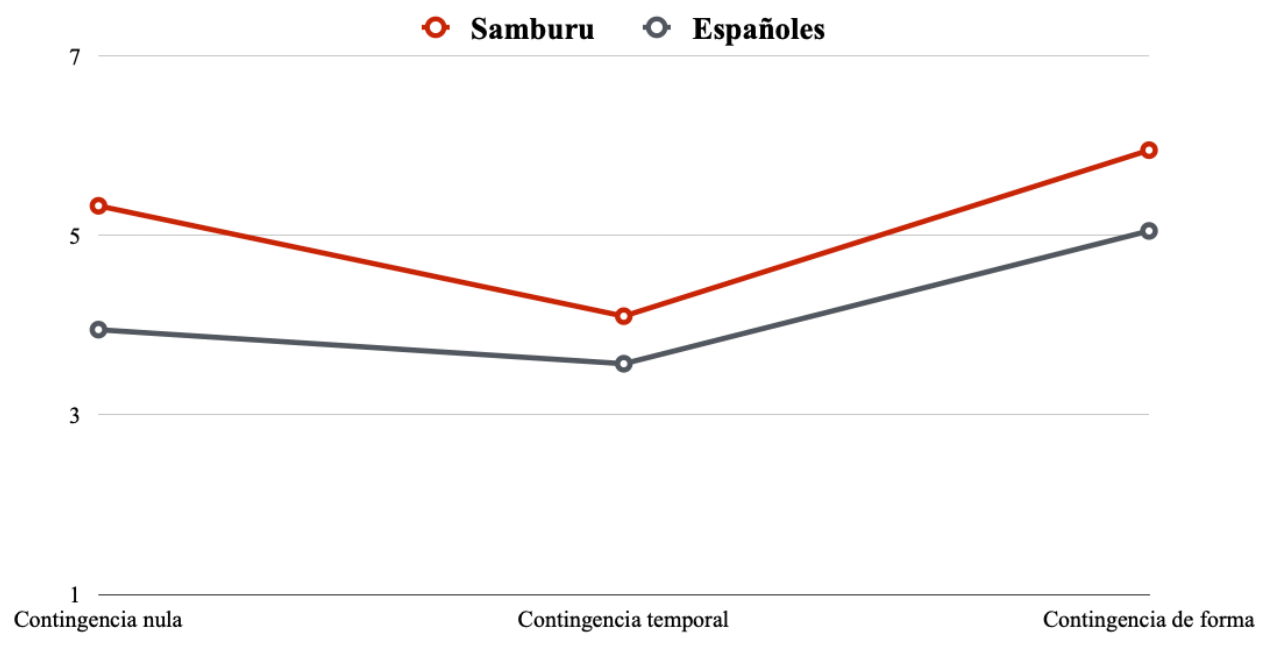

\begin{tabular}{c|l|c|c|c}
\hline Grupo & \multicolumn{1}{|c|}{ Video } & n & M & SD \\
\hline \multirow{3}{*}{ Samburu } & Contingencia de forma & 20 & 5.95 & 1.64 \\
& Contingencia nula & 18 & 5.33 & 2.06 \\
& Contingencia temporal & 20 & 4.10 & 1.62 \\
\hline \multirow{3}{*}{ Españoles } & Contingencia de forma & 22 & 5.05 & 1.46 \\
& Contingencia nula & 22 & 3.95 & 1.09 \\
& Contingencia temporal & 21 & 3.57 & 1.25 \\
\hline
\end{tabular}

Fuente: Elaboración propia.

Dado que las puntuaciones que los actores recibieron en la muestra Samburu son mayores para todas las condiciones en relación a la muestra española, y esto se podría atribuir quizás al hecho de que ambos actores son europeos y, por tanto, más 
similares entres si a los ojos de los Samburu (Levin \& Angelone, 2002), cabe la posibilidad que la ausencia de diferencias entre las condiciones Contingencia Nula y Contingencia de Forma se deba precisamente a esta percepción incrementada de similaridad. Esto se podría comprobar si en futuros estudios se emplearan actores Samburu para la muestra Samburu y actores españoles para la muestra española. En cualquier caso, esta divergencia en los resultados es importante tenerla en cuenta a la hora de diseñar futuros experimentos, porque nos alerta de la importancia de no precipitarse a la hora de generalizar los resultados obtenidos en las muestras WEIRD a otras culturas, y también, de ser muy cuidadosos con los diseños para hacerlos equiparables.

En resumen y referente a los resultados obtenidos en los experimentos 1 y 2 , podemos concluir que tanto en sociedades modernas industrializadas de gran escala como en sociedades de tipo rural pastoralista de pequeño tamaño, el mimetismo conductual es tomado como un indicador del grado de afiliación, y, por el contrario, realizar conductas distintas evoca distancia entre los interactuantes.

Por último, en el experimento 3, donde se eliminó el filtro oscuro de los tres vídeos y se podían ver tanto los rasgos fenotípicos de los actores como su estilo de vestimenta, las diferencias entre las tres condiciones experimentales (Contingencia Nula, Contingencia Temporal y Contingencia de Forma) se diluyeron. Es decir, la información de los marcadores ostensibles de pertenencia a grupo como son el fenotipo y el estilo de vestir tomaron precedencia y bloquearon cualquier efecto afiliativo que el movimiento pudiera suscitar en los participantes.

Tal y como ya comentamos en la discusión del experimento 3, es posible que el hecho que los actores fueran muy diferentes en los rasgos ostensibles de pertenencia a grupo, truncaría cualquier efecto de afiliación vinculado a los gestos, y que los gestos aún podrían jugar un papel relevante a la hora de atribuir afiliación si los 
Mimetismo conductual como marcador de afiliación.

actores fueran más similares en su aspecto físico y estilos. Esto es algo que merecería investigarse en el futuro. Es decir, sería interesante grabar tres nuevos vídeos con las mismas contingencias gestuales, pero con dos actores que se parecieran tanto en su aspecto fenotípico como en la manera de vestir, para ver si entonces el patrón de resultados reproduce lo que se vio en el experimento 1 y 2 de esta tesis.

Un aspecto que consideramos importante resaltar en relación a nuestro estudio es que los participantes tienen que emitir juicios sobre el grado de afiliación ("affiliation") o la pertenencia conjunta ("entitativity") de terceros. Es decir, ellos no toman parte en la interacción ni como imitadores ni como imitados. Si habláramos de atribución de estados mentales diríamos que los participantes adoptan una perspectiva de tercera persona, ya que deben observar la conducta de los dos actores e inferir el grado de relación existente entre ellos desde fuera, al modo de un científico, formulando hipótesis. Esto es interesante porque escasean los estudios de mimetismo que investigan la afiliación atribuida a terceros, y en este sentido nuestro estudio tiene un valor añadido, ya que corrobora los resultados obtenidos en estudios previos donde las personas que desarrollaban sentimientos afiliativos sí eran imitadas directamente. Entendemos que colocar a dos actores sentados uno al lado del otro, sin hablarse ni interactuar puede resultar una situación un tanto artificial. No obstante, el mimetismo entendido como la adopción de los mismos gestos y posturas se produce en lugares tales como una sala de espera, donde se sientan juntos completos desconocidos. Si bien no conocemos de otros estudios de mimetismo conductual donde la putativa afiliación se tenga que atribuir a dos actores sentados uno al lado del otro, sí hay evidencias de que un observador externo puede ver modificado su grado de mimetismo facial por lo que ve les ocurre a terceros en un vídeo. Por ejemplo, niños ("todlers") de 30 meses que observaban vídeos en los que una forma geométrica ("shape") había sido "marginada" ("ostrasized") por otras formas geométricas incrementaban el mimetismo facial posterior hacia modelos humanos proyectados en 
un vídeo (Klerk et al., 2020). Este estudio es especialmente interesante en relación a la presente tesis, ya que los bebés son observadores externos, y sin embargo, los efectos que produce el ser testigos de "ostracismo" son equivalentes a los experimentados por aquellos que sufren el "ostracismo" en primera persona (Lakin, Chartrand, \& Arkin, 2008).

\subsection{Aspectos proximales y funcionales que podrían ayudar a diferenciar entre la sincronía interpersonal y el mimetismo conductual, $y$ apuntar a su posible utilidad en la adapta- ción al ambiente.}

Como hemos visto en los estudios presentados en este trabajo de tesis, los efectos que produce tanto la sincronía interpersonal como el mimetismo conductual en cuanto al desarrollo de sentimientos positivos y de pertenencia conjunta, son virtualmente indistinguibles. Creemos por tanto conveniente especular sobre las posibles razones que justifican tener dos mecanismos diferenciados en nuestro repertorio conductual, que aparentemente producen los mismos efectos.

Es conveniente empezar por indagar en la parte más mecánica de lo que supone realizar acciones motoras de manera contingente en el tiempo (sincronía interpersonal) y/o la forma (mimetismo conductual). Hay una extensa literatura que describe como la compatibilidad entre las acciones motoras observadas y las que el sujeto experimental tiene que emitir se influyen, sin necesidad de hablar de imitación o de "agencialidad" ("sentient systems"). Por ejemplo, se sabe que la presentación de objetos activa sus atributos de acción y facilita las acciones motoras congruentes con su agarre (Tucker y Ellis, 1998; 2001, 2004; Vainio, Tucker y Ellis, 2007). Tucker y Ellis (2004) reportan efectos de compatibilidad estímulo-respuesta en una tarea en la que los participantes tenían que emitir una respuesta ante la presentación de objetos que se podían agarrar con toda la mano (agarre de fuerza) o con pulgar e índice (agarre 
Mimetismo conductual como marcador de afiliación.

de precisión) utilizando un dispositivo de respuesta que requería presionar un interruptor sostenido con el pulgar y el índice (precisión de respuesta) o usando los dedos medio, anular y meñique para apretar un cilindro (respuesta de fuerza). Estos efectos de compatibilidad ante las posibilidades de accionamiento elicitadas por la visión de objetos se ha replicado en numerosos estudios (p. Ej., Derbyshire, Ellis y Tucker, 2006; Symes, Tucker, Ellis, Vainio y Ottoboni, 2008; Vainio, Tucker y Ellis, 2007) y evidencia que la activación de áreas premotoras provocada por la visión de objetos accionables facilita la implementación automática y rápida de códigos motores congruentes con la interacción con dichos objetos (Chao y Martin, 2000; Körner, Topolinski, \& Strack, 2015; Murata, Fadiga, Fogassi, Gallese, Raos y Rizzolatti, 1997). Si hablamos de agentes intencionales, también se ha descrito facilitación de la imitación de gestos manuales por la presentación concurrente de movimientos manuales compatibles (Heyes, 2011). Un fenómeno similar ocurriría con la imitación neonatal, donde la mera presentación de acciones simples (especialmente sacar la lengua) por un modelo elicita en el recién nacido la repetición de la misma acción (sacar la lengua) (Metzoff \& Moore, 1998; Nadel y Butterworth, 1999). El hecho de que las personas con lesiones prefrontales no puedan dejar de imitar los gestos que observan en otros parece reforzar la idea de que estas repeticiones de la acción observada en terceros serían una especie de acción refleja (Lhermite y cols. 1986).

Aunque los primeros estudios que hemos citado no implican agencialidad, y se corresponden con una visión corporeizada de la cognición à la Gibson, y los segundos son estudios de imitación infantil que sí implican agencialidad, todos ellos comparten el efecto facilitador sobre la acción motora "elicitado" de manera automática (no parecen requerir de supervisión consciente, control ejecutivo “top-down") por la visión de acciones compatibles y/o idénticas a las que se tienen que implementar. Los psicólogos sociales atribuirán este tipo de facilitación "priming" motora a la existencia de un "link" percepción-acción (Chartrand y Bargh, 1999; Chartrand, Maddux y 
Lakin, 2005; Dijksterhuis y Bargh, 2001). La existencia de este link presupone que la mera percepción de un movimiento evoca la misma representación que la ejecución de ese movimiento, facilitando así la ejecución de lo percibido. Estos efectos facilitadores sobre la acción/imitación se situarían en un nivel "mecanístico" proximal y estarían vinculados supuestamente a los circuitos de neuronas espejo (Murata, Fadiga, Fogassi, Gallese, Raos y Rizzolatti, 1997). Posiblemente estos reflejos o predisposiciones a imitar sirven tanto a la sincronía interpersonal como al mimetismo conductual. Es en estos dos procesos donde podemos preguntarnos qué significado adaptativo tuvieron o tienen a un nivel funcional superior (ej. dinámicas sociales).

En cuanto a la sincronía interpersonal, o la tendencia a moverse siguiendo un ritmo común, es más fácil trascender el nivel de análisis "mecanístico" proximal y atribuirle posibles funciones que ofrecen ventajas adaptativas. Por ejemplo, sincronizar el movimiento puede ser útil en animales sociales que se desplazan en grupo, ya que ayuda a que sean menos vulnerables ante el ataque de posibles depredadores. Esto funcionaría en los bancos de peces, los animales que migran (ñus), e incluso en los chimpancés cuando salen en busca de alimento (forrajeo) al romper el día. En estos últimos, que además practican la caza cooperativa (Albiach-Serrano, 2015), la habilidad para sincronizar sus movimientos podría ayudarles en su faceta de depredador, cuando tienen que coordinar sus acciones para cazar pequeños mamíferos (Boesch, 2002). Si nos centramos en nuestro género, las prácticas rituales también siguen una cadencia o ritmo común, y a menudo es la música (percusión) que dota de un marco rítmico compartido a los participantes (Laland y cols, 2016). En este último ejemplo este sincronizarse puede tener también efectos cohesionadores (“affiliation”). Cabría preguntarse, no obstante, si estos efectos prosociales de la sincronización interpersonal son exclusivos para los miembros del grupo "In-group" o funcionan con cualquier otro ser humano. No tenemos conocimiento de estudios que hayan manipulado de manera experimental la variable "in-group vs out-group" para ver si las 
personas se sincronizan con aquellos a quienes les atribuyen condición de "ingroup". Sí tenemos información específica respecto al mimetismo conductual, que pasamos a discutir a continuación, y que puede ayudarnos a resolver esta incógnita. Lakin y colaboradores (Lakin y cols., 2003) postulan que la función del mimetismo conductual habría cambiado con el tiempo, pasando de tener un papel comunicativo inicial a ser un mecanismo que facilita la coordinación social. Si esta hipótesis es correcta el mimetismo conductual debería dirigirse preferentemente hacia aquellos a quienes les conferimos la condición de "in-group", puesto que la coordinación supondrá una ventaja competitiva especialmente cuando se produce en el contexto del grupo. Un estudio de Bourgeois y Hess (2008) aportaría evidencias en favor de esta hipótesis, ya que describe como la imitación de expresiones faciales asociadas a emociones negativas solo se observa en miembros del mismo grupo, y no en integrantes del "out-group"; además, como ya describimos con anterioridad, cuando las personas han sido excluidas por miembros de su propio grupo incrementan la imitación de los gestos de manera selectiva hacia los miembros de su grupo (Lakin, Chartrand y Arkin, 2008). En este mismo sentido, Cheng y Chartrand (2003) reportan como los individuos que son más tendentes a la auto-evaluación ("self-monitoring") imitan más los gestos de aquellos que perciben como "in-group".

Over y Carpenter (2015) proponen que el papel del mimetismo conductual sería el de demostrar similaridad con otros de manera externa, y estaría asociado a la tendencia natural de los humanos a sentir agrado por aquellos con quienes comparten parecido. Si esta hipótesis es correcta entonces la imitación de los miembros del mismo grupo se podría deber tanto a la identificación previa de estos como "in-group", como al hecho de que comparten más parecido. Suele ocurrir que los miembros de un grupo comparten más rasgos fenotípicos (ej: una determinada etnia). En un estudio de Genschow y Schindler (2018) desligaron el parecido físico entre participantes y modelos a imitar de la pertenencia a grupo, de manera que ambos factores pudieran 
ser tratados como variables independientes, y comprobaron que lo que determinaba el grado de mimetismo conductual era la atribución de "in-group" y no el parecido percibido. Concretamente el estudio consistía en pedirles a los participantes que probaran una nueva bebida energética con el pretexto de estar lanzando un nuevo producto al mercado, mientras en un vídeo se mostraba a un modelo bebiendo; este modelo podía tener mayor parecido físico con el participante y/o pertenecer o no a su grupo (nacionalidad compartida). Lo que hallaron es que con independencia del parecido percibido por el propio participante entre el modelo y él mismo, lo que determinaba el grado de mimetismo exhibido era que el participante atribuyera al modelo la condición de "in-group".

Aunque resulta un tanto especulativo nos gustaría acabar esta discusión proponiendo como la sincronía interpersonal y el mimetismo conductual encajarían en el marco de la evolución de nuestro propio género. Creemos que ambos fenómenos están ligados al llamado "link percepción-acción" y que estarían por tanto alimentados por los circuitos de neuronas espejo. Sin embargo, nos atrevemos a proponer que la sincronía interpersonal sería un fenómeno más básico e inespecífico, posiblemente previo en cuanto a su aparición y compartido con otros animales, mientras que el mimetismo conductual sería una adquisición más reciente y exclusiva de nuestro género. Mientras que la sincronía permitiría coordinar la acción en especies animales altamente gregarias, el mimetismo conductual serviría para fortalecer los vínculos de los miembros del grupo ("in-group") para volverlos más cohesionados internamente, y por tanto más aptos para competir con otros grupos de la misma especie, con quienes comparten nicho ecológico.

\subsection{Limitaciones y futuras líneas de investigación.}

En el apartado previo ya hemos dado pistas sobre cuales son las principales limitaciones del presente estudio, e incluso sugerido como abordarlas en el futuro. 
Mimetismo conductual como marcador de afiliación.

Queremos, no obstante, hacer referencia a ellas de forma explícita, así como plantear la manera concreta de sortear dichas dificultades.

Una limitación del presente estudio es que carece de una condición contingencia temporal y de ritmo. Es decir, una condición donde ambos actores se muevan al mismo tiempo haciendo gestos distintos pero siguiendo un tempo/ritmo común. Si al hacer gestos distintos pero siguiendo un ritmo común las puntuaciones de afiliación son más elevadas, entonces podríamos concluir que en la sincronía interpersonal el ritmo lo es todo, y no tanto el que se muevan al unísono. Esto lo podríamos verificar realizando un estudio en el futuro donde pongamos a nuestros actores en los vídeos a grabar los gestos en la condición contingencia temporal a ritmo de metrónomo ayudados de unos cascos, de manera que aunque siempre realicen gestos dispares el ritmo de emisión de los mismos esté envuelto en un tapiz temporal común.

Otra limitación del presente estudio hace referencia a la ausencia de efectos afiliativos del movimiento en el experimento 3. Como ya discutimos es posible que tener dos actores cuyos rasgos fenotípicos y estilo de vestir son tan dispares tiene un poderosos efecto a la hora de emitir juicios acerca del estatus afiliativo o su entidad conjunta. Por ello, sería interesante comprobar si grabando los vídeos con dos actores que se asemejan en su fenotipo y su estilo de vestir devuelve a las contingencias de movimiento su poder para evocar afiliación o entitatividad. Por tanto, la manera de sortear esta limitación sería grabar otra vez los tres vídeos con dos actores que se asemejen y replicar el experimento 3 con ellos.

Otra limitación del presente estudio es que en la condición contingencia de forma sigue habiendo contingencia de tiempo, ya que los movimientos de ambos actores siguen una contingencia imperfecta de 4-5 segundos. Sin embargo, no se nos ocurre como podríamos tener contingencia de forma sin cierto grado de contingencia de tiempo. Es decir, si colocamos los movimientos imitados muy separados entre si 
cabe la posibilidad que los sujetos experimentales no detecten la similaridad entre estos. Es decir, si separamos los gestos imitados mucho nuestra condición contingencia de forma se parecería peligrosamente a nuestra condición contingencia nula. La última limitación del presente estudio, tiene que ver con el hecho de que los participantes de la tribu Samburu atribuyeron mayores valores en cuanto al estatus afiliativo y la entidad conjunta a los actores en los tres vídeos, sugiriendo que podría haber algún efecto relacionado con una posible percepción categorial. Es decir, es posible que aun cuando solo percibían las siluetas de los actores fueran capaces de determinar que estos actores no eran de su propia raza/etnia, y ello les llevaba a percibirlos como categorías distintas. Si este fuera el caso, la ausencia de diferencias entre las puntuaciones obtenidas en el vídeo contingencia nula y contingencia de forma sería un artefacto. La manera de abordar este problema consistiría en grabar los vídeos que se les presentan a los Samburu empleando actores Samburu.

Todas estas limitaciones pueden ser abordadas en el futuro, y esperamos tener la oportunidad de responder a todas ellas cuando la actual pandemia que nos afecta permita recuperar las rutinas de trabajo experimental en laboratorio.

Aunque no es excusa queremos explicar brevemente el motivo de la no inclusión de actores Samburu en los vídeos del estudio. La razón principal es que dado que empleamos un filtro muy potente (nótese que en el trabajo las fotos de la Figura 3.1 son mucho menos oscuras que en los vídeos que se pasaron en el estudio) que solo dejaba ver las siluetas de los actores creímos que no habría manera de que los Samburu detectaran que los actores eran occidentales. Solo al ver los resultados se nos ocurrió la hipótesis de que los participantes Samburu podían detectar cierta extrañeza en los gestos de nuestros actores. El problema que se nos planteaba a la hora de grabar nuevos vídeos con actores Samburu y pasar el estudio es que por temas de calendario escolar debíamos esperar otro año entero antes de poder pasar más 
Mimetismo conductual como marcador de afiliación.

sujetos. Por si esto fuera poco en el transcurso de esta tesis se declaró la pandemia por COVID y esto de nuevo condicionó bastante las posibilidades de hacer los experimentos comparables. En este nuevo contexto si grabábamos nuevos vídeos debíamos exponer a nuestros actores Samburu a la posibilidad de contagiarse de COVID al estar muy próximos el uno al otro en un lugar cerrado. Este riesgo podría ser mitigado mediante el uso de mascarillas, pero ello representaba introducir un elemento de variabilidad. Al final decidimos que había demasiadas incertidumbres y que era mejor dejar esta condición para un posible estudio de seguimiento "followup". 


\section{Bibliografía general}





\section{Bibliografía general}

Abrams, R., \& Christ, S. (2003). Motion Onset Captures Attention. Psychological Science, 14(5), 427-432. doi: 10.1111/1467-9280.01458

Albiach-Serrano, A. (2015). Cooperation in primates. Coordination, Collaboration And Cooperation, 16(3), 361-382. https://doi.org/10.1075/is.16.3.02alb

Arnett, J. (2008). The neglected 95\%: Why American psychology needs to become less American. American Psychologist, 63(7), 602-614. doi: 10.1037/0003066x.63.7.602

Ashby, F., Turner, B., \& Horvitz, J. (2010). Cortical and basal ganglia contributions to habit learning and automaticity. Trends In Cognitive Sciences, 14(5), 208215. doi: 10.1016/j.tics.2010.02.001

Ashton-James, C., van Baaren, R., Chartrand, T., Decety, J., \& Karremans, J. (2007). Mimicry and Me: The Impact of Mimicry on Self-Construal. Social Cognition, 25(4), 518-535. doi: 10.1521/soco.2007.25.4.518 
Mimetismo conductual como marcador de afiliación.

Balsters, J., \& Ramnani, N. (2011). Cerebellar Plasticity and the Automation of FirstOrder Rules. Journal Of Neuroscience, 31(6), 2305-2312. doi: 10.1523/jneurosci.4358-10.2011

Balsters, J., Whelan, C., Robertson, I., \& Ramnani, N. (2013). Cerebellum and Cognition: Evidence for the Encoding of Higher Order Rules. Cerebral Cortex, 23(6), 1433-1443. doi: 10.1093/cercor/bhs127

Bandura, A. (1977). Social learning theory. Englewood Cliffs, N.J: Prentice-Hall.

Barkow, J., Cosmides, L., \& Tooby, J. (1995). The adapted mind: Evolutionary psychology and the generation of culture. New York: Oxford University Press.

Boesch, C. (2002). Cooperative hunting roles among taï chimpanzees. Human Nature, 13(1), 27-46. https://doi.org/10.1007/s12110-002-1013-6

Bourgeois, P., \& Hess, U. (2008). The impact of social context on mimicry. Biological Psychology,77(3), 343-352. https://doi.org/10.1016/j.biopsycho.2007.11.008

Brewer, M. B., Hong, Y., \& Li, Q. (2004). Dynamic Entitivity: Perceiving Groups as Actors. In V. Y. Yzerbyt, C. Judd, \& O. Corneille (Eds.), The psychology of group perception: Perceived variability, entitativity, and essentialism (pp. 2538). New York, NY, US: Psychology Press.

Byrne, R. (2003). Imitation as behaviour parsing. Philosophical Transactions Of The Royal Society Of London. Series B: Biological Sciences, 358(1431), 529-536. doi: 10.1098/rstb.2002.1219

Byrne, R., \& Russon, A. (1998). Learning by imitation: A hierarchical approach. Behavioral And Brain $\quad$ Sciences, 21(5), 667-684. https://doi.org/10.1017/s0140525x98001745 
Callahan, S., \& Ledgerwood, A. (2016). On the psychological function of flags and logos: Group identity symbols increase perceived entitativity. Journal Of Personality And Social Psychology, 110(4), 528-550. doi: 10.1037/pspi0000047

Carpenter, M., \& Tomasello, M. (1995). Joint Attention and Imitative Learning in Children, Chimpanzees, and Enculturated Chimpanzees*. Social Development, 4(3), 217-237. doi: 10.1111/j.1467-9507.1995.tb00063.x

Catmur, C., \& Heyes, C. (2013). Is It What You Do, or When You Do It? The Roles of Contingency and Similarity in Pro-Social Effects of Imitation. Cognitive Science, 37(8), 1541-1552. doi: 10.1111/cogs.12071

Chao, L., \& Martin, A. (2000). Representation of Manipulable Man-Made Objects in the Dorsal Stream. Neuroimage, 12(4), 478-484. https://doi.org/10.1006/nimg.2000.0635

Chartrand, T. L., Maddux, W. W., \& Lakin, J. L. (2005). Beyond the perceptionbehavior link: The ubiquitous utility and motivational moderators of nonconscious mimicry. In R. Hassin, J. Uleman, \& J. A. Bargh (Eds.), Unintended thoughts 2: The new unconscious (pp. 334-361). New York: Oxford University Press.

Chartrand, T., \& Bargh, J. (1999). The chameleon effect: The perception-behavior link and social interaction. Journal Of Personality And Social Psychology, 76(6), 893-910. doi: 10.1037/0022-3514.76.6.893

Chartrand, T., \& Lakin, J. (2013). The Antecedents and Consequences of Human Behavioral Mimicry. Annual Review Of Psychology, 64(1), 285-308. doi: 10.1146/annurev-psych-113011-143754 
Mimetismo conductual como marcador de afiliación.

Cheng, C., \& Chartrand, T. (2003). Self-Monitoring Without Awareness: Using Mimicry as a Nonconscious Affiliation Strategy. Journal Of Personality And Social Psychology, 85(6), 1170-1179. doi: 10.1037/0022-3514.85.6.1170

Cirelli, L., Einarson, K., \& Trainor, L. (2014). Interpersonal synchrony increases prosocial behavior in infants. Developmental Science, 17(6), 1003-1011. doi: 10.1111/desc. 12193

Clark, A., \& Kashima, Y. (2007). Stereotypes help people connect with others in the community: A situated functional analysis of the stereotype consistency bias in communication. Journal Of Personality And Social Psychology, 93(6), 10281039. doi: $10.1037 / 0022-3514.93 .6 .1028$

Cross, L., Turgeon, M., \& Atherton, G. (2019). How Moving Together Binds Us Together: The Social Consequences of Interpersonal Entrainment and Group Processes. Open Psychology, 1(1), 273-302. doi: 10.1515/psych-2018-0018

Csibra, G. Gergely, G. (2006). Social learning and social cognition: the case for pedagogy. In Y. Munakata \& M. H. Johnson (Eds.), Processes of Change in Brain and Cognitive Development. Attention and Performance, XXI. (pp. 249-274). Oxford: Oxford University Press.

Dalton, A., Chartrand, T., \& Finkel, E. (2010). The schema-driven chameleon: How mimicry affects executive and self-regulatory resources. Journal Of Personality And Social Psychology, 98(4), 605-617. https://doi.org/10.1037/a0017629

Dasgupta, N., Banaji, M., \& Abelson, R. (1999). Group entitativity and group perception: Associations between physical features and psychological judgment. Journal Of Personality And Social Psychology, 77(5), 991-1003. doi: 10.1037/0022-3514.77.5.991 
Bibliografia general

de Klerk, C., Albiston, H., Bulgarelli, C., Southgate, V., \& Hamilton, A. (2020). Observing third-party ostracism enhances facial mimicry in 30-month-olds. Journal Of Experimental Child Psychology, 196, 104862. https://doi.org/10.1016/j.jecp.2020.104862

de Klerk, C., Hamilton, A., \& Southgate, V. (2018). Eye contact modulates facial mimicry in 4-month-old infants: An EMG and fNIRS study. Cortex, 106, 93103. doi: $10.1016 /$ j.cortex.2018.05.002

Derbyshire, N., Ellis, R., \& Tucker, M. (2006). The potentiation of two components of the reach-to-grasp action during object categorisation in visual memory. Acta Psychologica, 122(1), 74-98. https://doi.org/10.1016/j.actpsy.2005.10.004

di Pellegrino, G., Fadiga, L., Fogassi, L., Gallese, V., \& Rizzolatti, G. (1992). Understanding motor events: a neurophysiological study. Experimental Brain Research, 91(1), 176-180. doi: 10.1007/bf00230027

Dijksterhuis, A., \& Bargh, J. A. (2001). The perception-behavior expressway: Automatic effects of social perception on social behavior. In M. P. Zanna (Ed.), Advances in experimental social psychology, Vol. 33, pp. 1-40). Academic Press.

Doyon, J., \& Benali, H. (2005). Reorganization and plasticity in the adult brain during learning of motor skills. Current Opinion In Neurobiology, 15(2), 161-167. doi: 10.1016/j.conb.2005.03.004

Drimalla, H., Landwehr, N., Hess, U., \& Dziobek, I. (2019). From face to face: the contribution of facial mimicry to cognitive and emotional empathy. Cognition And Emotion, 33(8), 1672-1686. doi: 10.1080/02699931.2019.1596068 
Duffy, K., \& Chartrand, T. (2015). Mimicry: causes and consequences. Current Opinion In Behavioral Sciences, 3, 112-116. doi: 10.1016/j.cobeha.2015.03.002

Fawcett, C., \& Tunçgenç, B. (2017). Infants' use of movement synchrony to infer social affiliation in others. Journal Of Experimental Child Psychology, 160, 127-136. doi: 10.1016/j.jecp.2017.03.014

Fernald, A., \& Morikawa, H. (1993). Common Themes and Cultural Variations in Japanese and American Mothers' Speech to Infants. Child Development, 64(3), 637. https://doi.org/10.2307/1131208

Fischer-Lokou, J., Guéguen, N., Lamy, L., Martin, A., \& Bullock, A. (2014). Imitation in Mediation: Effects of the Duration of Mimicry on Reaching Agreement. Social Behavior And Personality: An International Journal, 42(2), 189195. doi: 10.2224/sbp.2014.42.2.189

Fischer, A., \& Hess, U. (2017). Mimicking emotions. Current Opinion In Psychology, 17, 151-155. doi: 10.1016/j.copsyc.2017.07.008

Foley, R., \& Gamble, C. (2009). The ecology of social transitions in human evolution. Philosophical Transactions Of The Royal Society B: Biological Sciences, 364(1533), 3267-3279. doi: 10.1098/rstb.2009.0136

Gallese, V., Fadiga, L., Fogassi, L., \& Rizzolatti, G. (1996). Action recognition in the premotor cortex. Brain, 119(2), 593-609. doi: 10.1093/brain/119.2.593

Genschow, O., \& Schindler, S. (2016). The influence of group membership on crosscontextual imitation. Psychonomic Bulletin \& Review, 23(4), 1257-1265. doi: 10.3758/s13423-015-0983-4 
Genschow, O., \& Schindler, S. (2018). The influence of group membership on crosscontextual imitation. Psychonomic Bulletin \& Review, 23(4), 1257-1265. https://doi.org/10.3758/s13423-015-0983-4

Gordon, P. (2004). Numerical Cognition Without Words: Evidence from Amazonia. Science, 306(5695), 496-499. doi: 10.1126/science.1094492

Guéguen, N., \& Martin, A. (2009). Incidental Similarity Facilitates Behavioral Mimicry. Social Psychology, 40(2), 88-92. doi: 10.1027/1864-9335.40.2.88

Henrich, J., Heine, S., \& Norenzayan, A. (2010). The Weirdest People in the World?. SSRN Electronic Journal. doi: 10.2139/ssrn.1601785

Hermans, E., van Wingen, G., Bos, P., Putman, P., \& van Honk, J. (2009). Reduced spontaneous facial mimicry in women with autistic traits. Biological Psychology, 80(3), 348-353. doi: 10.1016/j.biopsycho.2008.12.002

Heyes, C. (2011). Automatic imitation. Psychological Bulletin, 137(3), 463-483. doi: $10.1037 / \mathrm{a} 0022288$

Heyes, C. (2018). Cognitive gadgets: The cultural evolution of thinking. Cambridge (Mass.): Harvard University press.

Holtzman, J. (1996). Transformations in Samburu domestic economy: The reconstitutionof age and gender-based processes of production and resource allocation among a Kenyan pastoral people (Doctoral dissertation). University of Michigan.

Hove, M., \& Risen, J. (2009). It's All in the Timing: Interpersonal Synchrony Increases Affiliation. Social Cognition, 27(6), 949-960. doi: 10.1521/soco.2009.27.6.949 
Mimetismo conductual como marcador de afiliación.

Iacoboni, M. (2009). Neurobiology of imitation. Current Opinion In Neurobiology, 19(6), 661-665. doi: 10.1016/j.conb.2009.09.008

Iacoboni, M., 2005. Understanding others: Imitation, language, empathy. In: Hurley, S., Chater, N. (Eds.), Perspectives on imitation: From cognitive neuroscience to social science. Cambridge, Massachusetts: The MIT Press, pp. 77-99.

Iacoboni, M., Woods, R., Brass, M., Bekkering, H., Mazziotta, J., \& Rizzolatti, G. (1999). Cortical Mechanisms of Human Imitation. Science, 286(5449), 25262528. doi: $10.1126 /$ science.286.5449.2526

Iriki, A. (2006). The neural origins and implications of imitation, mirror neurons and tool use.Current Opinion In Neurobiology, 16(6), 660-667. doi: 10.1016/j.conb. 2006.10 .008

Iriki, A., \& Sakura, O. (2008). The neuroscience of primate intellectual evolution: natural selection and passive and intentional niche construction. Philosophical Transactions Of The Royal Society B: Biological Sciences, 363(1500), 22292241. doi: 10.1098/rstb.2008.2274

Johnston, L. (2002). Behavioral Mimicry and Stigmatization. Social Cognition, 20(1), 18-35. doi: 10.1521/soco.20.1.18.20944

Karremans, J., \& Verwijmeren, T. (2008). Mimicking Attractive Opposite-Sex Others: The Role of Romantic Relationship Status. Personality And Social Psychology Bulletin, 34(7), 939-950. doi: 10.1177/0146167208316693

Keysers, C., \& Fadiga, L. (2008). The mirror neuron systems. London: Psychology Press. "A special issue of Social Neuroscience". 
Korb, S., Malsert, J., Strathearn, L., Vuilleumier, P., \& Niedenthal, P. (2016). Sniff and mimic - Intranasal oxytocin increases facial mimicry in a sample of men. Hormones And Behavior, 84, 64-74. doi: 10.1016/j.yhbeh.2016.06.003

Körner, A., Topolinski, S., \& Strack, F. (2015). Routes to embodiment. Frontiers In Psychology, 6. https://doi.org/10.3389/fpsyg.2015.00940

Kuwabara, M., \& Smith, L. (2012). Cross-cultural differences in cognitive development: Attention to relations and objects. Journal Of Experimental Child Psychology, 113(1), 20-35. https://doi.org/10.1016/j.jecp.2012.04.009

Lakens, D., \& Stel, M. (2011). If They Move in Sync, They Must Feel in Sync: Movement Synchrony Leads to Attributions of Rapport and Entitativity. Social Cognition, 29(1), 1-14. doi: 10.1521/soco.2011.29.1.1

Lakin, J. L., \& Chartrand, T. L. (2005). Exclusion and Nonconscious Behavioral Mimicry. In K. D. Williams, J. P. Forgas, \& W. von Hippel (Eds.), Sydney Symposium of Social Psychology series. The social outcast: Ostracism, social exclusion, rejection, and bullying (p. 279-295). Psychology Press.

Lakin, J. L., Jefferis, V. E., Cheng, C. M., \& Chartrand, T. L. (2003). The chameleon effect as social glue: Evidence for the evolutionary significance of nonconscious mimicry. Journal of nonverbal behavior, 27(3), 145-162.

Lakin, J., \& Chartrand, T. (2003). Using Nonconscious Behavioral Mimicry to Create Affiliation and Rapport. Psychological Science, 14(4), 334-339. doi: $10.1111 / 1467-9280.14481$

Lakin, J., Chartrand, T., \& Arkin, R. (2008). I Am Too Just Like You. Psychological Science, 19(8), 816-822. doi: 10.1111/j.1467-9280.2008.02162.x 
Mimetismo conductual como marcador de afiliación.

Lakin, J., Chartrand, T., \& Arkin, R. (2008). I Am Too Just Like You. Psychological Science, 19(8), 816-822. https://doi.org/10.1111/j.1467-9280.2008.02162.

Lakin, J., Jefferis, V., Cheng, C., \& Chartrand, T. (2003). Journal Of Nonverbal Behavior, 27(3), 145-162. doi: 10.1023/a:1025389814290

Laland, K., Wilkins, C., \& Clayton, N. (2016). The evolution of dance. Current Biology, 26(1), R5-R9.

Leander, N., Chartrand, T., \& Bargh, J. (2012). You Give Me the Chills. Psychological Science, 23(7), 772-779. https://doi.org/10.1177/0956797611434535

Leander, N., Chartrand, T., \& Wood, W. (2011). Mind your mannerisms: Behavioral mimicry elicits stereotype conformity. Journal Of Experimental Social Psychology, 47(1), 195-201. doi: 10.1016/j.jesp.2010.09.002

Levin, D., \& Angelone, B. (2002). Categorical Perception of Race. Perception, 31(5), 567-578. doi: 10.1068/p3315

Lhermitte, F., Pillon, B., \& Serdaru, M. (1986). Human autonomy and the frontal lobes. Part I: Imitation and utilization behavior: A neuropsychological study of 75 patients. Annals Of Neurology, 19(4), 326-334. https://doi.org/10.1002/ana.410190404

Lickel, B., Hamilton, D., Wieczorkowska, G., Lewis, A., Sherman, S., \& Uhles, A. (2000). Varieties of groups and the perception of group entitativity. Journal Of Personality And Social Psychology, 78(2), 223-246. doi: 10.1037/00223514.78.2.223

Likowski, K., Mühlberger, A., Seibt, B., Pauli, P., \& Weyers, P. (2008). Modulation of facial mimicry by attitudes. Journal Of Experimental Social Psychology, 44(4), 1065-1072. doi: 10.1016/j.jesp.2007.10.007 
Bibliografia general

Luria, A. (1931). Psychological expedition to central Asia. Science, 74(1920), 383384. doi: 10.1126/science.74.1920.383

Luria, A. (1971). Towards the Problem of the Historical Nature of Psychological Processes. International Journal of Psychology,6(4), 259-272. doi: $10.1080 / 00207597108246692$

Majka, E., White, M., Bowling, L., Garcia, R., Skinner, T., \& Bennett, K. et al. (2020). The affiliative consequences of same-race and cross-race mimicry. The Journal Of Social Psychology, 160(5), 603-612. https://doi.org/10.1080/00224545.2020.1719962

Maravita, A., \& Iriki, A. (2004). Tools for the body (schema). Trends In Cognitive Sciences, 8(2), 79-86. doi: 10.1016/j.tics.2003.12.008

Maravita, A., Spence, C., \& Driver, J. (2003). Multisensory integration and the body schema: close to hand and within reach. Current Biology, 13(13), R531-R539. doi: 10.1016/s0960-9822(03)00449-4

Martin, A., Guéguen, N., \& Fischer-Lokou, J. (2010). The Impact of Guilt on Mimicry Behavior. Social Behavior And Personality: An International Journal, 38(7), 987-991. doi: 10.2224/sbp.2010.38.7.987

Masuda, T., \& Nisbett, R. (2001). Attending holistically versus analytically: Comparing the context sensitivity of Japanese and Americans. Journal Of Personality And Social Psychology,81(5), 922-934. https://doi.org/10.1037/00223514.81.5.922

McIntosh, D. (2006). Spontaneous facial mimicry, liking, and emotional contagion. Polish Psychological Bulletin, 37(1), 31-42. 
Mimetismo conductual como marcador de afiliación.

Meltzoff, A., \& Moore, M. (1977). Imitation of facial and manual gestures by human neonates. Science, 198(4312), 74-78. doi: 10.1126/science.897687

Meltzoff, A., \& Moore, M. (1979). Interpreting "imitative" responses in early infancy. Science, 205(4402), 217-219. doi: 10.1126/science.451596

Meltzoff, A., \& Moore, M. (1997). Explaining facial imitation: a theoretical model. Early Development And Parenting,6(3-4), 179-192. doi: 10.1002/(sici)1099-0917(199709/12)6:3/4<179::aid-edp157>3.0.co;2-r

Meltzoff, A.N., \& Moore, M.K. (1998). Infant intersubjectivity: broadening the dialogue to include imitation, identity and intention. In S. Braten (Ed.), Intersubjective communication and emotion in early ontogeny (pp. 47-62). New York: Cambridge University Press. Meltzoff, A.N. (2002). Elements of a developmental theory of imitation. In A.N. Meltzoff \& W. Prinz (Eds.), The imitative mind: Development, evolution, and brain bases (pp. 19-41). New York: Cambridge University Press.

Miles, L., Nind, L., \& Macrae, C. (2009). The rhythm of rapport: Interpersonal synchrony and social perception. Journal Of Experimental Social Psychology, 45(3), 585-589. doi: 10.1016/j.jesp.2009.02.002

Miller, K., Smith, C., Zhu, J., \& Zhang, H. (1995). Preschool Origins of Cross-National Differences in Mathematical Competence: The Role of Number-Naming Systems. Psychological Science,6(1), 56-60. doi: 10.1111/j.14679280.1995.tb00305.x

Mukamel, R., Ekstrom, A., Kaplan, J., Iacoboni, M., \& Fried, I. (2010). Single-Neuron Responses in Humans during Execution and Observation of Actions. Current Biology, 20(8), 750-756. doi: 10.1016/j.cub.2010.02.045 
Murata, A., Fadiga, L., Fogassi, L., Gallese, V., Raos, V., \& Rizzolatti, G. (1997). Object Representation in the Ventral Premotor Cortex (Area F5) of the Monkey. Journal Of Neurophysiology, 78(4), 2226-2230. https://doi.org/10.1152/jn.1997.78.4.2226

Nadel, J., \& Butterworth, G. (1999). Imitation in infancy. Cambridge University Press.

Nelissen, K., Borra, E., Gerbella, M., Rozzi, S., Luppino, G., \& Vanduffel, W. et al. (2011). Action Observation Circuits in the Macaque Monkey Cortex. Journal Of Neuroscience, 31(10), 3743-3756. doi: 10.1523/jneurosci.4803-10.2011

Nisbett, R. (2004). The geography of thought: How Asians and Westerners think differently... and why. Free Press.

Oberman, L., \& Ramachandran, V. (2007). The simulating social mind: The role of the mirror neuron system and simulation in the social and communicative deficits of autism spectrum disorders. Psychological Bulletin, 133(2), 310-327. doi: 10.1037/0033-2909.133.2.310

Over, H., \& Carpenter, M. (2014). Children infer affiliative and status relations from watching others imitate. Developmental Science, 18(6), 917-925. doi: $10.1111 /$ desc. 12275

Over, H., Carpenter, M., Spears, R., \& Gattis, M. (2013). Children Selectively Trust Individuals Who Have Imitated Them. Social Development, 22(2), 215-224. doi: $10.1111 /$ sode. 12020

Over, H., Vaish, A., \& Tomasello, M. (2016). Do young children accept responsibility for the negative actions of ingroup members?. Cognitive Development, 40, 24-32. doi: 10.1016/j.cogdev.2016.08.004 
Mimetismo conductual como marcador de afiliación.

Papadourakis, V., \& Raos, V. (2018). Neurons in the Macaque Dorsal Premotor Cortex Respond to Execution and Observation of Actions. Cerebral Cortex, 29(10), 4223-4237. doi: 10.1093/cercor/bhy304

Parrill, F., \& Kimbara, I. (2006). Seeing and Hearing Double: The Influence of Mimicry in Speech and Gesture on Observers. Journal Of Nonverbal Behavior, 30(4), 157-166. doi: 10.1007/s10919-006-0014-2

Pearce, E., Launay, J., van Duijn, M., Rotkirch, A., David-Barrett, T., \& Dunbar, R. (2016). Singing together or apart: The effect of competitive and cooperative singing on social bonding within and between sub-groups of a university Fraternity. Psychology Of Music,44(6), 1255-1273. doi: $10.1177 / 0305735616636208$

Pennartz, C., Ito, R., Verschure, P., Battaglia, F., \& Robbins, T. (2011). The hippocampal-striatal axis in learning, prediction and goal-directed behavior. Trends In Neurosciences, 34(10), 548-559. doi: 10.1016/j.tins.2011.08.001

Preston, S., \& de Waal, F. (2002). Empathy: Its ultimate and proximate bases. Behavioral And Brain Sciences, 25(1), 1-20. doi: 10.1017/s0140525x02000018

Rizzolatti, G., \& Craighero, L. (2004). The Mirror Neuron System. Annual Review Of Neuroscience, 27, 169-192.

Rizzolatti, G., \& Sinigaglia, C. (2006). So quel che fai: : Il cervello che agisce e $i$ neuroni specchio. Milano: Cortina.

Rizzolatti, G., \& Sinigaglia, C. (2008). Mirrors in the brain. Oxford: Oxford University Press.

Rizzolatti, G., Fogassi, L., Gallese, V., 2004. Cortical mechanisms subserving object grasping, action understanding, and imitation. In: Gazzaniga, M.S. (Ed.), The 
cognitive neurosciences III. Cambridge, Massachusetts, The MIT Press, "A Bradford Book”, pp. 427-440.

Saarela, M., \& Hari, R. (2008). Listening to humans walking together activates the social brain circuitry. Social Neuroscience, 3(3-4), 401-409. doi: $10.1080 / 17470910801897633$

Segall, M., Campbell, D., \& Herskovits, M. (1966). The influence of culture on visual perception. New York: Bobbs-Merrill.

Sonnby-Borgström, M., Jönsson, P., \& Svensson, O. (2003). Emotional empathy as related to mimicry reactions at different levels of information processing. Journal Of Nonverbal Behavior, 27(1), 3-23.

Sowden, S., \& Catmur, C. (2015). The Role of the Right Temporoparietal Junction in the Control of Imitation. Cerebral Cortex, 25(4), 1107-1113. doi: 10.1093/cercor/bht306

Spencer, P. (2013). The Samburu: a study of gerontocracy in a nomadic tribe (26th ed.). London: Routledge.

Spencer, Paul (1985). Dance as Antithesis in the Samburu Discourse.' In: Spencer, P., (ed.), Society and the Dance. Cambridge University Press, pp. 140-164.

Tomasello, M., \& Call, J. (1997). Primate cognition. New York [u.a.]: Oxford Univ. Press.

Tsai, J., Sebanz, N., \& Knoblich, G. (2011). The GROOP effect: Groups mimic group actions. Cognition, 118(1), 135-140. doi: 10.1016/j.cognition.2010.10.007

Tucker, M., \& Ellis, R. (1998). On the relations between seen objects and components of potential actions. Journal Of Experimental Psychology: Human 
Mimetismo conductual como marcador de afiliación.

Perception And Performance, 24(3), 830-846. https://doi.org/10.1037/00961523.24.3.830

Tucker, M., \& Ellis, R. (2001). The potentiation of grasp types during visual object categorization. Visual

Cognition, 8(6),

769-800.

https://doi.org/10.1080/13506280042000144

Tucker, M., \& Ellis, R. (2004). Action priming by briefly presented objects. Acta Psychologica, 116(2), 185-203. https://doi.org/10.1016/j.actpsy.2004.01.004

Vainio, L., Tucker, M., \& Ellis, R. (2007). Precision and power grip priming by observed grasping. Brain And Cognition, 65(2), 195-207. https://doi.org/10.1016/j.bandc.2007.07.004

van Baaren, R., Horgan, T., Chartrand, T., \& Dijkmans, M. (2004). The Forest, the Trees, and the Chameleon: Context Dependence and Mimicry. Journal of Personality And Social Psychology, 86(3), 453-459. doi: 10.1037/00223514.86 .3 .453

van Baaren, R., Maddux, W., Chartrand, T., de Bouter, C., \& van Knippenberg, A. (2003). It takes two to mimic: Behavioral consequences of self-construals. Journal Of Personality And Social Psychology, 84(5), 1093-1102. doi: 10.1037/0022-3514.84.5.1093

van der Schalk, J., Fischer, A., Doosje, B., Wigboldus, D., Hawk, S., Rotteveel, M., \& Hess, U. (2011). Convergent and divergent responses to emotional displays of ingroup and outgroup.Emotion, 11(2), 286-298. doi: $10.1037 / \mathrm{a} 0022582$

Van Swol, L., \& Drury, M. (2006). The effects of shared opinions on nonverbal mimicry. Paper Presented At Annual Int. Communic. Assoc. Conf.,. 
Bibliografia general

Vrijsen, J., Lange, W., Becker, E., \& Rinck, M. (2010). Socially anxious individuals lack unintentional mimicry. Behaviour Research And Therapy, 48(6), 561564. doi: 10.1016/j.brat.2010.02.004

Washburn, M. (1913). The animal mind. New York, N.Y: MacMillan Co.

Waxman, S., Fu, X., Ferguson, B., Geraghty, K., Leddon, E., Liang, J., \& Zhao, M. (2016). How Early is Infants' Attention to Objects and Actions Shaped by Culture? New Evidence from 24-Month-Olds Raised in the US and China. Frontiers In Psychology, 7. https://doi.org/10.3389/fpsyg.2016.00097

Whorf, B. L. (1956). Language, thought and reality. New York: Wiley.

Witkin, H., \& Goodenough, D. (1981). Cognitive styles: Essence and origin. New York: International University Press.

Witkin, H., Goodenough, D., \& Karp, S. (1967). Stability of cognitive style from childhood to young adulthood. Journal Of Personality And Social Psychology, 7(3, Pt.1), 291-300. doi: 10.1037/h0025070

Woolhouse, M., Tidhar, D., \& Cross, I. (2016). Effects on Inter-Personal Memory of Dancing in Time with Others.Frontiers In Psychology, 7. doi: 10.3389/fpsyg.2016.00167

Yabar, Y., Johnston, L., Miles, L., \& Peace, V. (2006). Implicit Behavioral Mimicry: Investigating the Impact of Group Membership. Journal Of Nonverbal Behavior, 30(3), 97-113. doi: 10.1007/s10919-006-0010-6 
Anexos 



\section{Anexos}

Cada anexo está codificado en función del número del capítulo al que pertenece. El primer dígito corresponde al capítulo y el segundo al número consecutivo al cual corresponde. 


\subsection{Hojas de respuesta}

Marca la casilla que indicaría cuantas cosas tienen en común las personas del vídeo. Puedes marcar cualquier número del 1 al 7. Las etiquetas verbales que acompañan los números 1 (mínimo posible), 4 (grado intermedio) y 7 (máximo posible) sirven para tener una referencia de contenido familiar que ilustra el grado de cosas que comparten ambas personas.

\begin{tabular}{c|c|c|c|c|c|c}
\hline $\begin{array}{c}\text { Desconocidos } \\
\text { Distinta nacionalidad }\end{array}$ & & $\begin{array}{c}\text { Desconocidos } \\
\text { Misma nacio- } \\
\text { nalidad }\end{array}$ & & & $\begin{array}{c}\text { Son padre e hijo } \\
\text { Son hermanos }\end{array}$ \\
\hline 1 & 2 & 3 & 4 & 5 & 6 & 7 \\
\hline
\end{tabular}




\subsection{Autorización participación en el estudio transcultural}

Yo,

He leído la hoja de información que se me ha entregado.

He recibido suficiente información sobre el estudio.

He podido hacer las preguntas que he creído convenientes sobre el estudio.

He hablado con: .(Nombre y apellidos del informador)

Comprendo que la participación es voluntaria.

Presto libremente mi conformidad para participar en el estudio.

Doy mi conformidad para mis datos sean revisados por personal ajeno al centro, para los fines del estudio, y soy consciente de que este consentimiento es revocable.

He recibido una copia firmada de este Consentimiento Informado.

Firma del participante:

En (fecha):

He explicado la naturaleza y el propósito del estudio al participante Firma del Investigador:

En (fecha):

COPIA PARA EL PARTICIPANTE/ COPIA PARA EL PROYECTO 


\subsection{Entrenamiento Samburu}

Hoy vamos a practicar como cuantificar y evalúar diferentes cosas. Esto no es un examen, no hay respuestas correctas o incorrectas. Lo que me interesa es tu opinión sincera. Fíjate en el papel que tienes en frente. Verás una escala que va de 1 a 7. 1 significa nada en absoluto, y 7 significa totalmente/completamente. Deja que te lo explique con algunos ejemplos.

Mira este dibujo y dime: ¿Cúanto se parece a un elefante? Si crees que es un elefante perfecto marcarías 7 , si crees que se parece moderadamente a un elefante porque crees apreciar la trompa y las orejas, entonces le puedes dar una puntuación intermedia 4. Y si crees que no es más que un mamarracho y no se parece en absoluto a un elefante entonces marcarías 1 . También puedes marcar cualquier otro número del 1 al 7 que creas refleja el grado en que estas líneas se asemajan a un elefante.

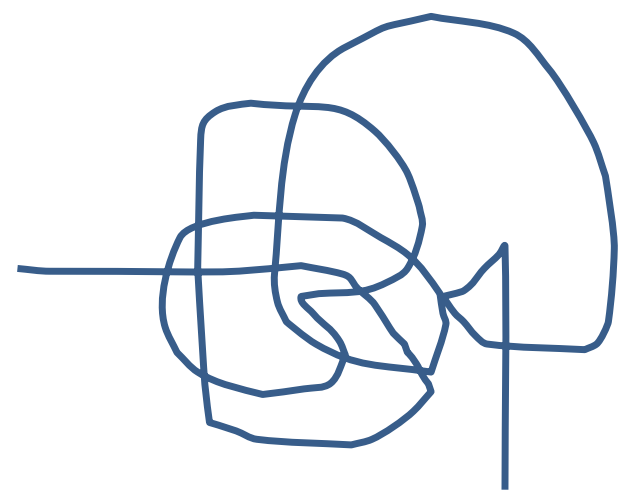

Ahora, mira con atención el dibujo y una vez te hayas decidido rodea el número que mejor refleja la semejanza con un elefante.

Ahora fijate en este otro dibujo. ¿Cuanto crees que se parece a un elefante? Puedes marcar cualquier número de 1 a 7 . Uno significa que no se parece en absoluto, 2 
significa que tiene una ligerísima semejanza, 3 significa que se parece un poquito más que 2,-y hasta 7 que significa que se parece $100 \%$ a un elefante.

Fíajte bien en el dibujo y rodea el número que crees en tu hoja de registro. Asegúrate que marcas en la seguna línea.. ¿Tienes alguna duda?

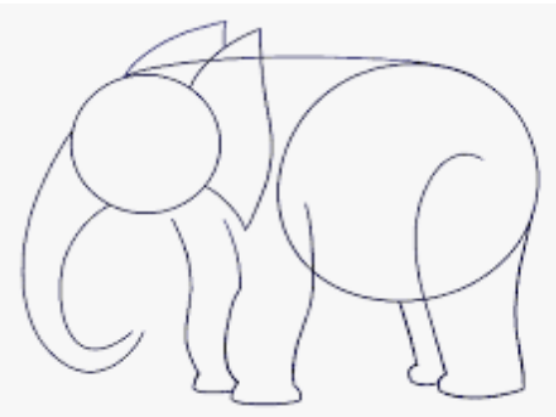

Ahora mira esta imagen. ¿Cuanto se parece a un elefante? Nada en absoluto? ¿Solo un poquito? ¿Mucho? Marca el numero en tu hojita.

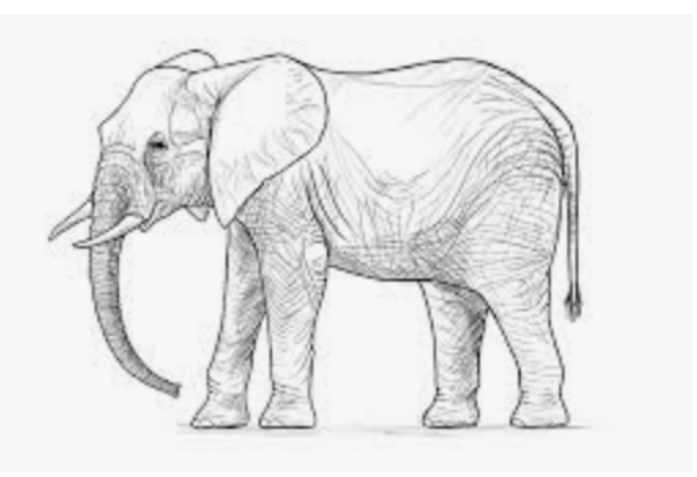

Ahora te hago una pregunta diferente. Pero se trata de hacer lo mismo, tienes que cuantificar. 
¿Cuánto te gusta X (comida de los Nasa)? Si no te gusta nada marca 1, y si es la comida que más te gusta del mundo marca 7. Si te gusta pero en un grado distinto, entre 1 y 7 marca el número que mejor refleje cuanto te gusta.

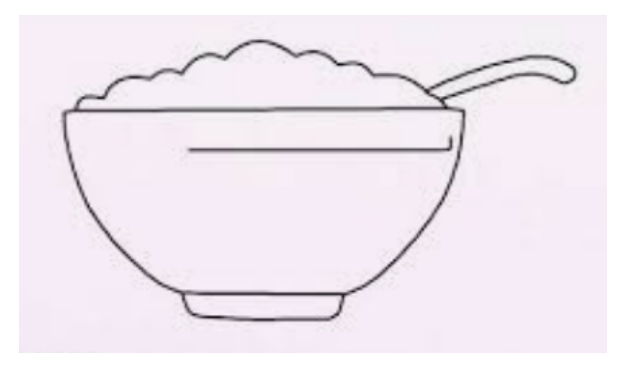

Ahora otro tipo de pregunta. ¿Cómo de bueno eres jugando a volleyball? Si eres un jugador extraordinario/perfecto marca 7, si no tienes ni idea de jugar marca 1, y si sabes jugar en un nivel distinto a 1 y 7 marca el número que mejor indique tu nivel de juego.

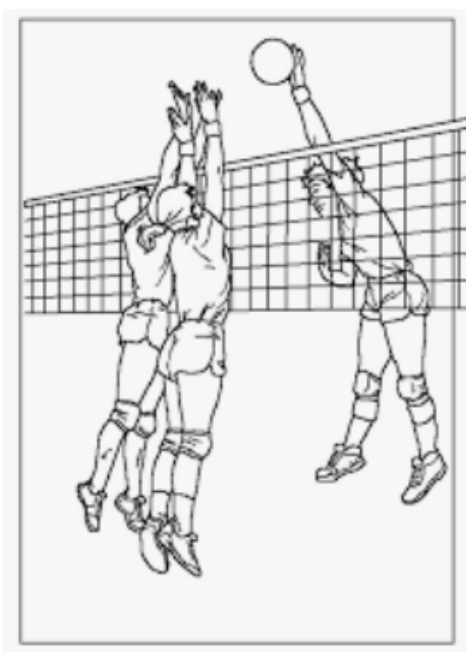

Ahora mira estos dos dibujos. ¿Cuánto tienen en común? Si crees que son idénticos, rodea el 7. Si crees que no tienen NADA en común, rodea 1 . Si crees que son en cierto modo similares escoge un número entre 1 y 7 que describa cuanto se ase- 
mejan. Por ejemplo, si apenas se parecen podrías rodear 2 y si son casi idénticos rodearías 6. Si se parecen en grados distintos puedes rodear 3,4, ó 5.
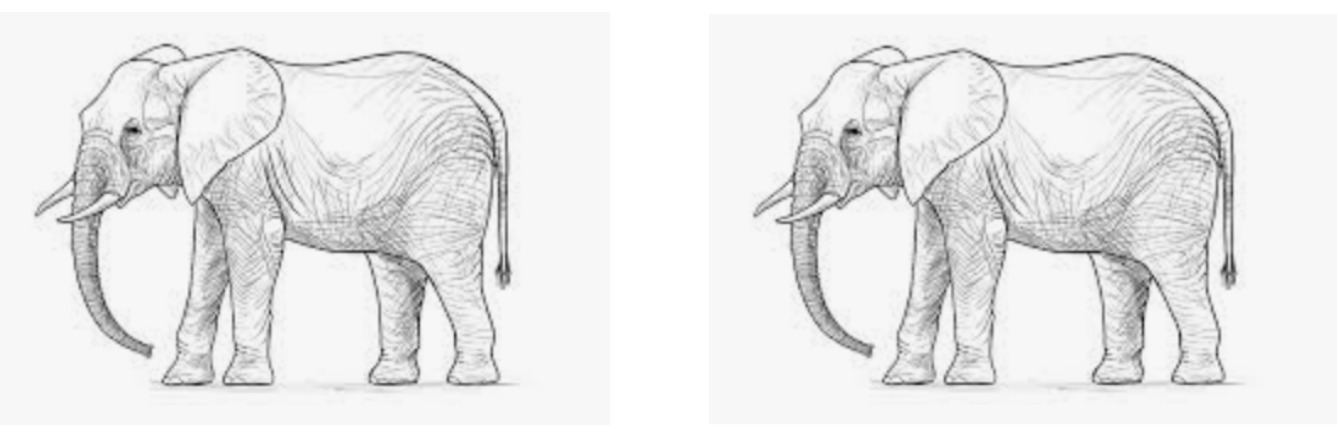

Otra pregunta. ¿Cuánto te gusta la carne asada? Piénsalo bien y rodea el número que mejor describe cuánto te gusta, desde 1 (nada en absoluto) hasta 7 (me gusta más que cualquier otra comida).

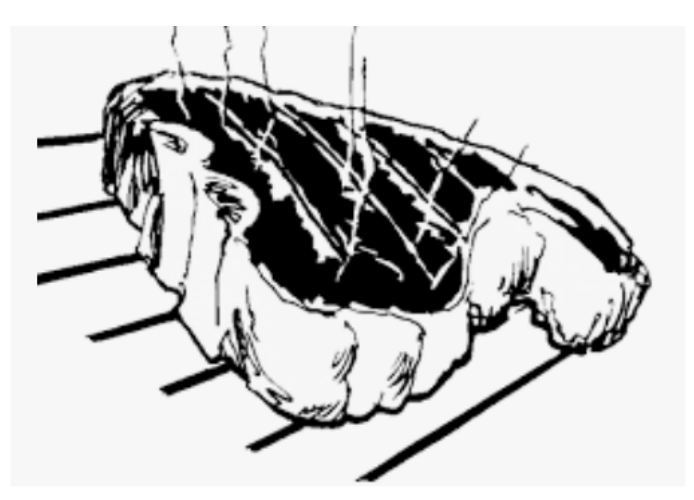

Ahora observa estas dos imágenes. ¿Cuánto tienen en común? Compara y decide que número rodear. 

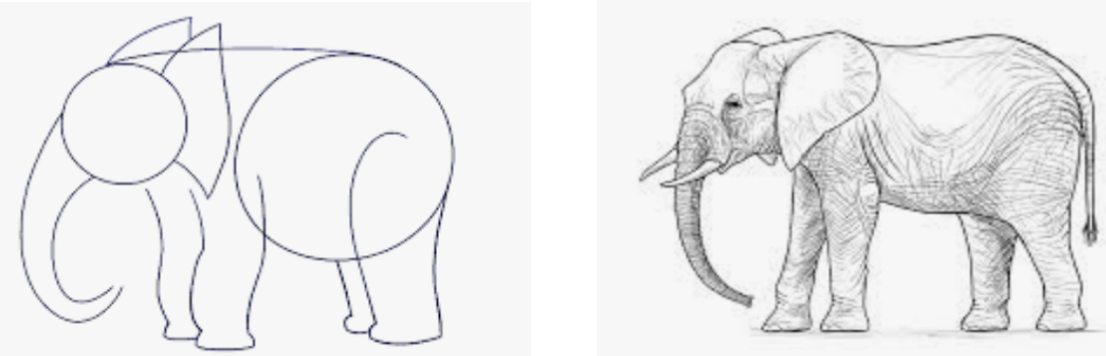

Y ahora observa estas dos. ¿Cuánto tienen en común?
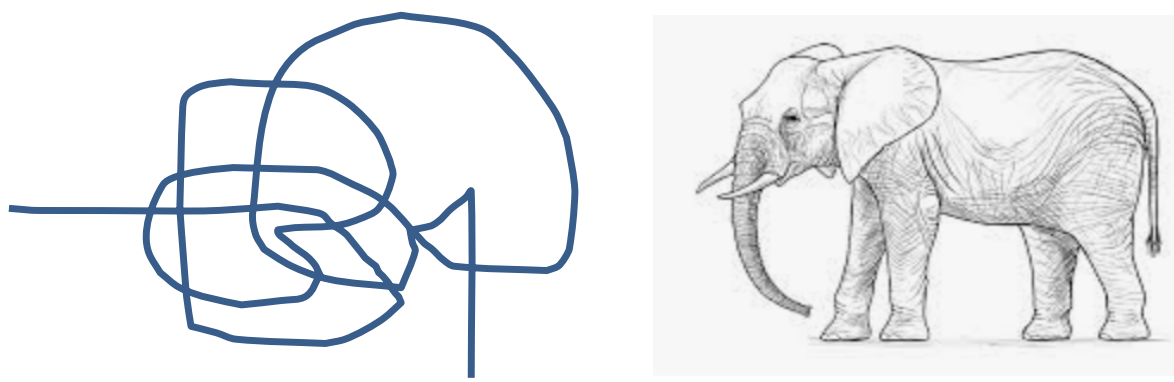

Otro tipo de pregunta. ¿Cómo de bien se te dan las matemáticas? Rodea el número que mejor lo describe- desde se me dan fatal (1), ni mal ni bien (4), hasta soy extremadamente bueno en matemáticas (7).

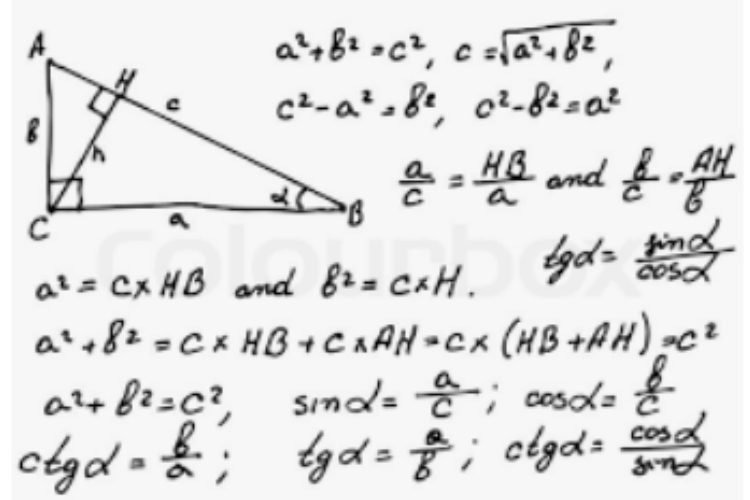


Y otra pregunta distinta. ¿Qué tal se te da la redacción? Rodea el número que mejor lo indique.

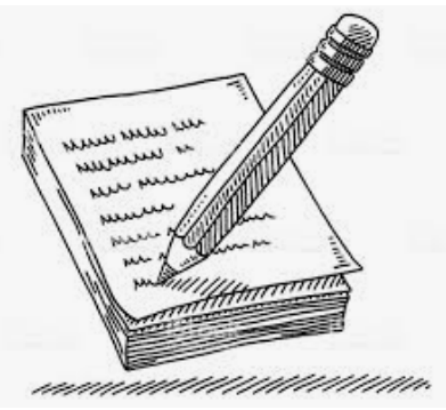

Ahora observa estos dos animales. ¿Cuánto crees que tienen en común? ¿Todo? ¿Algunas cosas solo? ¿Nada en absoluto? Rodea el número que creas.
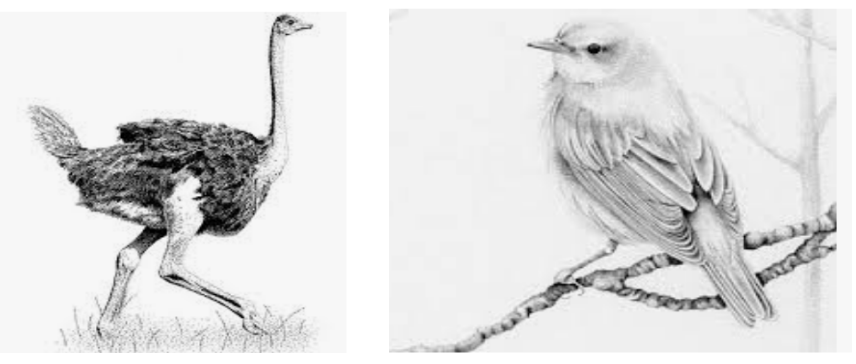

Y ahora mira estos dos animales. ¿Cuánto crees que tienen en común? ¿Todo? ¿Algunas cosas solo? ¿Nada en absoluto? De nuevo rodea el número que mejor lo indica.
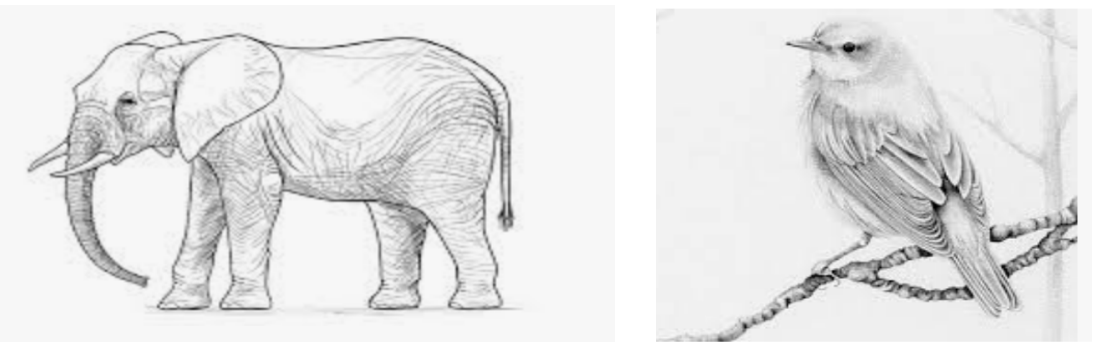
Y ahora la última pregunta por hoy: ¿Cuánto te gusta el futbol? ¿Mucho? ¿Un poquito? ¿Nada en aboluto?

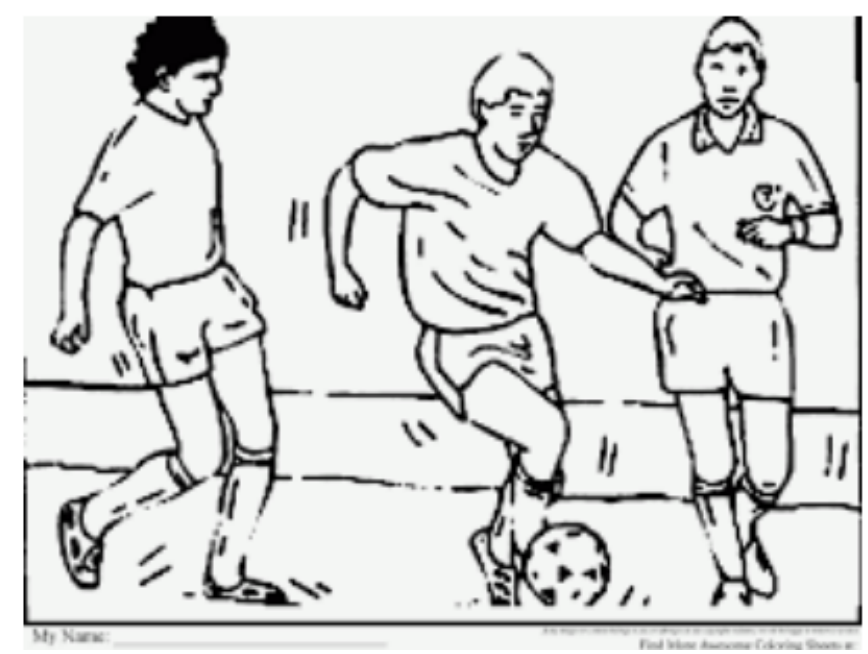




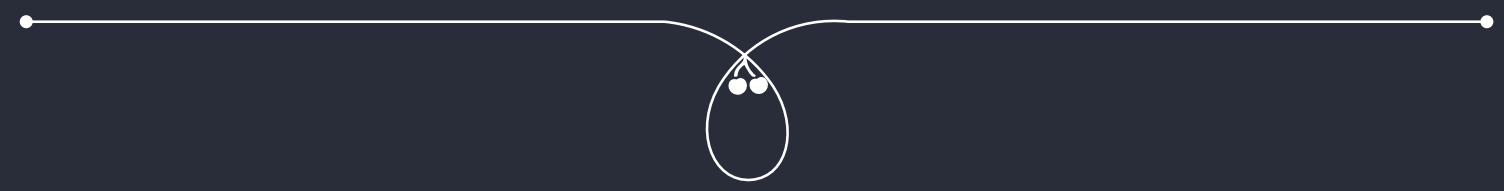

